\title{
Mechanisms for the Formation of Spiraled Inclusion Trails in Garnet Porphyroblasts from the Precambrian Core of the Laramie Mountains, Southeastern Wyoming
}

A Thesis Presented to the Faculty of the Graduate School at the

University of Missouri

In Partial Fulfillment of the Requirements for the Degree

Master of Science

by
MARK A. SUTCLIFFE

Dr. Robert L. Bauer, Thesis Supervisor

May 2013 
The undersigned, appointed by the dean of the Graduate School, have examined the thesis entitled

\section{Mechanisms for the Formation of Spiraled Inclusion Trails in Garnet Porphyroblasts from the Precambrian Core of the Laramie Mountains, Southeastern Wyoming}

presented by Mark A. Sutcliffe,

a candidate for the degree of Master of Science,

and hereby certify that, in their opinion, it is worthy of acceptance.

Dr. Robert L. Bauer

Dr. Alan Whittington

Professor Lou Ross 


\section{ACKNOWLEDGEMENTS}

I would like to acknowledge and thank the Geological Society of America

for funding this research, and for providing such a great platform for knowledge and discovery.

I would also like to thank the University of Missouri and the Department of Geological sciences for providing me with an excellent education, and for giving me the opportunity to teach some of tomorrow's great minds through my teaching assistantships. Special thanks to all of the professors and specifically my committee members Lou Ross and Alan Whittington.

Lastly, but certainly not least, I would like to thank Dr. Robert Bauer for all of his help and guidance along the way. I would not be where I am without his mentorship. 


\section{TABLE OF CONTENTS}

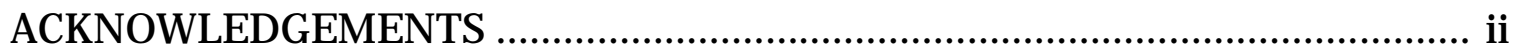

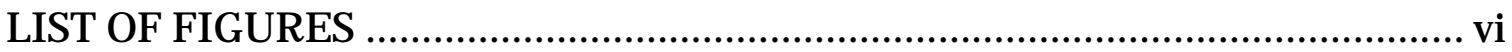

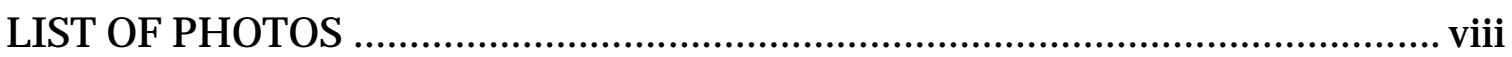

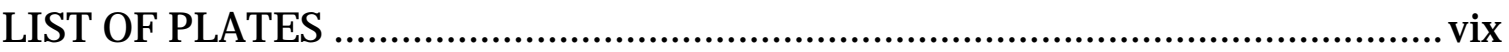

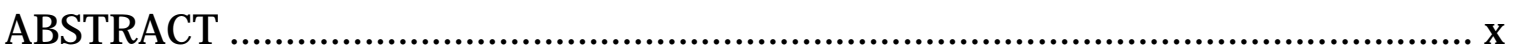

Chapter

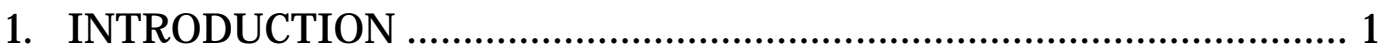

2. TRACKING TECTONIC PROCESSES USING THERMO-CHEMICAL

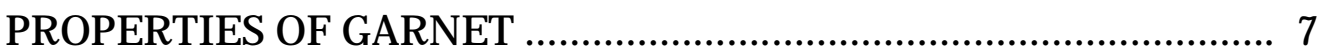

3. EXISTING MODELS FOR SPIRALED GARNET GROWTH ............. 14

End Member Models ................................................ 15

A Hybrid Model......................................................... 18

4. HISTORICAL METHODS AND TECHNIQUES OF ANALYSIS ........ 24

The Origin and Use of Porphyroblast Inclusion Trails.... 25

Garnet Textural Features: A Picture of the Past .............. 28

Inclusion grain size and their relationship to matrix grain size

Inclusion shape as a proxy for fabrics prior to garnet overgrowth shape of inclusion trails

Garnet Inclusion Trail Geometries and Spatial

Relationships: Snapshot vs. Integrated Picture?

Microanalytical Techniques to Aid in Our Understanding of the Nucleation, Growth, and Deformational Histories of Garnets

Chemical maps of garnet to determine nucleation and growth 
patterns

Electron backscatter diffraction on garnet to determine variations in crystallographic orientation

Truncations of Textural, Chemical, and Crystallographic Relationships within Garnet: A means of determining the Continuity of Growth

5. STRUCTURAL AND TECTONIC BACKGROUND OF THE STUDY

AREA

6. A SPIRALED GARNET EVALUATION WORKFLOW TO EVALUATE

THE CONTINUITY OF GARNET GROWTH

7. TECHNIQUES OF ANALYSIS AND METHODS OF

INTERPRETATION

Sample Collection and Preparation

Energy Dispersive Spectrometry (EDS) ....................... 64

Wavelength Dispersive Spectrometry (WDS) ................ 65

Electron Backscatter Diffraction (EBSD) ..................... 66

8. RESULTS

9. DISCUSSION

Concluding Remarks

10. SUGGESTIONS FOR FUTURE WORK IN THE STUDY AREA 95

Detailed Field Mapping of Geologic Units and Sampling Using High Precision GPS

Collect 1 inch Sample Cores in the Field Using a Cordless Drill and Diamond Impregnated Coring Big . 96

Incorporate High Precision Geothermochronology into the Sample Analysis 96 


\section{APPENDIX}

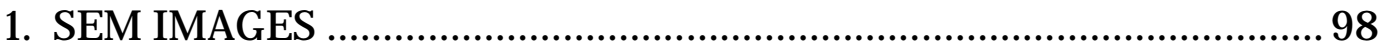

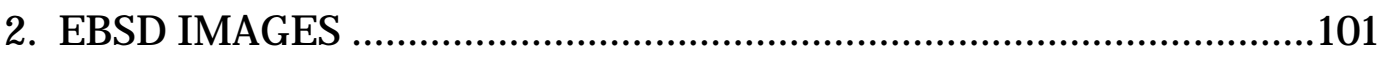

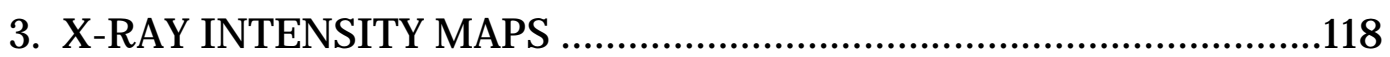

4. A SPIRALED GARNET EVALUATION WORKFLOW ...................128

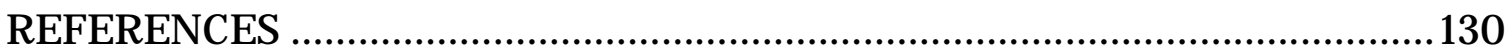




\section{LIST OF FIGURES}

Figure $\quad$ Page

1.1. Electron backscatter image of a spiral garnet .................................... 3

2.1. Temperature and pressure stability of minerals .............................. 9

3.1. The model of Schoneveld (1977) ............................................... 16

3.2. Progression of porphyroblast growth ........................................ 18

3.3. Relationship between folding and shear stress................................. 20

3.4. Relationships between porphyroblast inclusion trails and their surrounding matrix fabric elements ........................................... 22

4.1. Relative timing of porphyroblast growth and deformation .................... 27

4.2. Relationship between mineral grain inclusions …............................ 30

4.3. Electron backscatter diffraction (EBSD) and the existence of polycrystals in the Laramie Range of Wyoming .............................................. 37

4.4. Hypothetical chemical zonation atterns and crystallographic truncation boundaries of polycrystic garnets ............................................ 39

4.5. Polycrystal garnet from SE Vermont ............................................ 42

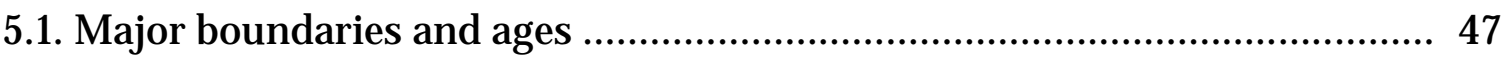

5.2. Crenulation foliation S2 contained within the study area ..................... 49

5.3. Stereographic projection ........................................................ 50

5.4. S2 being folded by D3 to form F3 folds ...................................... 51

5.5. Relationship between garnet growth and foliation development ............. 52

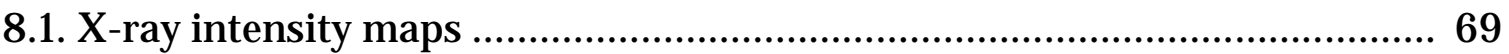


8.2. Stability fields of garnet in both the MnNCKFMASH systems

8.3. Overgrowth of asymmetric vs. symmetric crenulation cleavages ............ 72

8.4. The essential elements seen in spiraled garnets from the Laramie Range

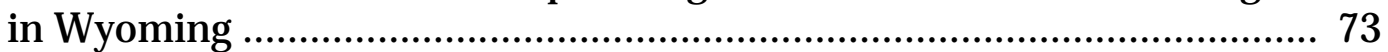

8.5. Inherited rotation sense from asymmetrically folded crenulation cleavage elements and potential porphyroblast rotation during growth resulting from layer parallel shear consistent with fold development ................. 74

8.6. Progressive development of a nearly orthogonal foliation, prograde metamorphic reactions, and the development of sigmoidal garnets ....... 75

8.7. Progressive development of foliation fabrics related to porphyroblast growth, water liberating prograde reactions, and enhanced strain rates as a result of hydro-weakening

9.1. Progressive development of a spiraled garnet during fabric overgrowth, continued shortening, and layer parallel shear ............................... 89

9.2. Progressive development of a spiraled garnet during fabric overgrowth, continued shortening, and layer parallel shear .............................. 91 


\title{
Mechanisms for the Formation of Spiraled Inclusion Trails in Garnet Porphyroblasts from the Precambrian Core of the Laramie Mountains, Southeastern Wyoming
}

\author{
Mark A. Sutcliffe \\ Dr. Robert L. Bauer, Thesis Supervisor
}

\begin{abstract}
Relationships between deformation fabrics and porphyroblasts have long been used to evaluate the metamorphic and deformation histories of mountain belts. However, some porphyroblast-fabric relationships, such as the growth and kinematic history of spiral inclusion trails in garnets, remain highly controversial. Two end-member models for their formation include: 1) a "rotational" model that invokes rotation of progressively growing garnet porphyroblasts relative to a fixed geographical reference frame, and 2) a "non-rotational", model that involves multiple periods of garnet growth, resorption, and successive overprinting of near-orthogonal foliations and crenulation cleavages. However, field, petrographic, and microanalytical techniques used to evaluate the origin of spiral inclusion trails from the Precambrian core of the Laramie Mountains are more consistent with a mechanism that includes overgrowth of an existing crenulation foliation and only modest rotation to produce complex spiral geometries.
\end{abstract}

The garnets in the study area are contained within interlayered pelitic and psammitic units that have been folded during the Paleoproterozoic TransHudson orogeny (D2). One of the products of this folding is an antiform that contains an associated axial plane crenulation foliation (S2). Within the well 
exposed antiformal structure, garnets on opposing limbs have different senses of rotation - clockwise on the left limb and counterclockwise on the right limb looking down the antiformal hinge. An Archean aged foliation (S1), which was folded by D2 deformation to produce the S2 crenulation foliation, is well developed in the S2 microlithons and is also apparent within the cores of the large garnet porphyroblasts.

Mapping of the interlayered sequence of metapelite, quartzite, and amphibolite suggests that flexural flow folding of this interlayered sequence produced flexural shear along unit boundaries that may have provided the mechanism for rotation of the garnets during their growth. To test this hypothesis, this study used petrographic textural examination of inclusion trails, Electron Probe Microanalysis (EPMA), and Electron Backscatter Diffraction (EBSD) techniques. Field structural context was provided by Dr. Robert Bauer, who collected orientation data (bedding, minor fold hinges, lineations and crenulation foliations) prior to my involvement in the project. I collected more oriented samples of spiraled garnets from multiple locations across the F2 fold structure discussed above.

The EPMA study involved analysis of low diffusivity elements, such as Mn, $\mathrm{Cr}$, and $\mathrm{Y}$ to determine the growth patterns of the garnets and to relate garnet growth to the geometries of the included crenulation foliation. The EBSD analysis evaluated crystallographic structures and substructures within garnet grains to determine whether the garnets contained crystallographic discontinuities. Analysis of the growth histories of spiraled garnets and the relationships between folding and garnet rotation sense is consistent with rapid growth of the garnets 
over an asymmetric crenulation foliation followed by progressive shortening that is locally associated with a component of rotation during garnet growth. This model involves $\sim 180$ degrees of apparent rotation as a result of the overgrowth of an asymmetric crenulation foliation during progressive shortening and continued crenulation foliation development. Additional rotation is the product of foliation wrapping that occurs around the hard spot created by the growing garnet and the onset of rotation that may occur during folding of interlayered units which can result in partitioning of shear strain around garnet porphyroblasts. An example is presented to explain $\sim 360$ degrees of apparent rotation via as little as 58 degrees of real rotation. 
CHAPTER 1:

INTRODUCTION 
Relationships between deformation fabrics and metamorphic porphyroblasts have long been used to evaluate the mid-crustal metamorphic and deformation histories of mountain belts (e.g. Zwart, 1962; Vernon and Powell, 1976; Vernon et al., 1989; Vernon et al., 1993; Bell and Rubenach, 1983; Bell, 1985; Bell and J ohnson, 1989; Passchier et al., 1992; J ohnson, 1993a; J ohnson, 1993b; J ohnson, 1999; Williams and Jiang, 1999; Schoneveld, 1979; Vernon, 1975). However, the interpretation of some porphyroblast-fabric relationships, such as the growth and kinematic history of spiral-shaped inclusion trails in garnets (Figure 1.1), remain highly controversial due to the complexities of reconstructing the tectono-metamorphic histories of garnet growth.

Two end-member models describe the mechanisms responsible for spiral inclusion trails in garnets. The classic "rotational" model for their formation invokes rotation of a progressively growing garnet porphyroblast relative to a fixed geographical reference frame (e.g. Rosenfeld, 1970; Schoneveld, 1977). The second "non-rotational" model involves multiple periods of garnet growth, resorption, and successive overprinting of near-orthogonal foliations and crenulation cleavages produced through alternating periods of horizontal and vertical compression (Bell and J ohnson, 1989).

Until recently, studies of spiraled garnet formation have relied almost entirely on field relationships and traditional geometrical micro-structural analysis to evaluate the rotational and non-rotational models. The problem with this approach is that most, if not all, geometrical features contained within spiraled garnets can be explained by either the rotational or non-rotational - 2 - 


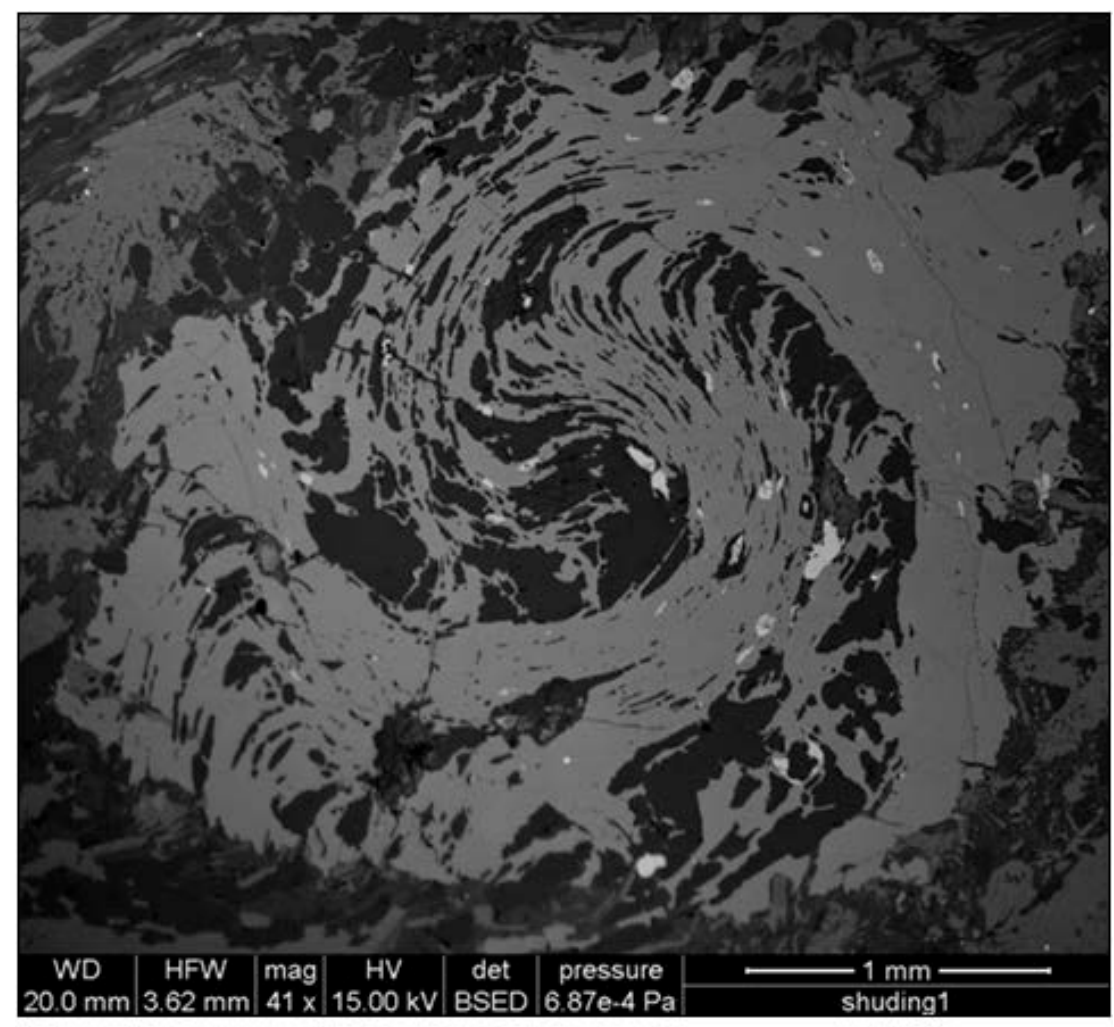

Figure 1.1. Electron backscatter image of a spiral garnet. Garnet has bright inclusion trails of ilmenite. (From Sample MP223-24BGRT2).

models for spiraled garnet formation (J ohnson, 1999; J ohnson, 1993a). Geometrical studies alone are unable to conclusively demonstrate the mechanisms responsible for complex spiral inclusion trails within garnets without understanding garnet nucleation and growth histories.

Recent studies have used detailed field context (Bauer et al., 2002) or detailed studies of nucleation and growth (Robyr et al., 2007; Robyr et al., 2009) to examine other mechanisms for the origin of spiral inclusion trails in garnet. Bauer's study examined an antiformal structure in the Laramie Range of southeastern Wyoming that contains an associated axial plane crenulation 
foliation that was overgrown by spiral garnets that appear to have rotated during the late stages of garnet growth. Bauer's field site is ideal for the study of spiral garnets because of the apparent relationship between folding and garnet rotation. Within the well exposed antiformal structure, garnets on opposing limbs have different senses of apparent rotation - clockwise on the left limb and counterclockwise on the right limb, as viewed toward the closure of the fold. Preliminary mapping of the interlayered sequence of metapelite, metapsammite, quartzite, and amphibolite at this site suggests that folding of this sequence produced flexural shear along unit boundaries that provided the mechanism for rotation of the garnets during the late stages of their overgrowth of an existing crenulation foliation (e.g. flexural flow folding, Hudleston et al., 1996; J iang, 2001). The proposed mechanism is interpreted to have produced spiral inclusion trails in garnets in response to low partitioned shear strain during flexural flow folding. As much as $180^{\circ}$ of the apparent rotation of the inclusion trails was a result of overgrowing a pre-existing crenulation foliation (Bauer et al., 2002).

Subsequently, Robyr et al. (2007) studied the nucleation and growth of garnets with spiral inclusion trails and concluded that neither of the end member models could explain the formation of spiraled garnets from the Lukmanier Pass area of the Swiss Alps. The authors proposed that a combination of garnet overgrowth of a crenulated matrix could produce an apparent rotation of $300^{\circ}$ with only $180^{\circ}$ of actual porphyroblast rotation. However, they concluded that additional chemical, structural, and crystallographic analyses on a larger sample population are required to better understand the formation of spiraled garnets. 
In 2009, Robyr et al. presented a more detailed analysis of two populations of garnet collected, respectively, from the fold hinge and fold limbs of a chevron-type fold. Results from the study showed that distinct differences existed between the two populations of garnet. Those from the fold hinge appear to have two distinct growth domains divided by the authors as the first 270 degrees of rotation and the last 90 degrees. These growth domains are apparent from microstructural, geochemical, and textural data. The garnets from the fold limbs appear only to have one growth domain and less than 270 degrees of apparent rotation. Robyr et al. (2009) interpreted their results to indicate that "in the first 270 degrees of rotation, growth occurred under rotational, non-coaxial flow, whereas in the last 90 degrees, garnet grew under a non-rotational shortening regime." Another interesting observation made in their study is that "nearly all central domains in the snowball garnet are characterized by one [001] axis oriented sub-parallel to the symmetry axis and by another [001] axis oriented sub-parallel to the orientation of the internal foliation."

My study builds on the detailed textural study of Bauer et al. (2002) using a microanalytical approach similar to that of Robyr et al. (2007). Garnet samples containing spiral shaped inclusion trails from the Laramie Range of SE Wyoming were analyzed to determine their nucleation and growth histories. The general goal of this study is to test the model of Bauer et al. (2002) using new chemical and textural data and to compare and contrast these findings with those presented by Robyr et al. (2009). Specific objectives of this study are to evaluate the mechanisms responsible for spiral garnet formation in relation to inclusion 
trail development, nucleation and growth, regional deformation history, and microfabric development through a combination of field structural analysis, Electron Probe Microanalysis (EPMA), and Electron Backscatter Diffraction (EBSD) techniques. The study relies on an understanding of: 1) the general thermo-chemical properties of garnet, 2) garnet growth patterns, and 3) the formation and use of inclusion trails in porphyroblasts. Background on these topics is provided below as a basis for the project. 
CHAPTER 2:

TRACKING TECTONIC PROCESSES USING THE THERMOCHEMICAL PROPERTIES OF GARNET 
Unlike most minerals, garnet is stable over very large ranges of pressure and temperature, from lower greenschist facies to granulite facies conditions (Figure 2.1). The wide stability field of garnet in $\mathrm{P}-\mathrm{T}$ space allows it to persist while other minerals are resorbed and the elements they contain are partitioned into new minerals or fluids (Figure 2.1). However, as garnet crystals grow, they change composition in response to changing $\mathrm{P}-\mathrm{T}$ and chemical conditions and commonly record these changes as a chemical growth zonation, which may persist and resist re-equilibration despite high-temperature conditions in excess of 700 degrees C. For example, in a garnet sample from the Makhavinekh Lake Pluton aureole in Labrador, Canada, Carlson (2006) showed that despite reaching a peak temperature of 765 degrees $C$, the chemical zonation patterns of Mn only experienced $.02 \mathrm{~cm}$ of apparent penetration of diffusion of the garnet structure.

Because of the wide stability field of garnet and its ability to withstand elemental diffusion at high temperatures, the preserved elemental zoning patterns of garnet have been used to estimate the nucleation and growth histories of garnet porphyroblasts and their relationship to mineralogical changes taking place in the matrix. Garnets can only incorporate into their structure elements that are available in the matrix; therefore, as the composition of garnet changes, an inferred change in composition of the matrix must occur. As garnet porphyroblasts grow, they deplete the matrix of elements that they incorporate into their crystal lattice. Therefore, compositional zoning patterns within garnets can be used as a proxy for the growth histories of the garnets, and they preserve a 


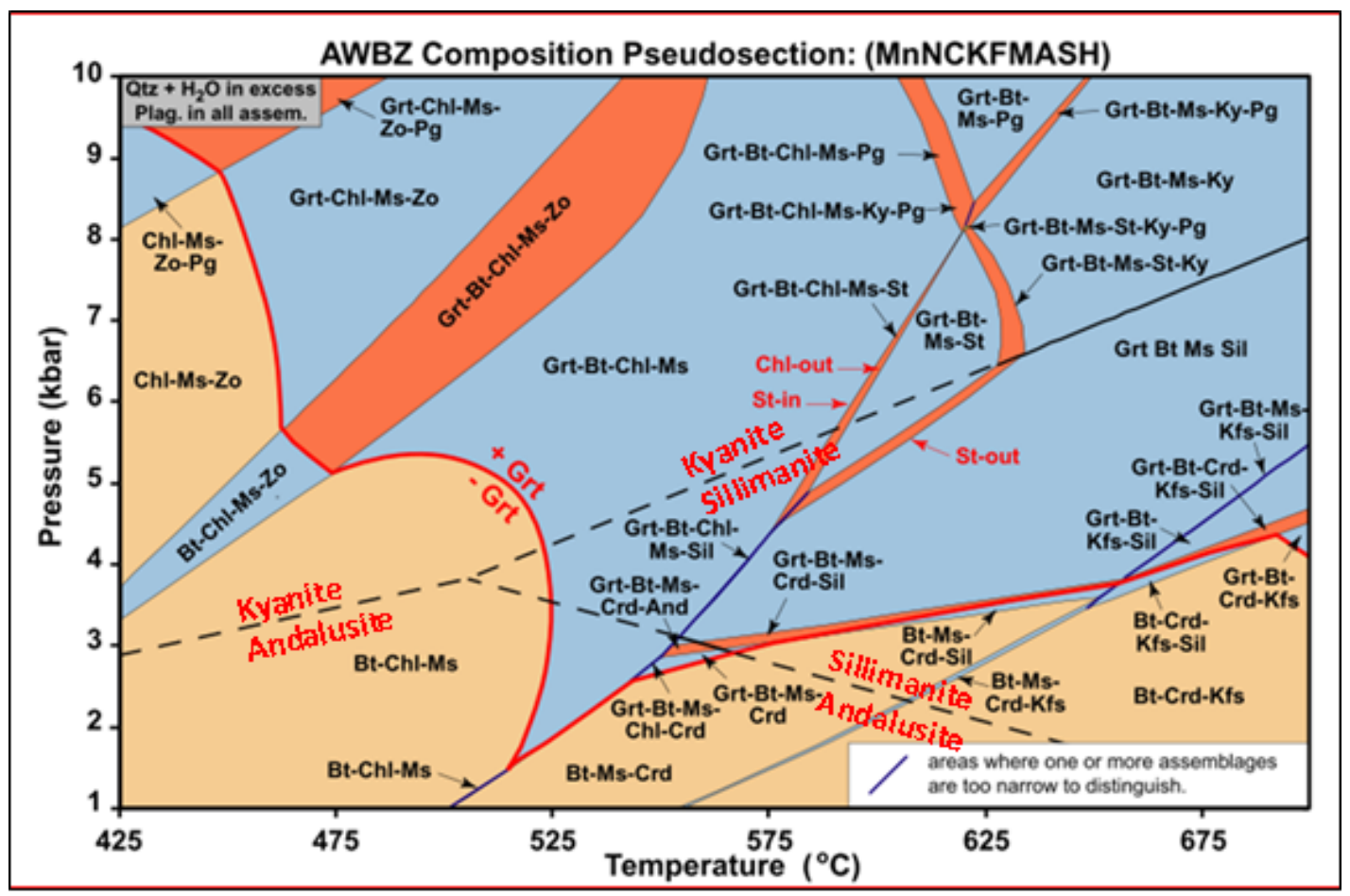

Figure 2.1. Temperature and pressure stability of minerals. Assuming a system containing $\mathrm{MnO}$ $-\mathrm{Na} z \mathrm{O}-\mathrm{CaO}-\mathrm{Kz} \mathrm{O}-\mathrm{FeO}-\mathrm{MgO}-\mathrm{Al}_{2} \mathrm{O}_{3}-\mathrm{SiO}_{2}-\mathrm{H} z \mathrm{O}$. The figure shows a garnet reaction line in red with a garnet stability at 6 Kbar pressure between approximately 425 degrees $\mathrm{C}$ togreater than 700 degrees $\mathrm{C}$. (Modified from Tinkham et al., 2001).

record of other changes going on within the matrix that affect the concentration of elements available for continued garnet growth.

The zoning patterns contained within garnet porphyroblasts, in conjunction with minerals they include or minerals near them, can also be used to estimate pressures and temperatures reached during growth (cf. Spear, 1993). Minerals, such as monazite, that may be included during garnet growth can be used to estimate the time at which the garnet grew (Pyle et al., 2001; Spear and Pyle, 2002). As a result, garnets can preserve the history of pressures and temperature during their growth and, in some cases, the absolute age of their formation. Since the time between the nucleation of garnet crystals and the point 
when they cease growing can be long, and the range of temperatures and pressures can vary significantly during their growth, the potential to see the pressure, temperature, and time path that a garnet crystal followed during its growth is sometimes possible.

Garnets provide a powerful tool for reconstructing the burial and metamorphic history of the mid-crust during orogenesis, but an understanding of the relationship of garnet porphyroblast growth to deformation fabrics preserved in their host rocks can also provide a better understanding of the deformational processes at work within the crust during garnet growth (e.g. Williams, 1994). Garnet porphyroblasts that grow during deformation events (synkinematic garnets) can record the progressive deformational evolution of the matrix while they grow. Spiraled garnets containing complex spiral inclusion trails are believed to be a synkinematic type of garnet, but the interpretation of the deformational histories they contain has been contested (e.g. Bell and J ohnson, 1989). The mechanisms behind their formation remain somewhat ambiguous (e.g. J ohnson, 1993a; Passchier et al., 1992). In order for spiraled garnets to be used as kinematic indicators and ultimately for determining the pressure, temperature, time, and deformation paths of the rocks containing them, the mechanisms behind their formation must be determined. Studying spiraled garnets in an area that has a well-documented tectonometamorphic history may elucidate the mechanisms behind their formation and allow these mechanisms to be applied to areas that lack a solid structural context. 
Spiraled garnets have long perplexed structural geologists and metamorphic petrologists due to their complex forms and the large angles of apparent rotation implied by their inclusion trail geometries. The sense of apparent rotation has been used as a local indicator of shear; however, debate as to whether these garnets actually rotate during growth calls into question their use as shear-sense indicators. A critical interpretation in this debate has been the relationship between progressive growth (and potential dissolution) of garnet during the incorporation of the complex inclusion trail patterns.

In order for garnet to grow in response to prograde metamorphic reactions, major elements compatible with the garnet structure must be available from reactant phases (minerals) within the matrix. Local variations in potential reactant phases can lead to asymmetric growth of garnets and potential elemental variations within the garnet (e.g. Hirsch et al., 2003; Spear and Daniel, 2001. Phases that do not participate in the garnet-forming reactions, or those phases that are in excess within the matrix, can be included within the garnet crystal and typically maintain their pre-existing alignment in the matrix to produce inclusion trails. The availability of structural elements from matrix reactant phases and local variations in the abundance of matrix reactants affects the orientation, quantity, and shape of garnet inclusion trails (Yang and Rivers, 2001). Microscale deformational features, such as foliations, folds, and shear offsets, can all affect the shape and pattern of inclusion trails whether they formed before or during garnet growth. Pre-existing foliation fabrics induced from burial or tectonic processes can be statically overgrown and preserved as inclusion trails. 
If a garnet is growing at the same time that deformation is occurring within the matrix, the orientation, quantity, and shape of inclusion trails may record the change in the matrix foliation through time.

The developmental stages of garnet porphyroblasts are related to the stages of the matrix and the nucleation and growth history of the garnet itself. During syntectonic metamorphism, changes in the mineral assemblages within the matrix are concurrent with deformation fabric development in the matrix.

A simplified history of events that take place during orogenesis will help to provide a context for the steps that lead to the formation of spiraled garnets. First, following burial, rising temperatures and pressures begin to transform sedimentary layers into assemblages of metamorphic minerals. In response to deformation and associated strain, metamorphic minerals become aligned to develop fabrics. Second, in response to metamorphic reactions, garnet begins to nucleate within the matrix and incorporate elements into their crystal structure from breakdown of the reactant matrix phases. Incorporated elements include those locally available from the reactant phases in response to their breakdown or chemical equilibration to changes in pressure and temperature. Third, as the garnets nucleate and grow, they overgrow (include) minerals and associated fabric features from the matrix such as shape, size, elongation, spatial geometries, etc. Fourth, if deformation continues during garnet growth, fabric features and geometries may change relative to the growing garnet. Fifth, rocks will approach maximum pressure as the core of the mountains reaches maximum burial depth. Sixth, buried rocks will approach maximum temperatures as the 
mountains begin to unroof, or as the rocks are exhumed through some tectonic process. After the buried rocks reach their maximum temperatures and pressures, only minor retrograde metamorphic changes will occur within the matrix because the prograde reactions that created the mineral assemblages are typically dehydration reactions that expel the water necessary to reverse the reactions that created the new minerals. Lastly, garnets will cease growth, approach the surface, and/ or become buried in another orogenic event.

Due to the many factors that affect the nucleation, growth, and alteration of garnet during the metamorphic processes described above, garnets can form many different shapes and contain a myriad of textural features. Evaluating the potential mechanisms of formation of the spiraled garnets considered in this study requires an understanding of how the processes of burial and metamorphism affect nucleation, growth, and alteration of garnets. As described in the introduction, the mechanisms behind the formation of spiraled garnets are controversial; the debate has included aspects of the deformation, growth, and metamorphic histories of spiraled garnets from various localities around the world. To examine why the contention exists, the following chapter reviews the main spiraled garnet models, provides a context for why the models have been debated, and highlights the main differences between two end-member models. 
CHAPTER 3:

EXISTING MODELS FOR SPIRALED GARNET GROWTH 
Porphyroblast behavior during growth and deformation is disputed by proponents of two end member models that explain the formation of spiraled porphyroblast inclusion trails. The end member models imply very different stress states and histories leading to the formation of spiraled garnets. As a result, the conclusions about the deformation history of an area based on spiraled garnet geometries could be vastly different depending on the model chosen. One model would imply a zone of very high shear (rotational) while the other would imply little to no shear with multiple periods of successive foliation development (non-rotational). Thus, it is important to develop a method to examine the chemical and textural properties of spiraled garnets in a way that allows researchers to determine whether shearing, shortening, or a combination of both are responsible for the growth of their garnets. In addition, inheritance of precursor mineral fabrics, such as matrix microfolds and crenulations, can greatly influence the amount of apparent rotation that any model would predict. Applying a model without justification of its use could lead to very erroneous results in a study of spiraled garnets.

\section{END MEMBER MODELS}

Spiraled inclusion trails are characterized by apparent rotations of greater than 180 degrees, and they seem to be restricted to garnets. Such structures are commonly referred to as snowball structure garnets (cf. Figure 1.1). Schoneveld (1977; 1979) proposed progressive rotation of porphyroblasts during growth to explain the development of spiral-shaped inclusion trails (Figure 3.1). The 


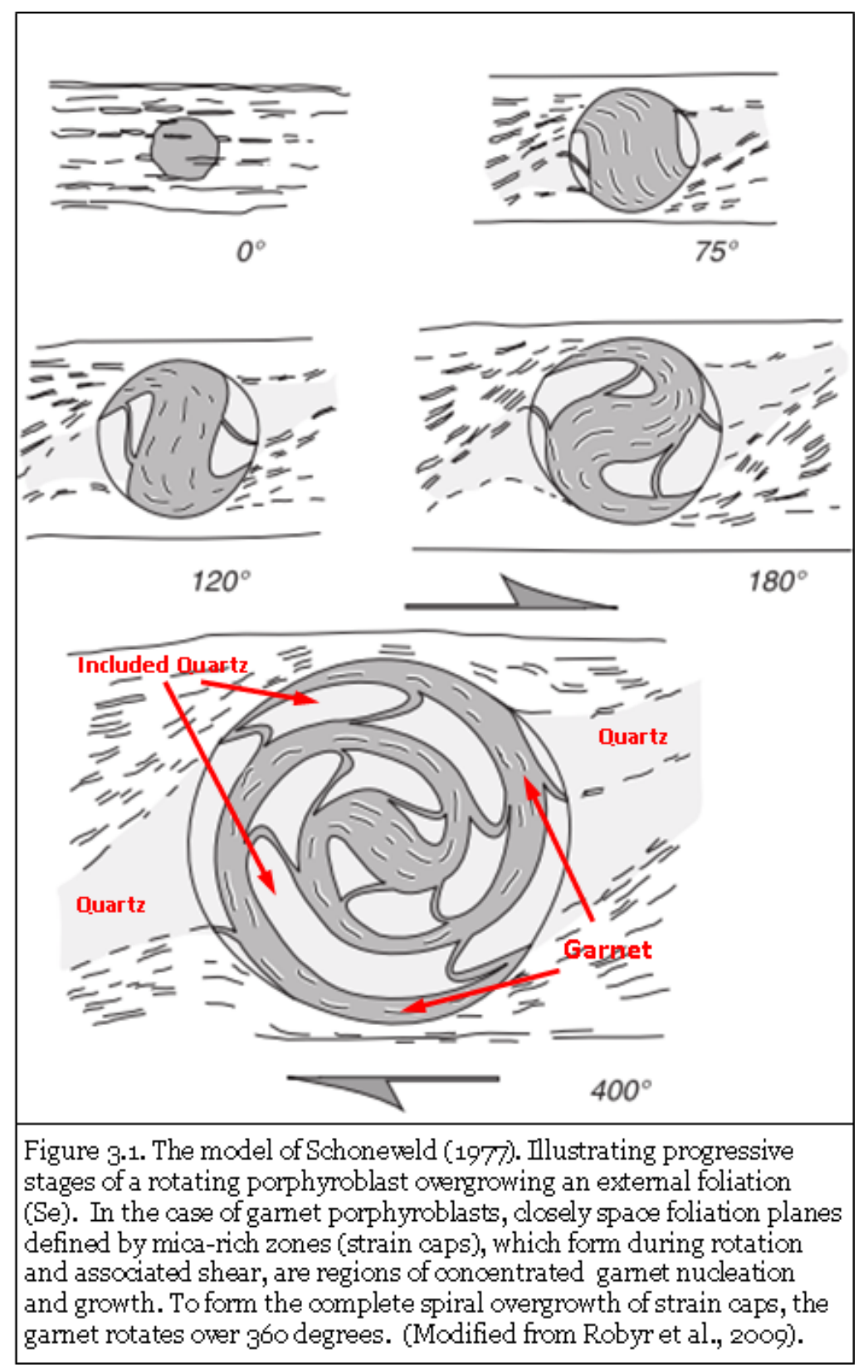

mechanism for the rotation was interpreted to be the result of shear coupling between rigid, progressively growing porphyroblasts and the surrounding actively flowing matrix (Williams \& Schoneveld, 1981).

In contrast to the papers by Schoneveld (1977; 1979), Bell and J ohnson (1989) argued that spiral-shaped inclusion trails form without rotation. They 
presented a model of porphyroblast nucleation and growth during crenulationcleavage development in which the spiral inclusion trail pattern forms by successive overprinting of near orthogonal foliations/ crenulation. The porphyroblasts in their model are assumed to grow during continuous prograde metamorphism, and the onset of deformation causes the onset of garnet growth. They argue that spiral inclusion trails develop as a result of the alternating, nearly orthogonal, stress fields that produce nearly-orthogonal foliations that are progressively overgrown by the garnet porphyroblast (Figure 3.2). Their tectonic model to produce the alternating stress fields calls upon increasing gravitational potential energy following the progressive shortening and thickening associated with collisional orogenesis (Bell and J ohnson, 1989). 
J ohnson (1993b) showed that serial thin sections through spiraled garnets could not demonstrate whether or not garnets rotated. His data did however determine that the garnets he studied had continued to undergo deformation after or during the latest stages of porphyroblast growth. Based on this conclusion, J ohnson inferred that porphyroblasts may not be a reliable indicator of shear sense on a main foliation. J ohnson (1993a) reviewed the models of spiraled garnet inclusions formation and showed that both the models presented by Schoneveld (1977;1979) and Bell and J ohnson (1989) would be capable of explaining most, if not all, of the micro-structural features that can be found in and around spiraled garnets. However, garnets exist that have spiraled shaped inclusion trails that come from areas where the rocks do not appear to have undergone significant shear strain.

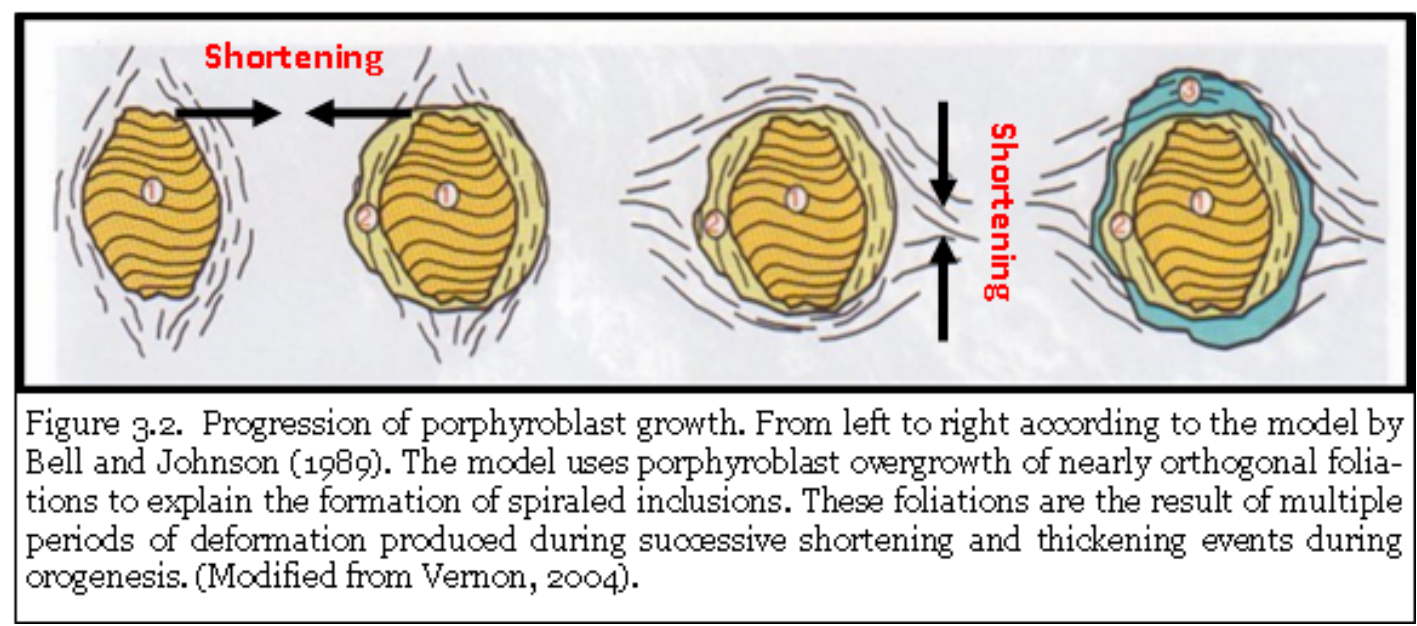

A HYBRID MODEL 
One mechanism that could potentially lead to rotation of porphyroblasts within rocks that are not contained within zones of high shear is that of flexural flow described in Figure 3.3.

Flexural flow has been presented as a mechanism for the rotation of porphyroblasts in areas that undergo multilayer folding of interlayered units with differing competency (Jiang, 2001). As a result of the competency contrast that can exist between interlayered rock units during folding, layer-parallel shear strain can develop (Hudleston et al., 1996). During multilayer folding, competent and less competent layers slide past one another, leading to layer parallel shear. In interbedded rocks that have been deformed by flexural flow or flexural slip, all folded layers are subjected to longitudinal strain, but within the less competent layers a component of layer parallel simple shear may develop. According to J iang (2001), folding of layered rocks in response to layer-parallel shortening can be described by a time-variable combination of flexural flow and pure shear components. These components of folding can lead to the partitioning of layerparallel shear in different layers, allowing porphyroblasts to rotate in response to the partitioned shear strain in the layers where the porphyroblasts grow. J iang concluded that the interplay between the layer competence factor, bulk folding history, and the history of strain partitioning, will control the amount of rotation that the porphyroblasts will undergo. Based on this theory, Jiang ( 2001) proposed that constraints could be placed on the history of folding and the relative competency of the rocks at the time of folding based on the amount of 


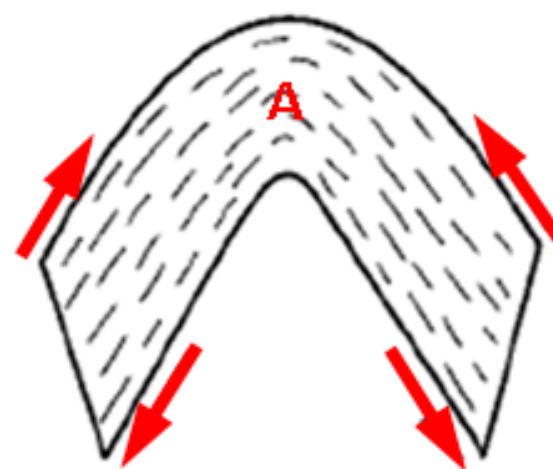

Flexural

Flow

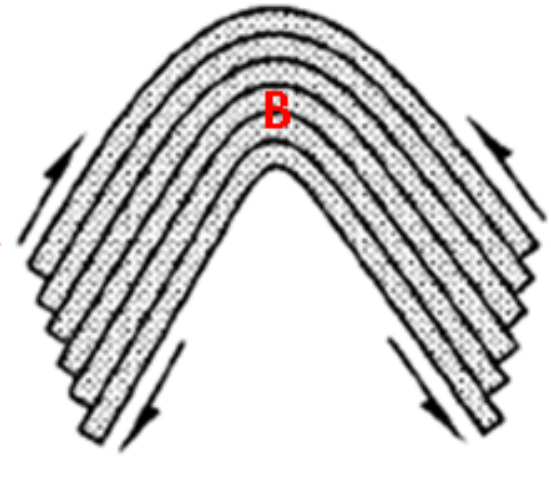

Flexural

Slip

Figure 3.3. Relationship between folding and shear stress. During flexural flow (A) and flexural slip (B) respectively, Flexural flow relies on the competency contrast between interlayers to create shear where as flexural slip is create when layers slide past each other during folding (e.g. folding a deck of cards). Note that the shear sense is reversed on opposing limbs of the fold in both cases.

(Modified from Hudleston et al., 1996).

rotation and the inclusion trail geometries. It can also be inferred from this theory that the location of a porphyroblast on a fold should influence the amount and rotation sense of a growing porphyroblast.

An observation that intuitively seems to be in contrast with the rotational model of spiraled garnet growth is the occurrence of sharp zones of truncation located at the margins of garnets and within inclusion trails.

Bell and J ohnson (1989) attribute these sharp truncations to rapid overgrowth of a cleavage that developed at strain caps on the edges of the garnet during continued deformation. In their model, once garnet overgrowth occurs and deformation progresses, the matrix is reset by a nearly orthogonal cleavage 
orientation, which is then followed by continued garnet growth. However, Passchier et al. (1992) demonstrate that what appear to be truncation planes within garnets could also be explained by intermittent growth of a rotating garnet during a single period of continued deformation (Figure 3.4). J ohnson (1993a) conceded that the formation of sharp zones of truncation that occur in spiraled garnet inclusion patterns could be explained by many growth and rotation mechanisms during continued deformation.

Despite the many micro-structural techniques used by authors to explain the formation of spiral inclusion trail geometries within porphyroblasts (e.g. Schoneveld, 1979; Bell and J ohnson, 1989; J ohnson, 1993a; Bell et al., 1992; Passchier et al., 1992), the rotation, non-rotation, or hybrid explanations of inclusion trail geometries commonly remain inconclusive. Proponents of rotation and non-rotation can provide mechanisms for the formation of all possible 


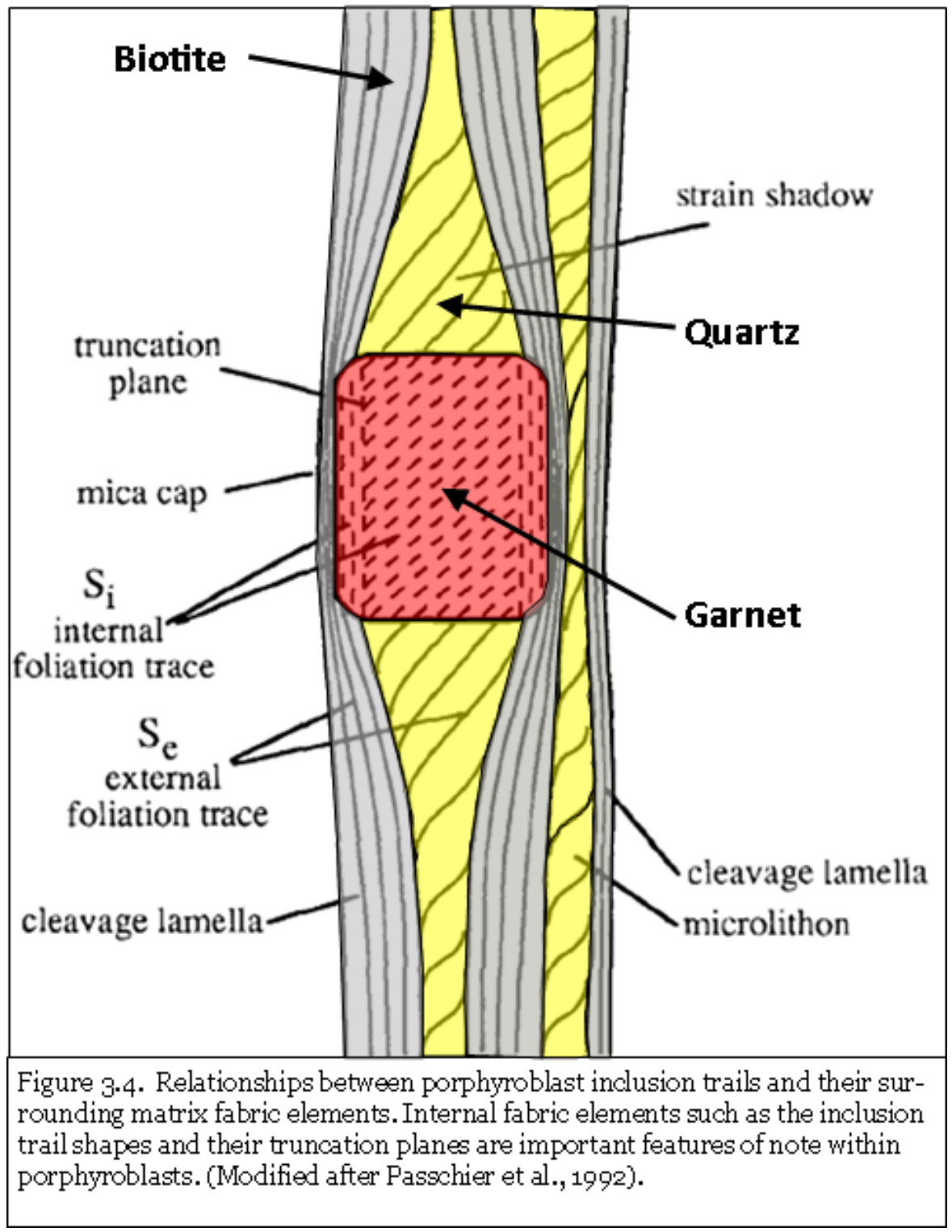

inclusion trail geometries. Some mechanisms seem more plausible than others, but the unlikely mechanisms cannot be disproven by simply relying on the textural relationships of inclusion trails. Because of the ambiguity surrounding the formation of spiraled garnets, authors have begun to utilize many new microanalytical techniques to evaluate garnet nucleation, grouth, and deformation histories. These techniques are used in conjunction with the textural 
relationships recognized and used by early researchers. Before introducing the new techniques, the following chapter describes the historical techniques of analysis that have been used to develop and defend the existing rotational and non-rotational models of spiraled garnet growth. 
CHAPTER 4:

HISTORICAL METHODS AND TECHNIQUES OF ANALYSIS 
Various textural relationships observed within porphyroblasts have historically been used to aid in deciphering the progressive development of spiraled garnets. Subtle changes in the fabrics contained within garnets can provide insight into the matrix at the time of garnet growth and changes undergone during growth. The first part of this chapter provides an overview of how inclusion trails have been used to determine the timing of metamorphism relative to deformation. The second section explains how various textural features within garnet porphyroblasts can be used to describe the makeup of the matrix prior to garnet growth. Lastly, the third section describes the different garnet forms and features that can be used to define the shape of inclusion trails and gives a brief introduction into their possible meaning.

\section{THE ORIGIN AND USE OF PORPHYROBLAST INCLUSION TRAILS}

Porphyroblasts commonly contain inclusion trail patterns that are believed to reflect the geometrical and compositional makeup of the matrix during their growth. Minerals containing elements that do not participate in the porphyroblast-forming reaction, or occur as excess reactants, are not displaced by the growing porphyroblasts. Instead, they are overgrown and included within the porphyroblast (e.g. Zwart, 1962; Vernon and Powell, 1976; Barker, (1990;1998); Yardley, 1989). The distribution of porphyroblasts in the rock and their inclusion trails depend on the growing porphyroblast's need for the reactant phases required to build their crystal lattice. Due to the relative inability of Al to be transported at greenschist to lower amphibolite facies conditions, compared to 
other elemental ions such as $\mathrm{Si}, \mathrm{Fe}, \mathrm{Mg}, \mathrm{K}$, or $\mathrm{Ca}$ (Carmichael, 1969; Slack et al., 1993), the ability of garnet to nucleate and grow is dependent on the availability of $\mathrm{Al}$ in the precursor phases it overgrows. Similarly, the abundance of Ti-rich inclusions (e.g. ilmenite) in garnet porphyroblasts is due to the inability of excess Ti to be transferred away from the growing garnet because of its limited mobility (Slack et al., 1993). The presence of quartz rich inclusions result from excess Si in the garnet growth reaction or the unavailability of other elements required for garnet growth. Once formed, a rigid porphyroblast protects inclusion trail patterns from further modification, whereas the matrix may be subjected to subsequent deformation, fabric generation, recrystallization, and grain growth. For this reason, comparisons between porphyroblasts and their surrounding matrix can provide valuable insight into the timing of porphyroblast growth relative to deformation. Zwart (1962) used the relationship between inclusion trails within porphyroblasts (internal foliations, $\mathrm{Si}$ ) and the foliations contained within the matrix (external foliations, Se) to develop a model for determining the relative timing of porphyroblast growth relative to the onset of deformation. The model distinguishes between pre-tectonic, inter-tectonic, syn-tectonic, and posttectonic porphyroblasts. A modified example of Zwart's model from Trouw and Passchier (2005) is shown in Figure 4.1.

Careful interpretation of geometrical relationships between internal and external foliations in porphyroblasts can provide useful insight into the progression of metamorphic prograde reactions relative to deformation; however, 


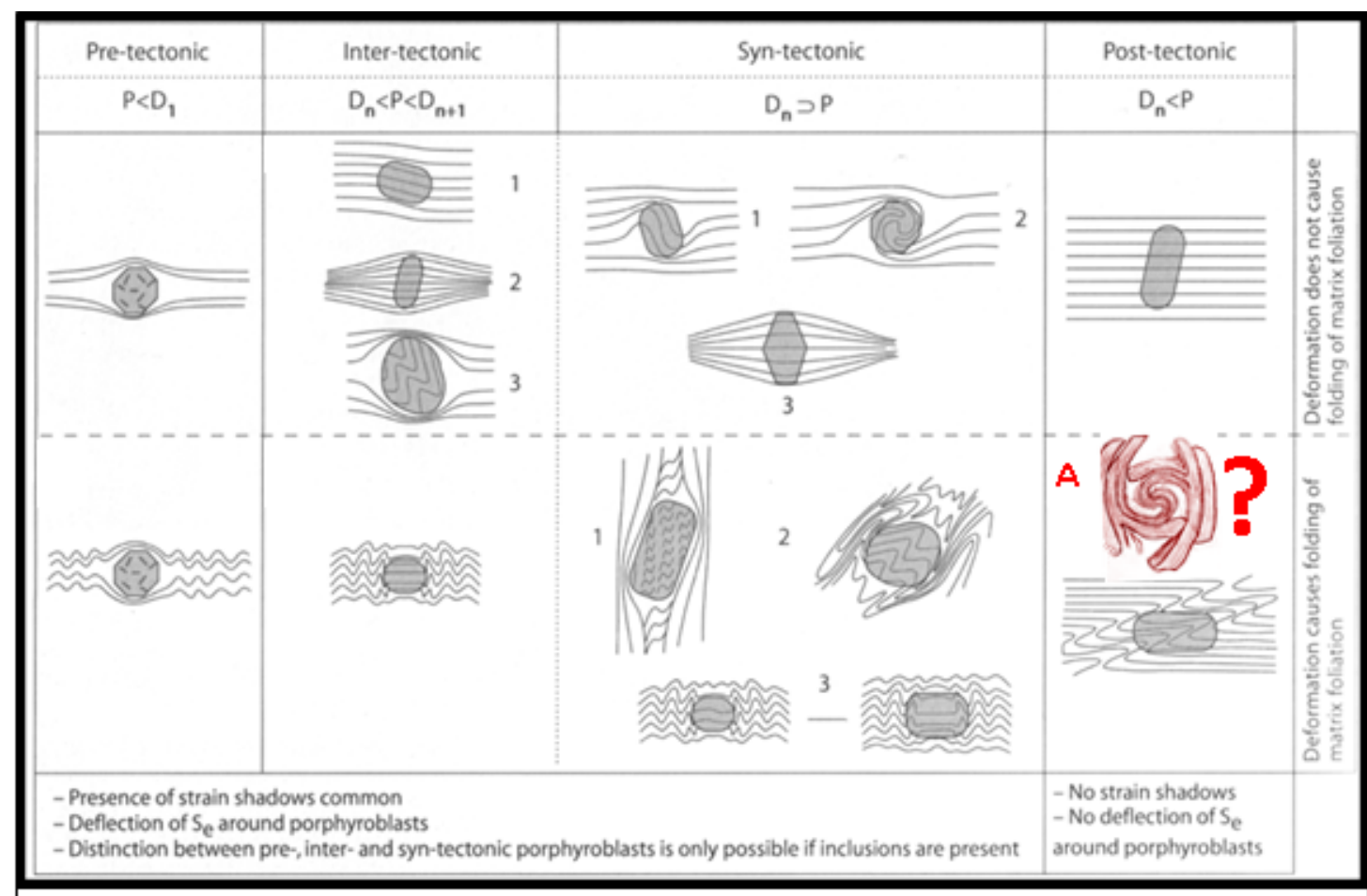

Figure 4.1. Relative timing of porphyroblast growth and deformation. Based on the geometric relationship of inclusion trails in a porphyroblast, internal foliations ( $\mathrm{Si}_{\mathrm{i}}$ ), to external foliations (Se) apparent in the matrix. Based on these relationships, porphyroblasts can be categorized into classes: pre-, inter-, syn-, and post- tectonic (Zwart, 1960\&1962). This relationship is explained in further detail below. Caution: ( $A$ s in $A$ above when $S i$ to Se relationships are discontinuous or ambiguous this model is underdetermined)

1. Pre-tectonic $\left(\mathrm{P} \Leftrightarrow \mathrm{D}_{1}\right)$ The porphyroblasts show randomly oriented inclusions, because they grew prior to the first deformation ewent $\left(D_{1}\right)$ which leads to the development of a later fabric that does not appear in the Porphyroblast. Inter-tectonic $\left(D_{n} \leqslant P \leqslant D_{n+1}\right)$ The Porphyroblasts show a fabric consistent with the fabric of the rock which existed between deformation events $\mathrm{D}_{\mathrm{n}}$ and $\mathrm{D}_{\mathrm{n}+1}$, because they grew sometime between the two deformation events.

a. Syn-tectonic- The Porphyroblasts grew during deformation, and thus show inclusion variations consistent with a changing fabric during growth.

3. Post-tedonic $\left(D_{n} \leqslant P\right)$ the porphyroblast grew after all deformation events ended, and thus has a fabric consistent with the surrounding matrix.

(Modified from Passchier and Trouw, 2005).

many porphyroblast-matrix relationships remain ambiguous (cf. Vernon, 2004,

pages 419-456). Despite these ambiguities, studies of inclusion trails, integrated 
with chemical zoning, nucleation, and crystallization patterns of garnet growth, can help to elucidate such relationships (Ikeda et al., 2002; Ikeda et al., 2003).

\section{GARNET TEXTURAL FEATURES: A PICTURE OF THE PAST}

Porphyroblasts often contain inclusion trails or patterns that reflect the structure of the matrix that existed just prior to their growth. Once overgrown by a porphyroblast, inclusion patterns are preserved from further modification, whereas the matrix can potentially be subjected to deformation, recrystallization, and grain growth. Because of this preservation of internal fabric elements, the inclusions contained within garnet porphyroblasts can provide clues about the state of strain and other fabric elements that were contained within the matrix.

Unfortunately, in many garnets, if the fabric elements of the matrix are no longer continuous with the included fabrics (as a result of subsequent deformation), it is not as easy as to distinguish between pre-tectonic, intertectonic, syn-tectonic, and post-tectonic porphyroblasts as suggested in Figure 4. Therefore, caution must be used when describing the internal and external foliation elements and their relationships with each other.

Despite the complications associated with determining the timing of deformation using inclusion trails, inclusion patterns in porphyroblasts still provide information about the structure of the rock matrix that existed at the time of their growth. For instance, inclusion pattern relationships can be used to reconstruct the timing of mineral growth relative to deformation for a given set of 
metamorphic conditions. Through growth zoning, porphyroblasts may also record their metamorphic evolution from core to rim. In combination, inclusion patterns and growth zoning can provide enough detail to discern the pressure, temperature, and deformation history during the garnet's growth.

Since the growth of porphyroblasts is mainly controlled by diffusion of elements to mineral nucleation sites, elements necessary for growth that are not present within close proximity of the growing garnet have to be transported by diffusion to the surface of the porphyroblast. Minerals that do not participate in the garnet growth reaction are overgrown and enclosed by porphyroblasts as inclusions. As a result, growth zoning patterns and inclusion patterns develop.

INCLUSION GRAIN SIZE AND THEIR RELATIONSHIP TO MATRIX GRAIN SIZE

When garnet porphyroblasts overgrow minerals that do not participate in the garnet growth reaction, the size and shape of included minerals at the time of their inclusion are typically preserved. As a result, shape-preferred orientations, crenulation cleavages, and compositional layering can be preserved as inclusion patterns within porphyroblasts. Once included within porphyroblasts, inclusion patterns can remain unaffected by later deformation or modifications that may affect the matrix. In this way, porphyroblasts may preserve stages in the tectonometamorphic evolution that would otherwise be lost (Figure 4.2). 


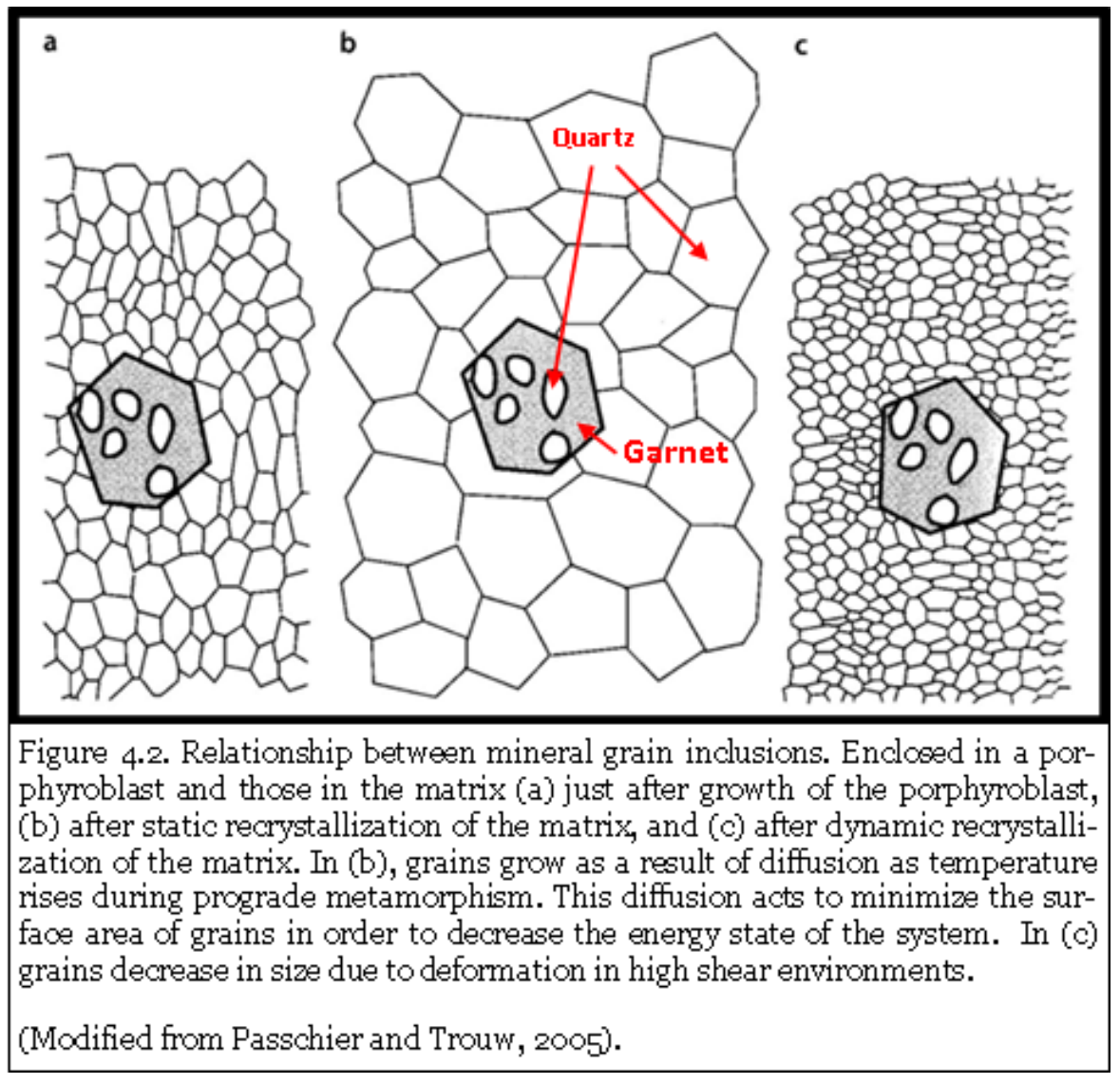

\section{INCLUSION SHAPE AS A PROXY FOR FABRICS PRIOR TO GARNET OVERGROWTH}

If a foliation exists in a matrix which is being overgrown by porphyroblasts, mineral grains included by the porphyroblast will typically maintain their pre-inclusion shape and orientation once included and will appear as inclusion trails within the porphyroblast. The maximum elongation direction of such included grains can generally be assumed to have been normal to the maximum finite shortening strain orientation at the grain site prior to their inclusion. They may be used to estimate the nature of fabric changes with time and the orientation of the fabric relative to the progressively growing garnet porphyroblast. These data could also be useful in unraveling the history of 
spiraled garnets because they may be used to discern whether inclusion trails are continuous or truncated (discussed below). Minerals that do not participate in the prograde garnet-growth reaction should preserve the preexisting fabric orientation unless they are modified by strain increments during the growth of the porphyroblast; however, those that participate in the growth reaction may be affected by shape and size changes as they break down or grow as nutrients are provided to or received from the garnet growth reaction and may not be representative of the prior fabric.

As a result, inclusion trail shapes can give insight into the history of garnet growth based on their geometric shape, relationships to the matrix, and continuity. The geometry of inclusion trails can be representative of the foliation that was overgrown by the garnet, the change in fabric over time during overgrowth, the evolution of the garnet during multiple periods of deformation, or some combination of the three. Because of the myriad of different factors affecting the matrix prior to and during growth of garnet, inclusion trails can have many different configurations and geometries. For ease of classification and based on precedence in the literature, I will use the terms straight, sigmoidal, spiraled, and complex.

GARNET INCLUSION TRAIL GEOMETRIES AND SPATIAL RELATIONSHIPS: SNAPSHOT VS. INTEGRATED PICTURE?

Straight inclusion trails are linearly oriented inclusion trails that appear not to change orientation within a porphyroblast. Their origin is likely the result 
of porphyroblast growth within a uniform stress field. Sigmoidal inclusion trails could be the result of overgrowth of a fabric that was crenulated prior to growth or could be the product of a rotational strain field during garnet growth. Differentiation between the two possibilities would require age dateable inclusions and a very precise age measurement. Syntectonic deformation could take on any shape as a result of the balance between the timing of growth initiation, angle of change between the foliation at time 1 and time 2 , growth rate, and deformation rate. Assuming that a stress field reorientation perpendicular to a preexisting foliation occurred prior to or during a period of syntectonic garnet growth, sigmoidal inclusion trails could form with variable curvature, depending on the rate of deformation relative to garnet grouth. For instance, if the deformation rate were high and growth rate slow, the inclusions would have steep sigmoidal tails. If the deformation rate were slow and the growth rate fast, the sigmoidal tails would have a shallow slope.

In addition to all of the complexities that revolve around sigmoidal inclusion trails, spiraled inclusion trails could be the result of many periods of deformation and porphyroblast growth (e.g. non rotational model), progressive rotation and growth of a porphyroblast in a deforming matrix (e.g. rotational model), or a combined model that takes into consideration the overgrowth of preexisting foliation fabrics during continuous deformation and metamorphism (Bauer et al. 2002).

The term complex inclusion trails is used for any inclusion trail geometry that does not fit into the categories above. 
As mentioned earlier, if inclusion trail relationships between the internal garnet inclusion fabric ( $\mathrm{Si}$ ) and the external foliation in the matrix (Se) are continuous, the matrix relationships can be useful in discerning the relative timing of the garnet growth relative to the deformation of the matrix. However, if this is not the case, then it becomes far more difficult to discern the relative timing of garnet growth and deformation. When trying to decide the relative timing of deformation and garnet growth within the internal foliations of garnets, it is important to not only look at the geometry of the inclusion trails but also the continuity of the inclusion trails and indicators of their growth.

The next chapter introduces and explains how two microanalytical techniques can provide additional information about the nucleation, growth, and deformational histories of garnet. This additional insight into the histories of spiraled garnets can provide a better understanding of the relative timing of garnet growth and deformation. When these data are incorporated with the textural relationships of garnet inclusion trails, additional insight into the mechanisms behind the formation of spiraled garnets may be gleaned. After the microanalytical techniques are introduced in the first section of the next chapter, the second section explains how apparent truncations within chemical zonation patterns, inclusion trails, and crystallographic axis orientation maps can be used to tie all of the textural relationships together to evaluate the continuity of garnet growth. 
MICROANALYTICAL TECHNIQUES TO AID IN OUR UNDERSTANDING OF THE NUCLEATION, GROWTH, AND DEFORMATIONAL HISTORIES OF GARNETS

CHEMICAL MAPS OF GARNET TO DETERMINE NUCLEATION AND GROWTH PATTERNS

This section explains how chemical zonation maps can be used to provide evidence for garnet growth patterns resulting from the replacement of overgrown reactants and the inclusion of remnant phases. The use of nucleation and growth patterns within chemical zonation maps do not completely eliminate the ambiguities associated with inclusion trail relationships and the rotational/nonrotational garnet growth models. They do, however, limit the relative timing of foliation development and garnet overgrowth as well as the direction of garnet growth.

Spear (1993) summarizes how chemical zonation patterns can be used to infer the nucleation and growth histories of garnet porphyroblasts. This relationship is based on the strong partitioning of elements such as Mn into growing garnets during porphyroblast growth. Since diffusive transport is required to replenish the matrix of depleted elements partitioned into garnet during growth, the matrix concentrations of such elements are depleted continuously during growth. Thus, garnet porphyroblasts will have their greatest Mn concentration at the time of nucleation and a progressively lower Mn concentration during continued growth in response to depleted matrix Mn. Since internal elemental diffusion within garnet does not occur easily until high temperatures, Florence and Spear (1991) 
showed that modification of growth zoning patterns by diffusion should be insignificant. From these relationships, and the near coincidence of garnet growth contours with Mn zoning contours in P-T space Spear (1993), it is believed reasonable to use such patterns as a proxy for nucleation and growth within garnet (Daniel and Spear, 1998). That is, nucleation areas can be inferred from isolated Mn maxima within garnet porphyroblasts.

Spear and Daniel (1998) observed that many Mn maxima existed within garnet crystals from the Harpswell Neck area of Maine and interpreted these as multiple nucleation sites that continued to grow together to form the porphyroblasts. This interpretation relied on the assumption that $\mathrm{Mn}$ was in equilibrium over the extent of a thin section. However, Spear and Daniel (2001) subsequently determined that $\mathrm{Mn}, \mathrm{Fe}, \mathrm{Mg}$, and Ca could not all be in equilibrium simultaneously and thus local bulk composition in addition to diffusion also affects garnet nucleation and growth kinetics. The assumption that high Mn regions represent initial garnet nucleation sites was further called into question by Hirsch et al. ( 2003) based on Electron Backscatter Diffraction (EBSD) results, which did not show crystallographic misorientations across zones of high Mn regions. However, Spear and Daniel (2001) determined from their analysis that garnet nucleates first on crenulations, containing high concentrations of mica and chlorite that provide the reactants locally and induce rapid overgrowth of an entire crenulation. This leads to the complex apparent zoning patterns in a single 2D section through a garnet porphyroblast. Hirsch et al. (2003) attributed high Mn concentrations within single garnet crystals to garnet replacement of 
precursor phases rich in $\mathrm{Mn}$. As the garnet grows during prograde metamorphism, $\mathrm{Mn}$ is incorporated into the garnet's crystal structure at the location of the replacement. Although, local Mn maxima within garnets may not represent nucleation zones because they may be zones of inherited Mn from the replacement of precursor phases. It is also likely that garnet would nucleate on Mn rich precursor phases such as chlorite.

These studies demonstrated that the controls on Mn concentrations within growing garnet can be a result of the concentration of $\mathrm{Mn}$ within the precursor phase overgrown by the garnet. The diffusion of Mn from the matrix to the location of garnet growth and the time at which garnet grew relative to matrix depletion are, therefore, complicated by the chemical inhomogeneity of the material overgrown by the garnet. To minimize the impact of variable elemental concentrations within precursor phases, multiple elements such as $\mathrm{Mn}, \mathrm{Cr}$, and $\mathrm{Y}$, which all have an affinity for early incorporation into the growing garnet, should be used and compared when analyzing the nucleation and growth histories of garnets. Some of the potential issues associated with differentiating multiple nuclei from local heterogeneities inherited from precursor phases potentially can be resolved using a method called Electron Backscatter Diffraction (EBSD) (Figure 4.3) (Hirsch et al., 2003; Prior et al., 1999; Spiess et al., 2001; Whitney et al., 2008; Whitney and Seaton, 2010). The following section will introduce EBSD and explain what it is and how it may allow for locating multiple nuclei that have coalesced during growth. 


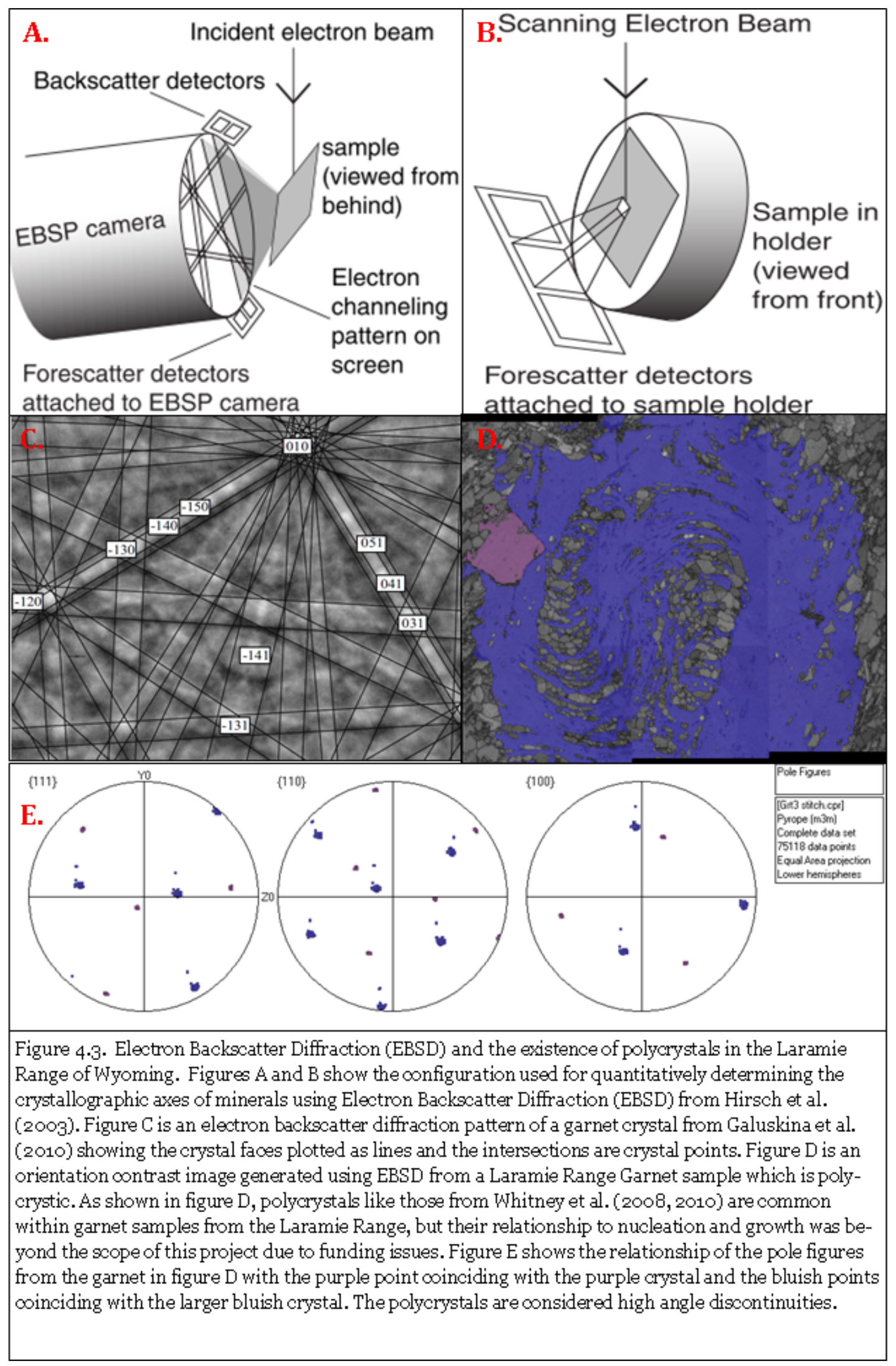


ELECTRON BACKSCATTER DIFFRACTION ON GARNET TO DETERMINE VARIATIONS IN CRYSTALLOGRAPHIC ORIENTATION

Variations in the lattice-preferred orientation (LPO) of garnet grains can be used to better understand the nucleation, growth, internal deformation, and deformation mechanisms of porphyroblasts. In the case of garnet porphyroblasts, LPO variations may correlate with chemical variations or inclusion trail patterns. However, unlike minerals of lower crystal symmetry, such as quartz or calcite, garnet’s isometric crystal structure does not allow LPO determination using a universal stage on a polarized light microscope. However, LPO variations can be detected using Electron Backscatter Diffraction (EBSD), a micro analytical technique that uses patterns from elastically scattered electrons backscattered off mineral crystallographic boundaries. The technique is capable of spatial resolutions on the order of 0.25 um (McDonnell 1997; Fliervoet et al., 1999), and the capability of measuring crystallographic misorientation angles as low as 0.1 degree (Prior et al., 1999). Because the mineral phase and orientation can be determined using electron backscatter patterns, EBSD serves as a quantitative way of determining the LPO relationships between mineral grains in deformed rocks.

Polycrystals, which are defined as crystals that are comprised of two or more distinct lattices separated by high-angle boundaries, are believed to form during garnet growth (Figure 4.4) (Spiess et al., 2001; Whitney et al., 2008; Whitney and Seaton, 2010). The development of garnet crystals with grains that have crystallographically distinct lattice preferred orientations is dependent on many factors associated with the nucleation, growth, and deformation histories of 


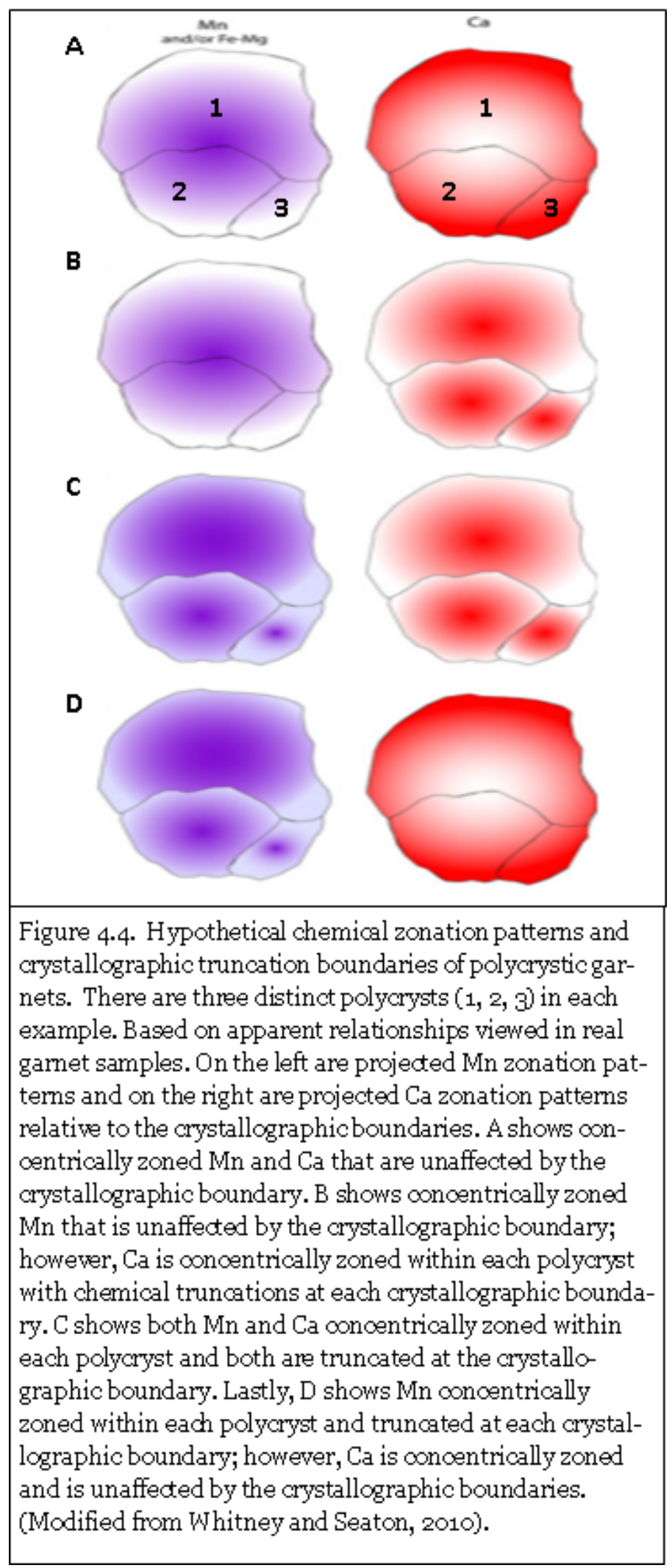


the garnets. Understanding the distribution of polycrystals and their dependency on the metamorphic and deformational history of the garnets could aid in the understanding of spiraled garnet formation. However, for reasons described below, the crystallographic history preserved in garnets may be incomplete. Examples of polycrystic garnet in the literature show that high-angle boundaries of 28-61 degrees are preferentially found in garnets, and that these boundaries are often oriented such that they can be rotated into coincidence along the same low energy planes that exist within euhedral garnet crystals (Whitney et al., 2008). Although polycrystals appear to exist frequently within garnets, their existence does not appear to always affect chemical zoning patterns or inclusion trail relationships (Whitney \& Seaton, 2010). Garnet polycrystals, similar to the garnets of Whitney et al. (2008) (Figure 4.4), were recognized in garnet samples in the Laramie Range study area (Figure 4.3). Although the garnets collected for this study were not evaluated for polycrystals, works completed on garnets adjacent to the study area were evaluated for polycrystals using EBSD at the University of Minnesota. This unpublished work of mine, included in the appendix, showed that high angle boundaries existed within spiraled garnet samples but that low angle boundaries were not present. Unfortunately, due to a lack of funding, this same EBSD work could not be completed on the garnet samples from this study; therefore, inferences were made that these sorts of features exist within our garnets, but they were not characterized. 
Although low angle crystallographic boundaries might randomly occur less often than high angle boundaries within garnet samples from both the studies of ( Whitney et al., 2008) and those of the author (unpublished), it seems unlikely. The apparent preferential preservation of minimum energy boundaries in garnets (Whitney et al., 2008; Whitney \& Seaton, 2010) could mean that lower angle or higher energy boundaries are recrystallized to a dominant crystallographic domain during growth coalescence, or that they rotate such that their euhedral faces coincide during overgrowth. If individual garnet nuclei rotate and coalesce along euhedral faces, the record of their coalescence would be preserved as high angle (low energy) crystallographic boundaries (Figure 4.5) (Whitney et al., 2008), and inclusion trail patterns should be disturbed.

However, if high energy or low angle boundaries are recrystallized during garnet growth or post growth, such that only low energy or consistent crystallographic lattice orientations are preserved, EBSD techniques may not recognize such coalesced nuclei or deformation features if a crystallographic boundary is not preserved. In the latter case, chemical zonation patterns could be used to identify potential coalesced nuclei, but there would not be a change in LPO from nuclei to nuclei.

The potential ability for garnet nuclei to recrystallize calls into question the significance of EBSD as a means of evaluating the nucleation, growth, and coalescence history of garnets. The absence of crystallographic boundaries within garnet crystals may not preclude a history of coalescence within the garnets. As a result of this finding and the expense and time of running EBSD, EBSD 


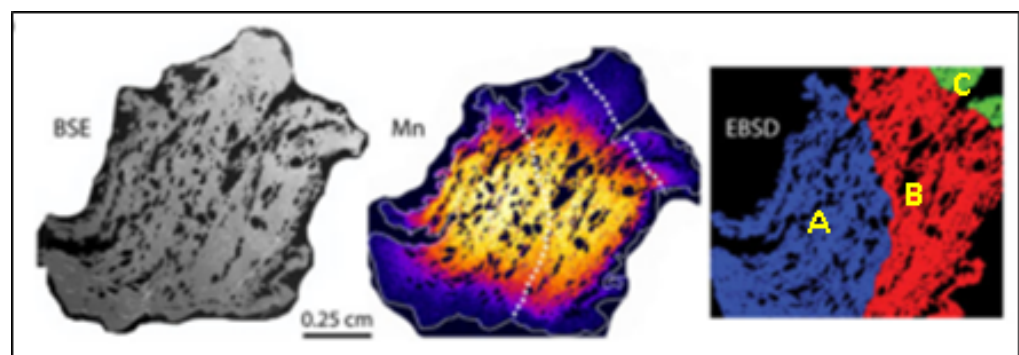

Figure 4.5. Polycrysticgamet from SE Vermont. Howewer, the polycrystals do not exhibit any change in $\mathrm{Mn}$ concentration or inclusion trail patterns at across the crystallographic boundaries. If these polycrystals were to have nucleated at different times and grew together they should be changes in Mn concentration at the boundaries. This garnet appears to have been growing continuously without any change in fabric relationships, yet it preserves multiple lattice orientations. This is an apparent conflict between the nucleation and growth from chemical mapping and the nudeation and growth from crystallography. It appears from this ad slice through the garnet and the representative maps that gamet grew continuously from core to rim yet the lattice preferred orientation changed three times ( $\mathrm{A}, \mathrm{B}, \mathrm{C}$ above) during growth. What the EBSD map tells us about the nucleation and growth history of this garnet is unclear. (Modified from Whitney and Seaton, 2010).

techniques were not used in this study; however, EBSD does aid in the identification of multiple nuclei when preserved, and it can be a useful tool in evaluating the nucleation and growth histories of garnet when combined with other analyses.

\section{TRUNCATIONS OF TEXTURAL, CHEMICAL, AND CRYSTALLOGRAPHIC RELATIONSHIPS WITHIN GARNET:A MEANS OF DETERMINING THE CONTINUITY OF GROWTH}

The continuity of inclusion trails within garnet can be used to evaluate how continuously a garnet has grown and potentially how it was deforming. The location of discontinuities within garnet porphyroblasts can be a result of zones of resorption, hiatuses in garnet growth, or rapid changes in the orientation of the foliation relative to the growth rate of the garnet. Interpreting these 
discontinuities may require a combination of data from other sources, such as chemical zonation patterns and the location of crystallographic domain boundaries, but noting their locations is useful in itself. Truncations of inclusion trails, crystallographic orientation maps, and chemical zonation patterns potentially hold answers to changes that took place within the matrix during garnet growth.

Inclusion trail truncations can be caused by changes in the orientation of stress during garnet growth, changes in growth rate of garnet, reactions that result in the resorption of garnet or pressure dissolution prior to a subsequent period of growth.

Truncations of chemical zonation patterns within garnets can be caused by diffusive transport of elements from the garnet during growth hiatuses, followed by multiple periods of garnet growth, rapid changes in the composition of the matrix (other minerals grow or resorb that contain the element being mapped), or local variations in chemical composition of precursor phases that may be incorporated into the garnet as local maxima (cf. Bell and J ohnson, 1989; Florence and Spear, 1991; Pyle and Spear, 1999; Daniel and Spear, 1998; Trouw and Passchier, 2005; Carlson, 2006; Hirsch et al., 2003).

Sharp changes in crystallographic orientation within a garnet crystal may produce visible truncations on orientation contrast maps through EBSD (Prior et al., 1999). These domain boundaries may result from the coalescence of multiple nuclei or by deformation, which may lead to the formation of low angle misorientations in the garnet crystal (e.g. Prior et al., 1999; Prior et al., 2000; 
Storey and Prior, 2005; Spiess et al., 2001; Kleinschrodt and Duyster, 2002). Therefore, EBSD may allow for identification of distinct garnet domains not seen by other methods.

Distinct differences in truncation patterns would result from the different truncation-forming mechanisms, and the relationships that exist between truncation types can help in the evaluation of what lead to a specific set of truncations. For example, multiple periods of garnet growth and reorientation of the stress field, separated by hiatuses, should lead to the formation of truncations in both chemical zoning and inclusion trail patterns at the same location (e.g. Bell and J ohnson, 1989). If this were the case, the orientations of truncations would generally be along planes normal to the direction of maximum shorting at the time of dissolution. Of course, this assumes that garnets did not rotate relative to a geographically fixed reference frame (cf. Bell et al., 1992).

In contrast to the previous example, one period of continuous garnet growth should show continuous growth zoning and varied rates of change in inclusion trail patterns without defined inclusion trail truncations. However, discerning whether the same garnet rotated or the fabric rotated around the garnet during growth would still remain ambiguous. 
CHAPTER 5:

\section{STRUCTURAL AND TECTONIC BACKGROUND OF THE STUDY AREA}


The field area selected for this study has a well preserved and documented tectonometamorphic history, so we can place the features observed within the spiraled garnets from the study into this context.

The Laramie Range of southeastern Wyoming (Figure 5.1) contains a core of Archean gneiss and interlayered metasedimentary and metavolcanic rocks along the southeastern margin of the Wyoming Province that were intruded by a mafic dike swarm ca. 2010 Ma (Cox et al., 2000). The rock units were reworked during two younger periods of Paleoproterozoic orogenesis - the Trans-Hudson and Medicine Bow orogenies (Bauer et al., 2010). The reworked metapelitic and metapsammitic units contain numerous porphyroblasts of kyanite, staurolite, and garnet that record a period of high-pressure (ca. $10 \mathrm{~kb}$,) amphibolite facies metamorphism (Goergen and Bauer, 2002) associated with E-W shortening and the formation of a series of recumbent, west-verging folds (Bauer et al., 2010). In several locations, large garnet porphyroblasts (1-3 cm diameter), which grew during this event, contain complex spiral inclusion trails (Bauer et al., 2002) which are the focus of this study.

As shown in Figure 5.1, the garnets in the study area occur within interlayered metapsammite which contains an older Archean foliation (S1) that was folded and deformed to produce a crenulation foliation (S2). One of the products of this folding is an antiform that contains the associated S2 axial plane crenulation foliation and is exposed over approximately $1 / 2$ a square mile within the Moonshine Peak quadrangle. The spiral garnets have overgrown this crenulation foliation and appear to have rotated during the late stages of 


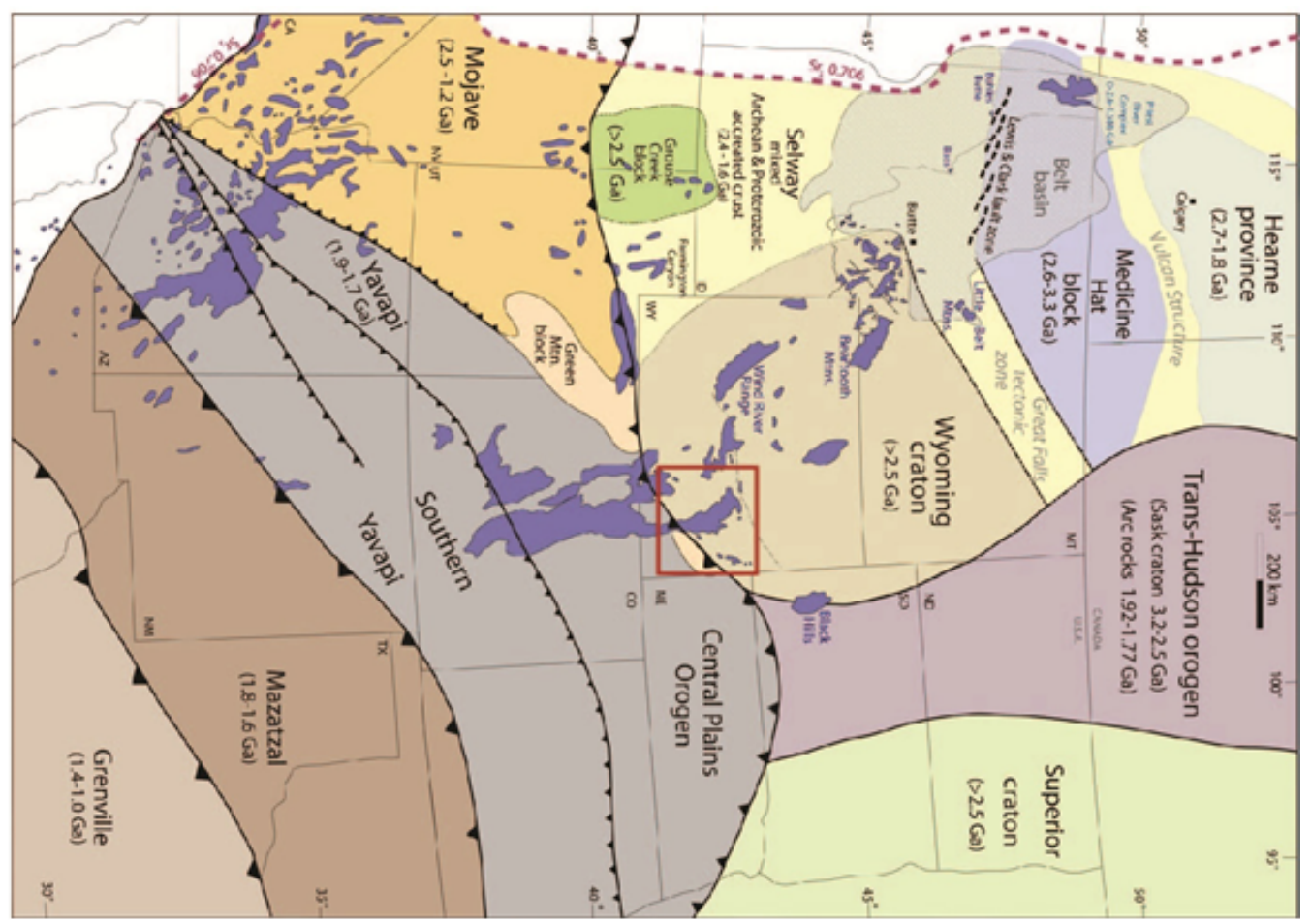

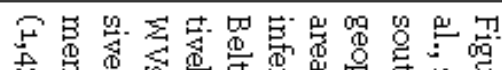

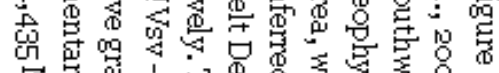

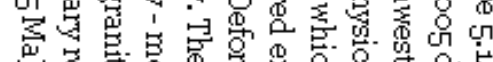

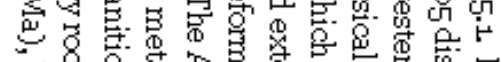

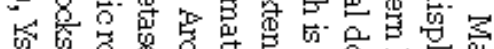

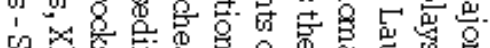

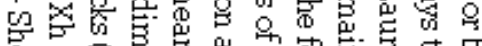

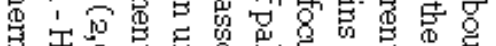

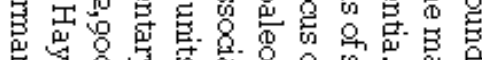

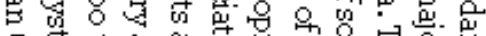

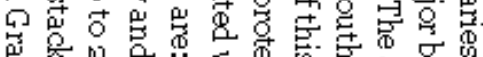

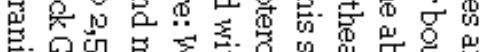

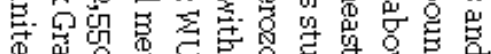

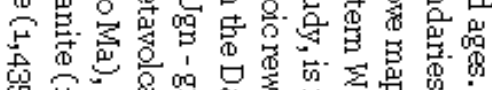

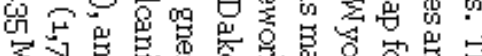

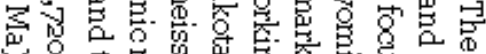

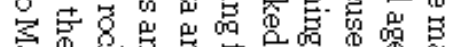

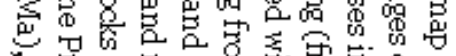

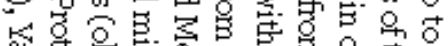

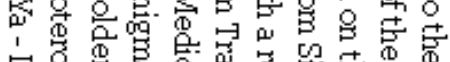

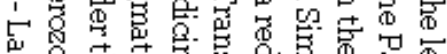

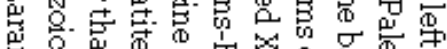

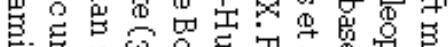

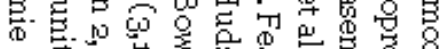

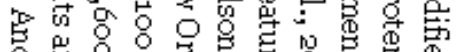

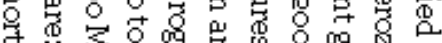

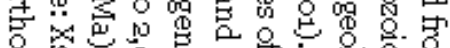
尊

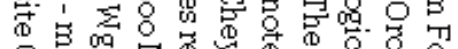

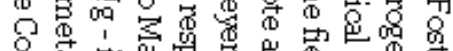

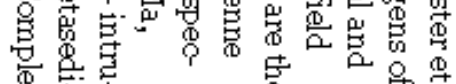

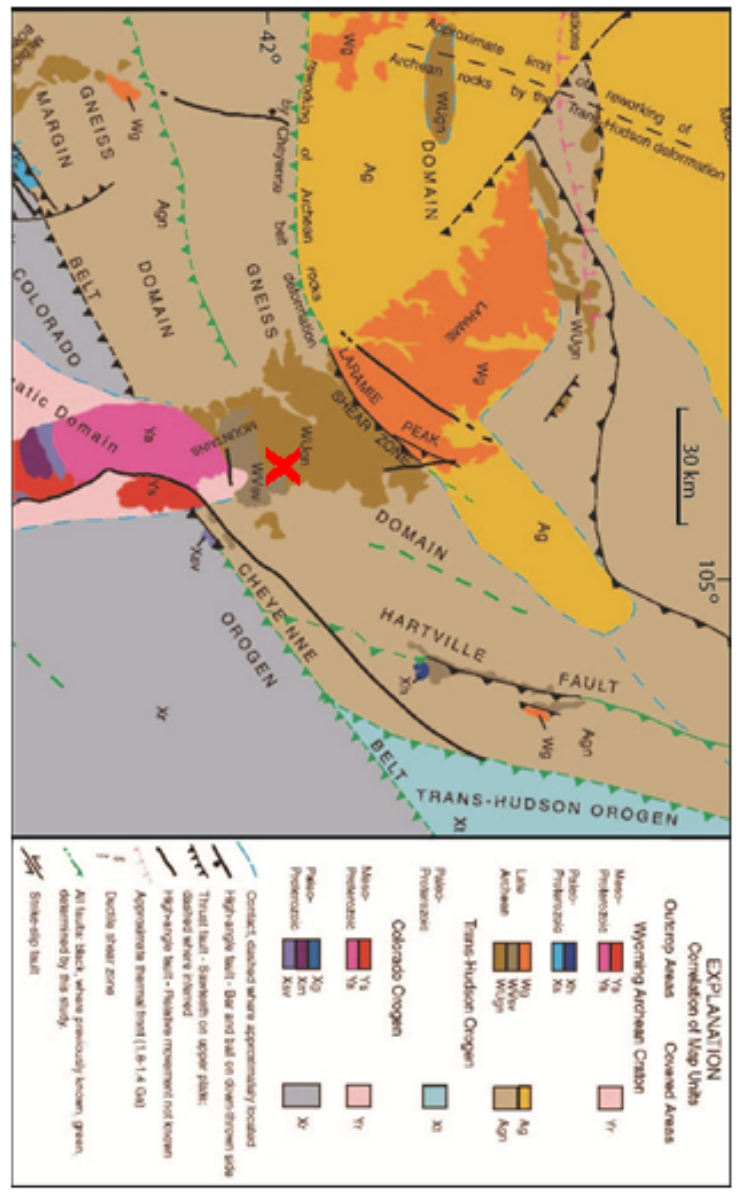


continued F2 folding (Bauer et al., 2002). This site is ideal for the study of spiral garnets because of the apparent relationship between folding and garnet rotation. Within the well exposed antiformal structure, garnets on opposing limbs have different senses of rotation - clockwise on the left limb and counterclockwise on the right limb, when facing the fold closure. Preliminary mapping of the interlayered sequence of metapelite, metapsammite, quartzite, and amphibolite suggests that flexural flow folding of this interlayered sequence produced flexural shear along unit boundaries that may have provided the mechanism for rotation of the garnets during their growth (Bauer, et al. 2002).

R. Bauer completed an extensive field study within the region surrounding the antiformal structure which provided a detailed context for sampling and relating garnet internal foliations to matrix foliations identified throughout the region. Bauer's analysis showed that crenulation of the S1 foliation was penecontemporaneous with the onset of F2 folding and garnet growth. Continued deformation destroyed the crenulated S1 foliation in many of the metapelitic units, which developed a dominant S2 foliation; however, many of the psammitic units clearly retain the crenulation foliation (Figure 5.2). Stereographic projection of the D2 orientation data from the study area are plotted in Figure 5.3.

After garnet growth, a third period of deformation and F3 folding occurred (Figure 5.4), and a sparse S3 foliation developed locally and truncates the garnet porphyroblasts (Figure 5.5). S3, where present, crosscuts S2 and garnet fabrics and destroys S2i and S2e relationships. The regional analysis completed by 


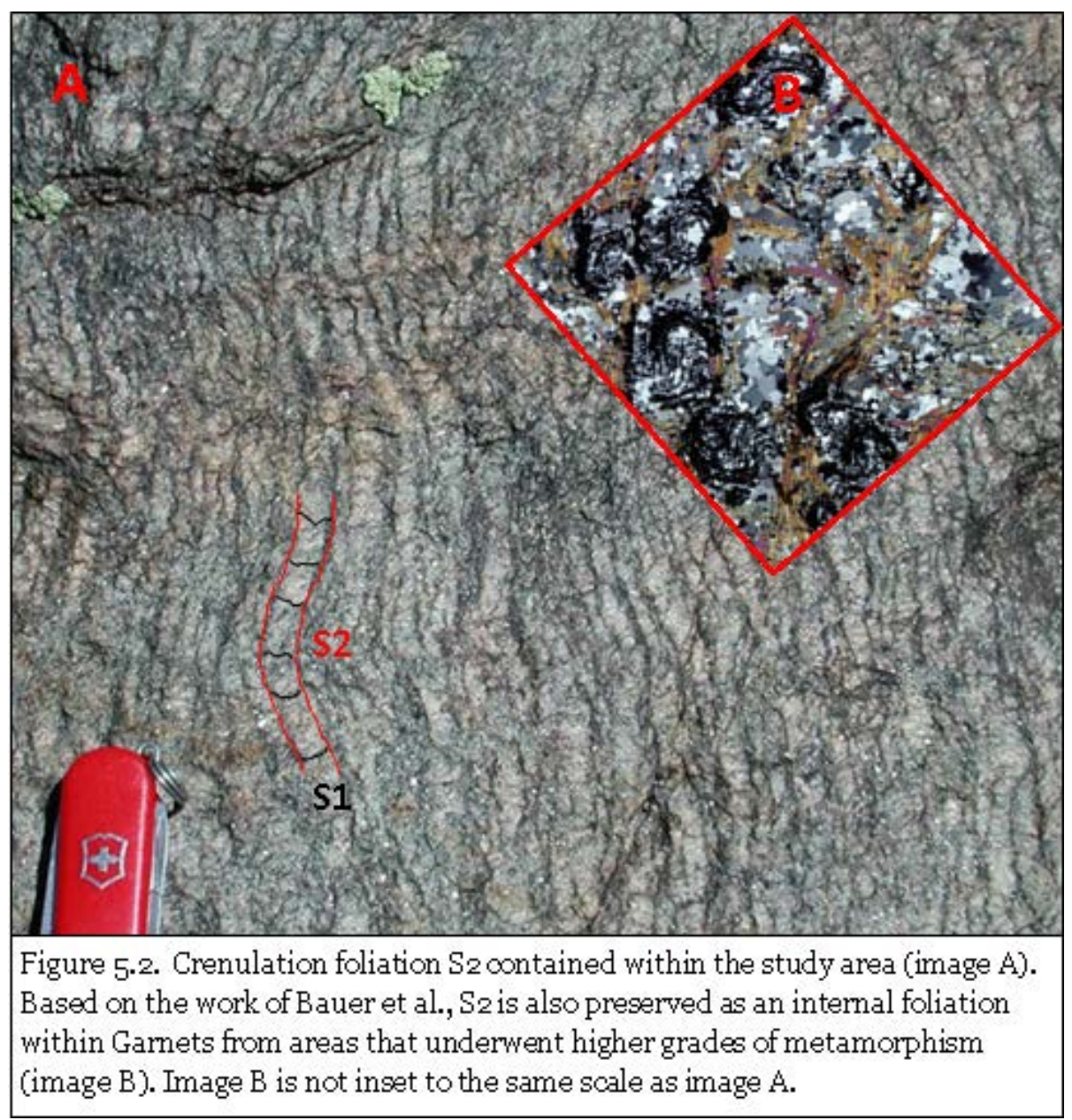

Bauer established the deformation and metamorphic relationships necessary to compare garnet growth structures to folding and foliation events. In addition, the observation by Bauer that opposite rotation senses occur on opposing sides of the F2 fold, containing many of the spiral garnets, served as a basis for many of the issues addressed within this study.

As Bauer et. al. (2002) established in their study comparing the rotation sense of spiraled garnets on either side of the fold, they observed that field strain 


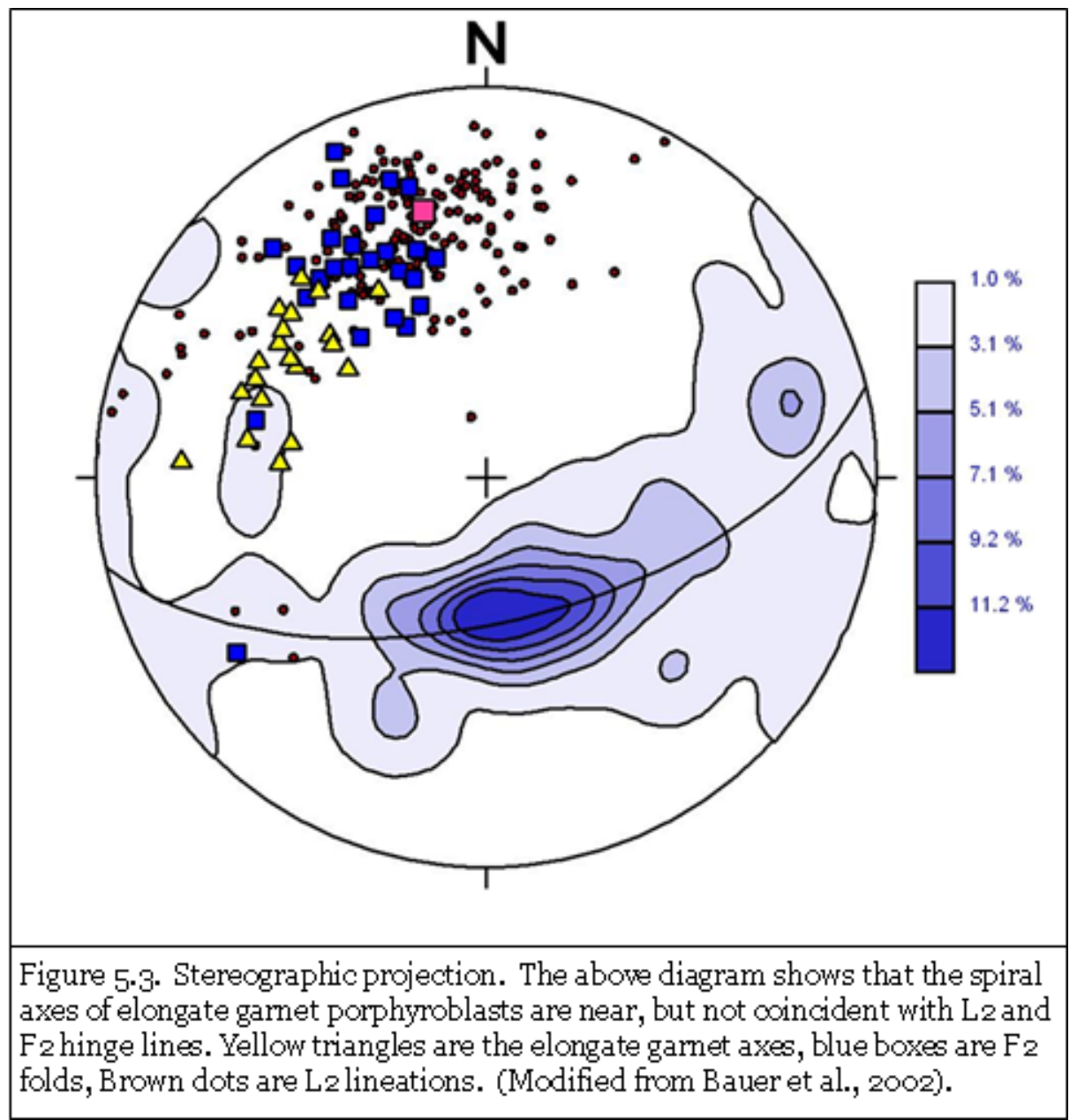

relationships can be used to constrain regional deformation trends, and deformation trends may potentially shed light on the micro-scale features seen within spiraled garnets. Despite the apparent difference in rotation sense of the spiraled garnets on opposing fold limbs in the field area, deformation relationships can vary at many different scales. For instance, a plethora of garnet forms can be observed within close proximity of each other as a result of variable amounts of apparent rotation, nucleation in units with different development of the included crenulation foliation, or differences in the observed section through 


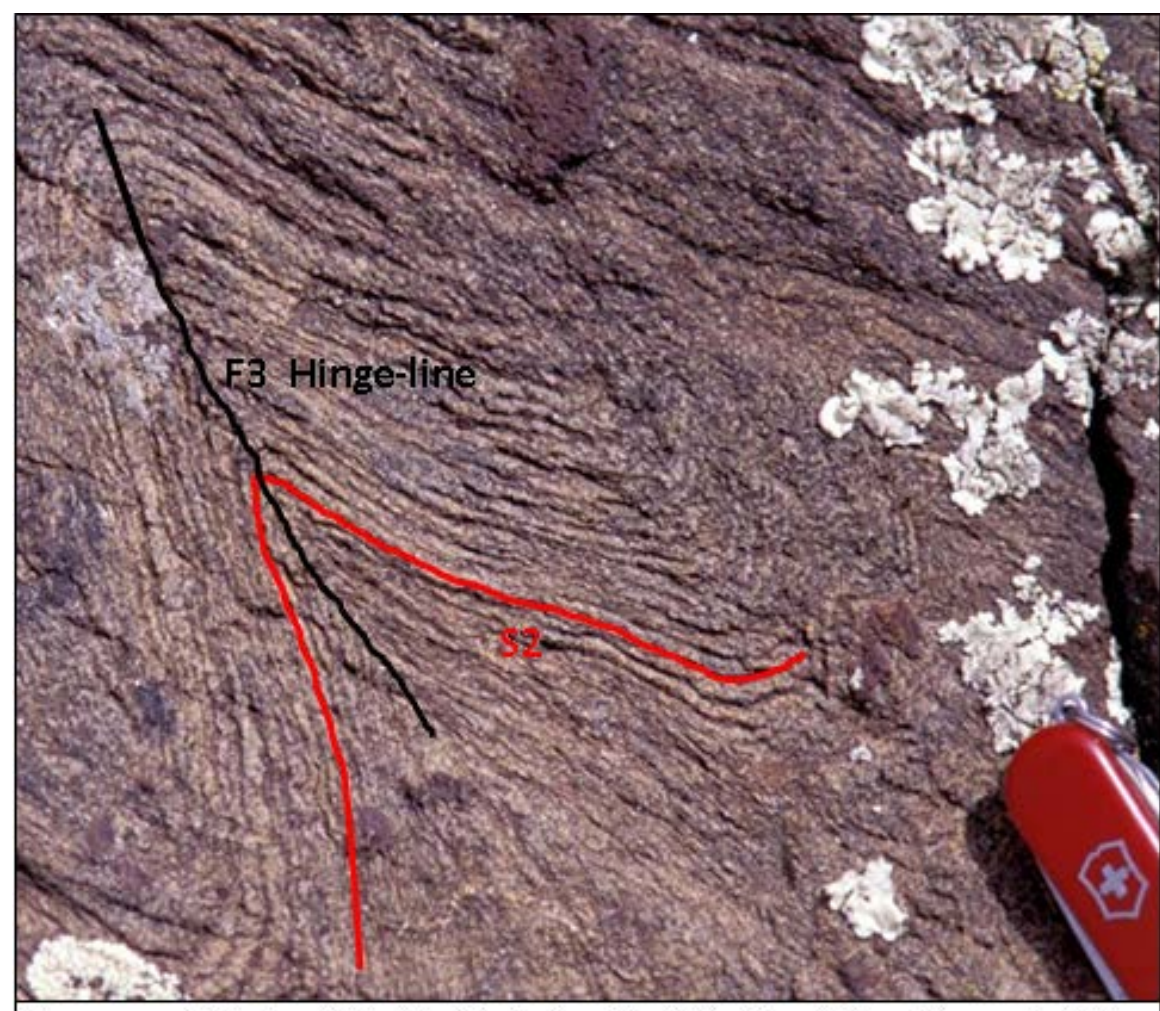

Figure 5.4. $\mathrm{S}_{2}$ being folded by $\mathrm{D}_{3}$ to form $\mathrm{F}_{3}$ folds. The distinct change in folding style from $\mathrm{D}_{2}$ to $\mathrm{D}_{3}$ allows for quick differentiation of foliation surfaces in the field. Gently folded $D 2$ related strata are often crosscut by tight $D_{3}$ related chevron style folds.

the spiral garnet even though they formed in the same regional shortening field and underwent a similar pressure-temperature-time path.

In order to determine whether the garnets within the field area grew continuously, a new spiraled garnet evaluation workflow was developed. Unraveling the mechanisms behind the formation of spiraled garnets is a complex task that requires an integration of many different techniques. It is difficult to interpret and relate observations derived from the different textural and analytical techniques into a straight forward conclusion about the growth of garnet and the timing of deformation events. The following chapter describes the 


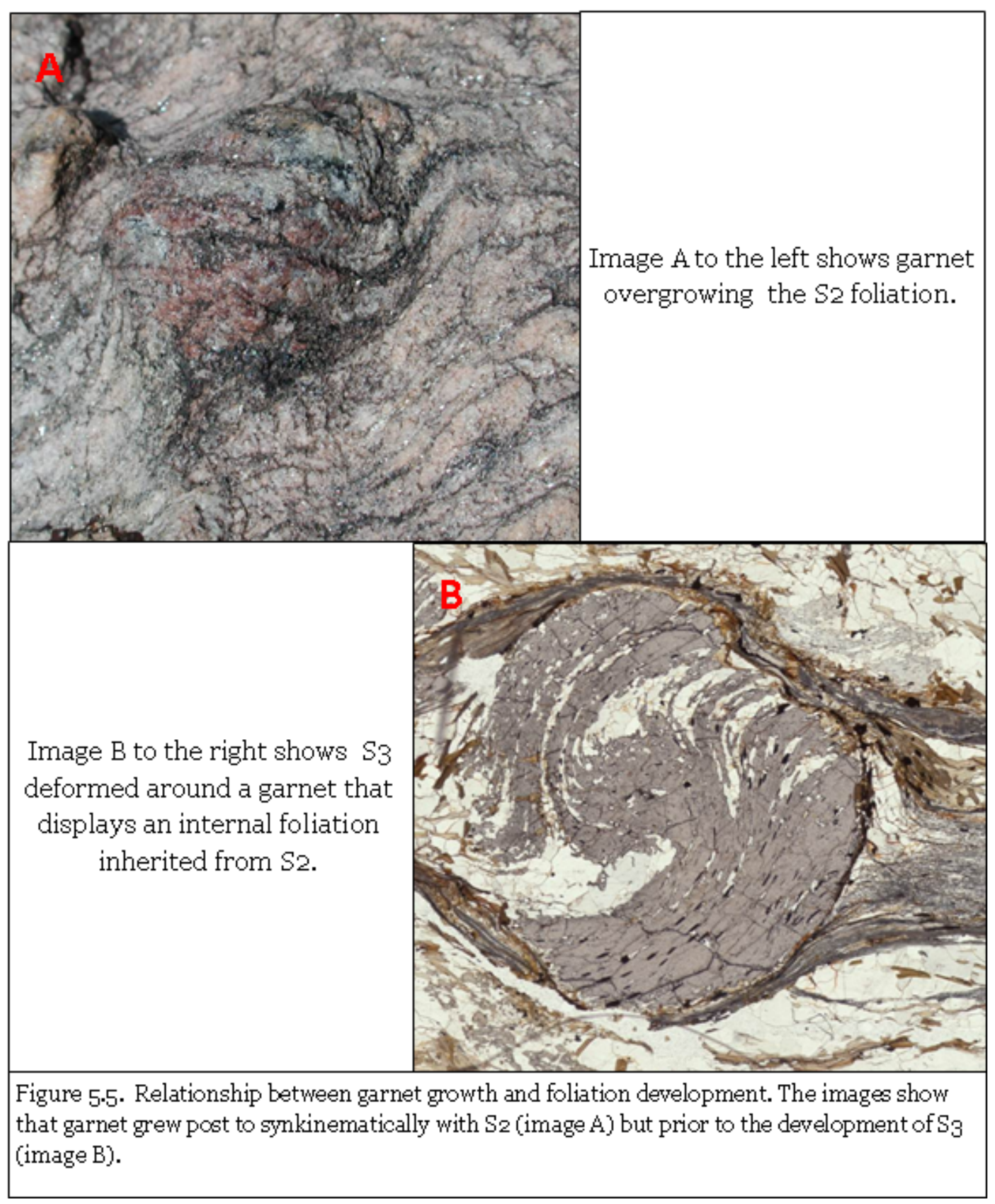

systematic approach used during this study to evaluate the origin of spiraled garnets based on these multiple techniques. The approach does not directly address whether or not the garnet samples rotated during growth, but instead focuses on the timing of their growth relative to deformation. The flow diagram 
presented belowillustrates the information that various analytical methods provide to evaluate the relationship between garnet nucleation, growth, and deformation that would produce spiral garnet-inclusion trail geometries, chemical zonation patterns, and crystallographic discontinuities.

One key difference between the non-rotational model of Bell and J ohnson (1989) and the models of both Bauer et al. (2002) and Schoneveld (1979) is that the model of Bell and J ohnson involves multiple periods of garnet growth, separated by reorientation of the stress field and potential garnet resorption. Both Bauer and Schoneveld call on continuous overgrowth of a foliation.

The field area of this study does not appear to demonstrate deformation fabrics that that would be indicative of high shear strain which is needed in order to form spiraled garnets via the rotational model of Schoneveld (1979). Although the garnet inclusion trails are spiral shaped, they do not appear to exhibit any major truncations. The evidence from S2 and S3 deformation fabrics shows that the garnets grew during one period of metamorphism. If it can be further demonstrated that no apparent hiatuses exist within the garnets, then the continuity of garnet growth makes it unlikely that the non-rotational model proposed by Bell and J ohnson can explain the spiraled garnets found within the field area of this study. The model of Bauer et al. (2002) could explain the sigmoidally shaped garnet cores in the area, but the suggestion that garnets rotated during the late stages of fold-induced flexural flow would need to be verified as the mechanism leading to the full apparent spiral intensities of greater than 180 degrees. 
This study: 1) uses chemical maps and inclusion trail relationships to verify that the spiraled garnets within the field area grew continuously, 2) shows examples of how S1 and S2 fabrics appear to be contained within garnets; whereas, S3 is discontinuous and only contained within the matrix, 3) investigates whether spiraled garnets within the Laramie Range contain polycrystals, 4) notes relationships between core structures of garnets relative to their rims to define whether mechanisms acting on the garnets appear similar through time and between garnets, 5) investigates rotation relationships using the intensely spiraled examples of Bauer et al. (2002) in order to compare apparent mechanisms to our garnets , 6) compares and contrasts the mechanisms proposed in the existing models for spiraled garnet growth with those apparent in our garnet samples, and lastly, 7) presents a combined model to explain spiraled garnet growth within the Laramie Range.

The garnet workflow, presented in the next section, was developed to provide a simple way of evaluating the continuity of garnet growth. 


\section{CHAPTER 6:}

A SPIRALED GARNET EVALUATION WORKFLOW TO EVALUATE THE CONTINUITY OF GARNET GROWTH 
A systematic microanalytical approach to reconstruct the nucleation, growth, and parts of a garnet porphyroblast's kinematic history can aid in the interpretation of the rotational history of the garnet being evaluated; however, even using such an approach, it may still not be possible to discern whether spiraled garnets are the result of garnet rotation or some other mechanism. Nevertheless, the purpose of this chapter is to introduce such a systematic approach to evaluating whether a garnet has grown through one period of garnet growth or through multiple periods of garnet growth. As such, this approach would at least evaluate whether the spiral garnets in question could have formed by the mechanism proposed by Bell and J ohnson (1989). This process takes into consideration: 1) the presence of truncations in inclusion trails, 2) chemical zonation patterns, and 3) crystallographic orientation contrast images to mark potential hiatuses in garnet growth. Determining that a spiraled garnet grew continuously makes it highly unlikely that the model of Bell and J ohnson (1989) would apply in explaining a spiraled appearance. It would not mean that the model of Schoneveld (1979) is applicable. The overgrowth of preexisting fabric elements and/ or rotation of external foliation fabrics during growth could allow a spiraled garnet to form without rotation of the garnet itself.

The following flow diagram is designed to provide a step-by-step guide to interpreting the growth history of garnets and their relationship to deformation and included fabrics. It is organized based on apparent truncations associated with internal and external foliation fabrics (Si to Se), chemical zonation patterns, crystallographic orientation maps, and inclusion trail fabrics (Si). Electron 
backscatter diffraction (EBSD) is used to determine if a garnet has a uniform crystallographic orientation. Electron Probe Microanalysis (EPMA) is used to construct chemical zonation maps. Visual inspection of inclusion trail relationships in photomicrographs and chemical maps are used to discern internal foliation $(\mathrm{Si})$ truncations.

As displayed in Plate 1 of Appendix 4, the flow diagram starts by presenting a list of tasks that should be completed prior to the analysis of samples at the thin section scale. Measurement of field deformation features and determining their relationship to the foliations and lineations at the hand sample scale will aid in the analysis of samples in the lab and provide a context for the deformational history of the observed samples. Once a sample locality has been selected, it is important to orient the samples relative to a geographical reference frame. Foliations within the fabric of the sample should be oriented based on their strike and dip, and if recognized in the field, the trend and plunge of elongate garnet axes. Trend and plunge of garnet samples can be calculated in the lab as long as the hand sample was properly oriented. Knowing the orientation of the garnet will make it possible to determine whether garnet fabric trends vary regionally. Once samples are selected and thin sections have been made, interpretation of garnet fabrics can begin.

There are multiple ways to work through the sequential analysis of each method used; however, the flow diagram starts by looking for the occurrence of $\mathrm{Si}$ to Se truncations. This is a useful first step to establish whether the Se truncations can be used to help aid in the interpretation of the garnet itself. If Se 
cannot be followed into the $\mathrm{Si}$, and an $\mathrm{Si}$ to Se truncation exists, the apparent relationships between the garnet inclusion trails and the matrix fabric should not be used to determine kinematic history of the garnet. In other words, the matrix fabric may not be representative of the deformation events within the garnet, and thus it should not be used to interpret these events.

If no truncations exist within the garnet inclusion trails and the inclusion trails are continuous with the matrix ( $\mathrm{Si}$ continuous with $\mathrm{Se}$ ), then it is possible to determine the relationships between deformation and metamorphism by comparing the Si to Se in a fashion similar to that of Zwart (1962) (cf. Figure.

4.1). However, if truncations do exist within the garnet's inclusion trails or between the $\mathrm{Si}$ and Se, then other methods (e.g. chemical zonation maps) must be used to examine the timing of growth and metamorphism.

The continuity of the inclusion trails within garnets can be used to evaluate how continuously a garnet may have grown and can give insight into how deformation events may have evolved. Interpreting the meaning of discontinuities apparent within inclusion trail patterns will often require additional information since there may be many potential causes of inclusion trail discontinuities such as zones of resorption, hiatuses in garnet growth, inherited foliation features, or rapid changes in the orientation of the foliation relative to the growth rate of the garnet. However, noting truncation locations is useful in itself. Although the presence of inclusion trail truncations is not very diagnostic of the growth history of the garnet on their own, additional data that can be collected on growth zoning and crystallographic orientations (discussed -58 - 
below) can be much more telling when interpreted together. For instance, if a truncation exists in the inclusion trails and a chemical boundary also exists at the same point, then it supports a period of resorption. Since the inclusion trail patterns represent the orientation of matrix minerals just before overgrowth and the chemical zoning is representative of growth direction, then the existence of a truncation in both indicates that the matrix changed, and the growth rate or matrix chemical composition changed rapidly, or a period of the growth history is absent.

On their own, growth zoning truncations show that either the matrix composition of the mapped element changed during the garnet's growth or that the growth rate of garnet changed significantly during the garnet's growth. Truncations resulting from changes in growth rate could be the result of resorption of garnet and a later period of growth.

Crystallographic boundaries could prove useful in deciphering the history behind garnet nucleation and shear deformation; however, annealing can remove crystallographic differences that were once present. In other words, as a result of potential annealing, the absence of crystallographic truncations does not preclude that they were there. Because of this potential for annealing, at what appear to be lower temperatures than the resetting of chemical zonation patterns (e.g. Whitney et al., 2008 and Whitney and Seaton, 2010), the appearance of crystallographic truncations are only used as a means to verify the existence of multiple nuclei and deformation fabrics. 
The spiraled garnet evaluation workflow of Appendix 4 addresses many cases that were not discussed above. The workflow diagram is meant to stand alone such that it can evaluate any type of garnet for continuity of grouth and therefore will not be covered exhaustively within this text. The above introduction to the diagram should aid in the use of the diagram, but it is not meant to explain every potential outcome. 
CHAPTER 7:

\section{TECHNIQUES OF ANALYSIS AND METHODS OF INTERPRETATION}


Rock specimens were collected from outcrops at various locations throughout the study area where garnet porphyroblasts with spiral inclusion trails were identified. They were selected based on the size and quality of the spiral shaped garnets they contained and location relative to fold structures and deformation features observed at the outcrop. Large samples were preferentially selected so that foliation relationships to the garnets could be observed and oriented for later analysis in the lab. The samples were collected in the context of the distribution of foliation, lineation, and the areal extent of geologic units supplied by R. Bauer (personal communication). The sample locations were noted on a map and sample orientations were noted in a field book.

Upon returning from the field, samples were cut into one inch thick slabs and the cut faces were oriented based on the field measurements. These faces were cut perpendicular to both the lineation and foliation of the samples. The long axis of the spiraled garnets were oriented sub parallel to the lineations of the samples, and rotation sense about the long axis of the garnets (clockwise or counterclockwise) viewed down the plunge of the L2 lineations were recorded. The degree of garnet rotation varied from location to location in magnitude and direction (clockwise or counterclockwise).

One inch thick cores were then taken of exemplary garnets using a drill press and a diamond impregnated coring bit. The flat oriented faces of the garnets were then polished with one micron diamond paste on a low nap 
polishing wheel before being mounted with clear epoxy onto one inch round glass thin section plates. Once the epoxy cured, the extra core was sliced off using a thin sections diamond saw and then progressively polished down to 30 micron thickness. Grit on a glass plate was used to get a rough polish, and one micron diamond paste on a low nap polishing wheel was used to reach a final polish. Thin sections were thus doubly polished and could be viewed perpendicular to the main S2 foliation and elongation direction to show the spirals within the garnets. Samples were prepared using the EBSD sample prep guide.

All thin sections created from samples collected during this field study were made by me using equipment at the University of Missouri.

Samples supplied by Dr. Robert Bauer from a nearby field area were professionally prepared into doubly polished thin sections in a similar fashion. These samples were used to do preliminary EBSD work to determine if garnets had one uniform crystallographic axis or whether low angle dislocations existed that would/ could indicate shear strain deformation along garnet edges during growth (e.g. Prior et al., 2000). These samples required an additional polishing step in order to be analyzed via EBSD. This polishing step was completed at the University of Minnesota prior to the start of our scheduled SEM time. This extra polishing step is required to remove the surface damage zone created during the thin section making process. This thin zone of crystal lattice damage is created when cutting and polishing thin sections, and it must be removed before EBSD analysis can be performed. Syton Ht50 Colloidal Silica was used to polish out the lattice damage at 40 rpms on a Malvern Instruments Multipol 2 Precision 
polishing machine. Each section was polished for three hours, and two thin sections could be polished at a time. Following the polishing process, each sample was coated with approximately $3.5 \mathrm{~nm}$ of carbon to prevent electron charging of the surface of the thin sections. This step is necessary because garnets and silicates are nonconductive and electrons will build up on the surface of the sample, degrading backscatter and secondary electron images on the SEM and causing problems with EBSD characterization. The carbon coating must not be applied too thick, however, because the electrons emitted from the field emission gun must be able to penetrate to and be scattered off the crystal lattice of the minerals intended to be observed.

After carbon coating the samples, carbon tape or silver paint was used to make a conductive contact between the sample holder and the carbon coat on the top of the thin section. This step must be completed before installing the samples in the SEM, or the electron charging will remain on the sample surface.

\section{ENERGY DISPERSIVE SPECTROMETRY (EDS)}

As part of my research, I attempted to use Energy Dispersive Spectrometry as a means of analyzing the chemical makeup of my garnet samples. This research work was undertaken on a Quanta 600F SEM at the University of Missouri characterization facility under the supervision of Lou Ross. Backscatter and secondary electron images were taken of spiraled garnet samples to qualitatively denote boundaries between minerals and to test if $\mathrm{Z}$ contrast could 
be related to zonation within the garnets. Chemical maps were then taken to quantitatively characterize the chemical composition of the garnets spatially. Mn maps were computed and evaluated to determine whether they could be used as a proxy for garnet growth given the limited spectral resolution of the SEM's EDS and the trace Mn concentrations of the garnet.

\section{WAVELENGTH DISPERSIVE SPECTROMETRY (WDS)}

Wavelength dispersive spectrometry has a much greater analytical accuracy and sensitivity when compared to the energy dispersive spectrometer, so I attempted to use it to establish a more statistically significant zonation pattern of $\mathrm{Mn}$ and to collect zonation data for the trace elements $\mathrm{Y}$ and $\mathrm{Cr}$. Chemical maps were created using the JEOL Microprobe at Washington University in Saint Louis under the supervision of Paul Carpenter. Ti maps were made to determine the shape, location, and geometric relationships of ilmenite inclusions within the garnets. Phosphorous maps were made to determine the shape, location, and geometric relationship of monazites within the garnets. Mn, $\mathrm{Y}, \mathrm{Cr}, \mathrm{Ca}, \mathrm{Fe}, \mathrm{Mg}$, and $\mathrm{Na} \mathrm{X}$-ray intensity maps were compiled to determine the nucleation and growth history of the garnets. X-ray intensity maps of $\mathrm{K}, \mathrm{O}$, and $\mathrm{Al}$ were also created, and backscatter images were taken in order to distinguish mineral boundaries. 
EBSD images were created using a J EOL J SM-6500F Microprobe with a Centaurus detector at a working distance of $18.1 \mathrm{~mm}$ and $20 \mathrm{kV}$ at the University of Minnesota under the supervision of Nick Seaton and Eric Goergen. Maps were evaluated to determine whether the garnets had crystallographic misorientations within the garnets or at their interface with the matrix. High angle misorientations within the garnet were evaluated to determine whether they were the result of fracture displacement, or coalescence of nucleated garnets. Low angle dislocations were not observed in the samples. This meant that if shearing had occurred during the growth and deformation of the garnets along the interface between them and the matrix that there was not any record of it crystallographically at the resolution of the EBSD detector. Because of this result, the expense of the procedure, and lack of funding, we did not run EBSD on the spiraled garnets I collected. 
CHAPTER 8:

RESULTS

- 67 - 
The Mn chemical zonation patterns within the garnets from our study appear to contain nearly concentric decreases in Mn concentrations from core to rim with potentially a minor preferred growth pattern parallel to S1 as it curves into S2. The inclusion trail patterns are more obviously spiraled compared to the growth zonation patterns. Garnet inclusion trail patterns preserve opposite rotation senses on either side of the regional fold structure, and the rotation senses are preserved inside the core of the garnets, not solely at the rims.

The Si to Se transitions in all of my analyzed garnets are discontinuous as a result of continued D2 shortening and localized D3 deformation. D3 deformation postdates the growth of garnet and is oblique to S2 (Figure 5.5). Because D3 postdates the growth of garnet its associated foliation (S3) is not present within the internal foliation fabric of the garnets within the study area. However, S2 is often present as a linear fabric within garnet rims, and S1 is contained mostly in the cores of garnets as an asymmetric crenulated fabric of inclusion trails (Figure 8.1). Based on the appearance of the high Mn concentrations and crenulated inclusion trails in the cores of garnets, it appears that garnet initially nucleated on the S1 fabric and then it spread to the early developed/ evolving spaced S2 foliation (Appendix 3). Due to the intense curvature and the apparent wrapping of the crenulation fold hinges around the nucleation sites within the samples from this study, garnet appears to nucleate in the asymmetrically crenulated S1 foliation as it continues to be shortened during the continued development of S2 (Appendix 3). Deformation may aid the nucleation of garnet because it allows for nutrient transport from pressure 


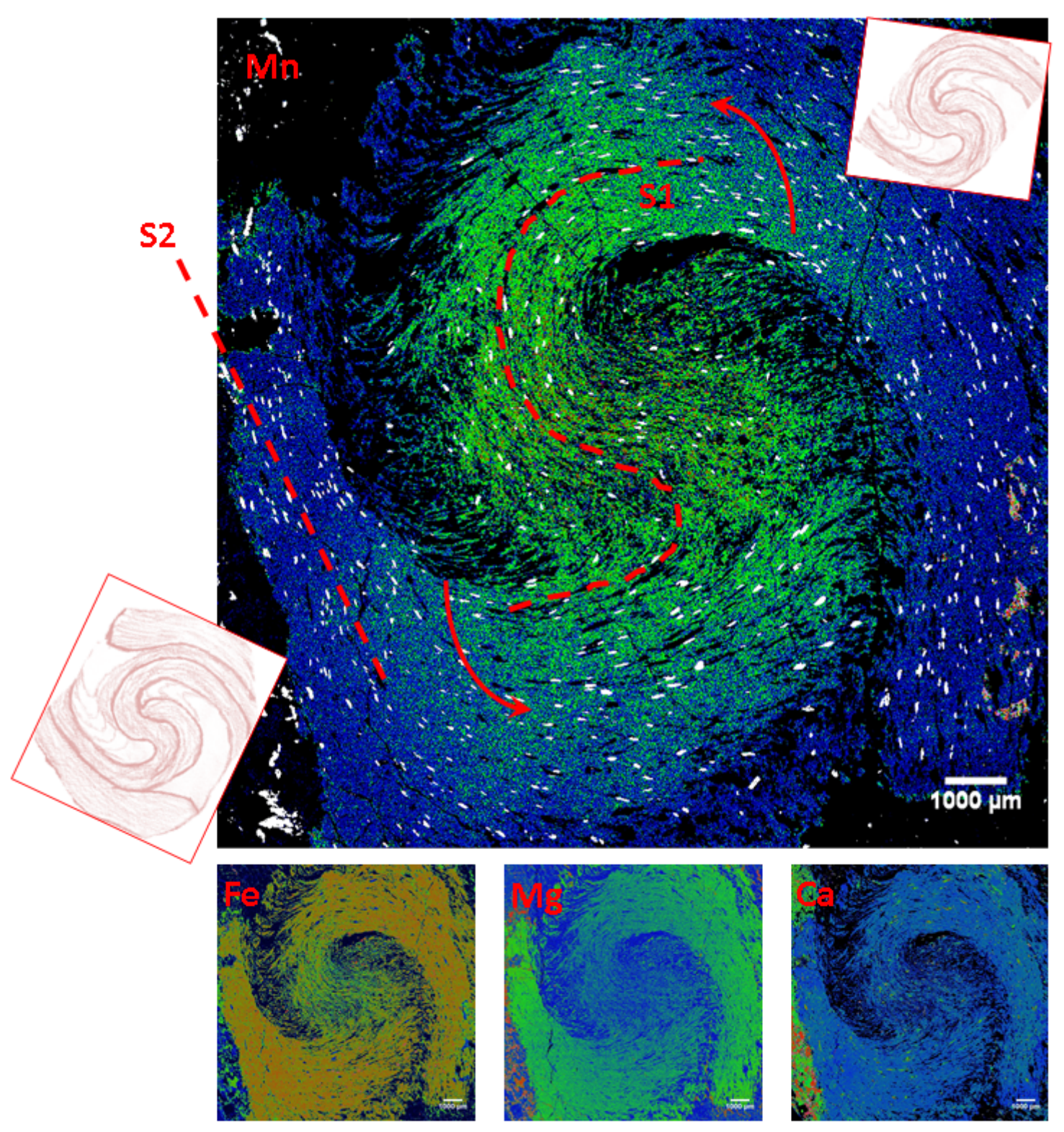

Figure 8.1. X-ray intensity maps. The figure shows the distribution of elements within a two dimensional thin section slice through a spiral garnet from the Laramie Range of Wyoming. The garnet appears to show near concentric zoning in Mn, Fe, and Mg. Garnet rotation sense is counter clockwise and can be explained via overgrowth of an asymmetric crenulation foliation with either subsequent rotation of approximately 25 degrees or wrapping of the $\mathrm{S} 2$ foliation around the garnet core during continued shortening and overgrowth.

dissolution zones to low pressure regions (such as foldings and pressure shadows). In addition, Mn may be more readily available in the microlithons aiding in the development of early garnet growth within the crenulating fabric (e.g. Williams, 1994). Mn has been shown by Mahar et al. (1997) to lower the 
predicted temperature of the garnet-in isograd by as much as 100 degrees $C$ when added to the KFMASH System. In addition Mn appears to widen the stability of garnet to higher pressures and temperatures (Mahar et al., 1997).

The Mn rich cores within the garnets from this study appear to have overgrown folded S1 features. The high Mn content within the cores of the garnets from this study may support that Mn was part of the early garnet growth reaction (Appendix 3). If high Mn concentrations were available within precursor phases contained within the early S1 fabric, garnet would nucleate and grow at low temperatures (circa 450 degrees C) in the MnNCKFMASH system compared to the temperatures required in the KFMASH system (circa 600 degrees C) (Figure 8.2) (Tinkham et al., 2001; Spear and Daniel, 1998). Inter-granular diffusion would be very slow, limiting transport and equilibration of elements to the growing garnets (Hirsch et al., 2003). The asymmetries of the sigmoidal inclusion trails contained within the cores of garnets from this study are consistent within a sample locality (left lateral or right lateral). If the cores of these garnets are the result of the overgrowth of a crenulation, the consistent orientation and asymmetries of the cores would imply that the matrix crenulation was asymmetric prior to overgrowth (Figure 8.3). In other words, if the crenulations were symmetric, the cores of the garnets would have a 50-50 chance of being right lateral or left lateral in any given locality. This however, does not match with sample observations (Appendix 3) that the cores of the garnets tend to preserve similar asymmetries from garnet to garnet in a sample locality (Figure 8.4). Assuming the cores of the garnets inherited their inclusion trail geometries 


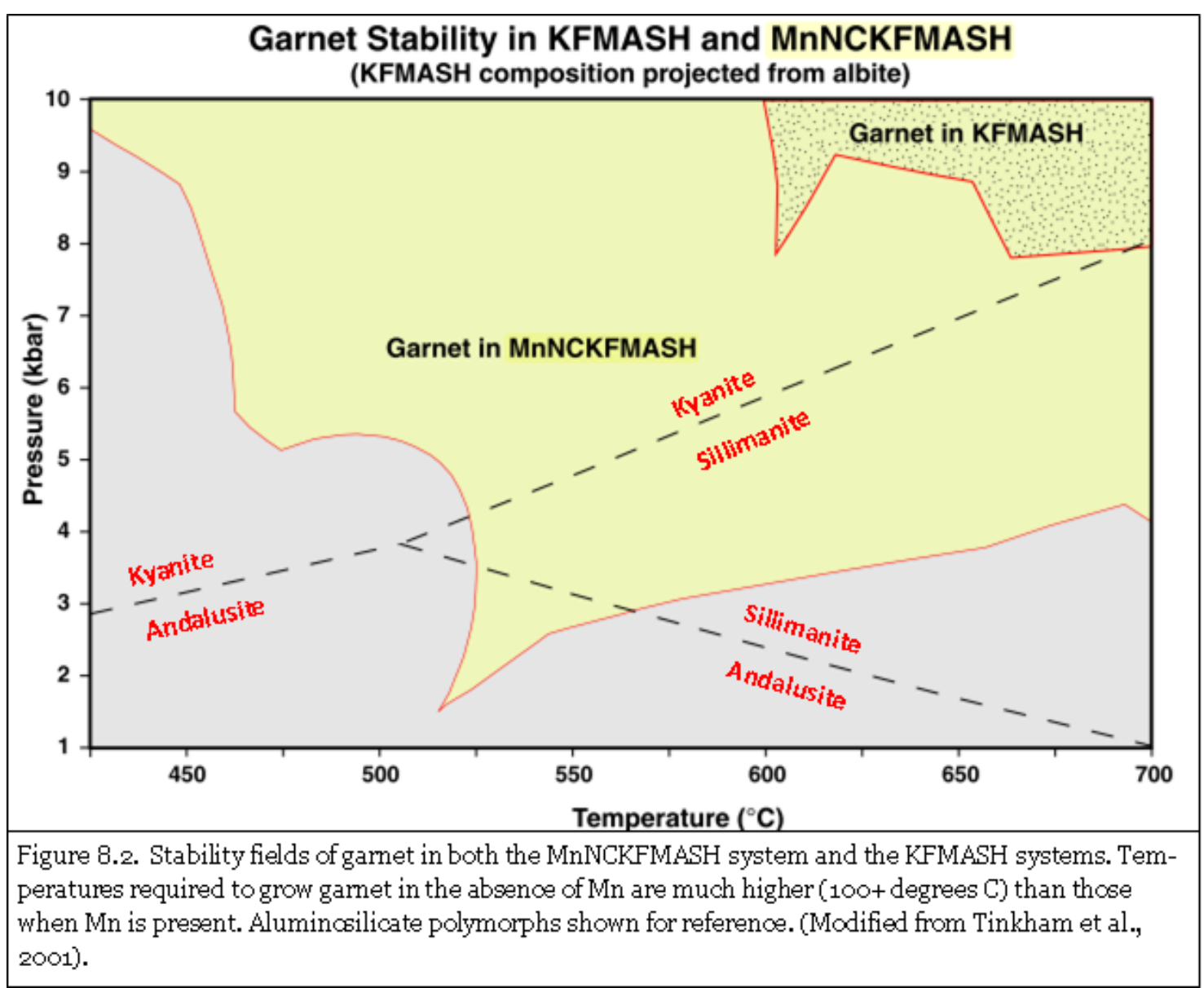

from asymmetrically folded fabric elements that existed during the early stages of a D2 deformation event, they would potentially record the fold limb geometries that existed during their growth before continued deformation eliminates such asymmetric fabrics from the matrix (Figure 8.5). Williams (1994) noted the remarkable consistency of orientations and asymmetries of sigmoidal inclusion trails within garnet samples from his study. Williams (1994) also noted that despite the consistency of the inclusion trails, the matrix rarely records the same sigmoidal forms within the present day fabric, meaning that matrix folds were completely obliterated by deformation and recrystallization post garnet grouth. The Mn-rich cores of our garnets are also often rich in quartz inclusions. 

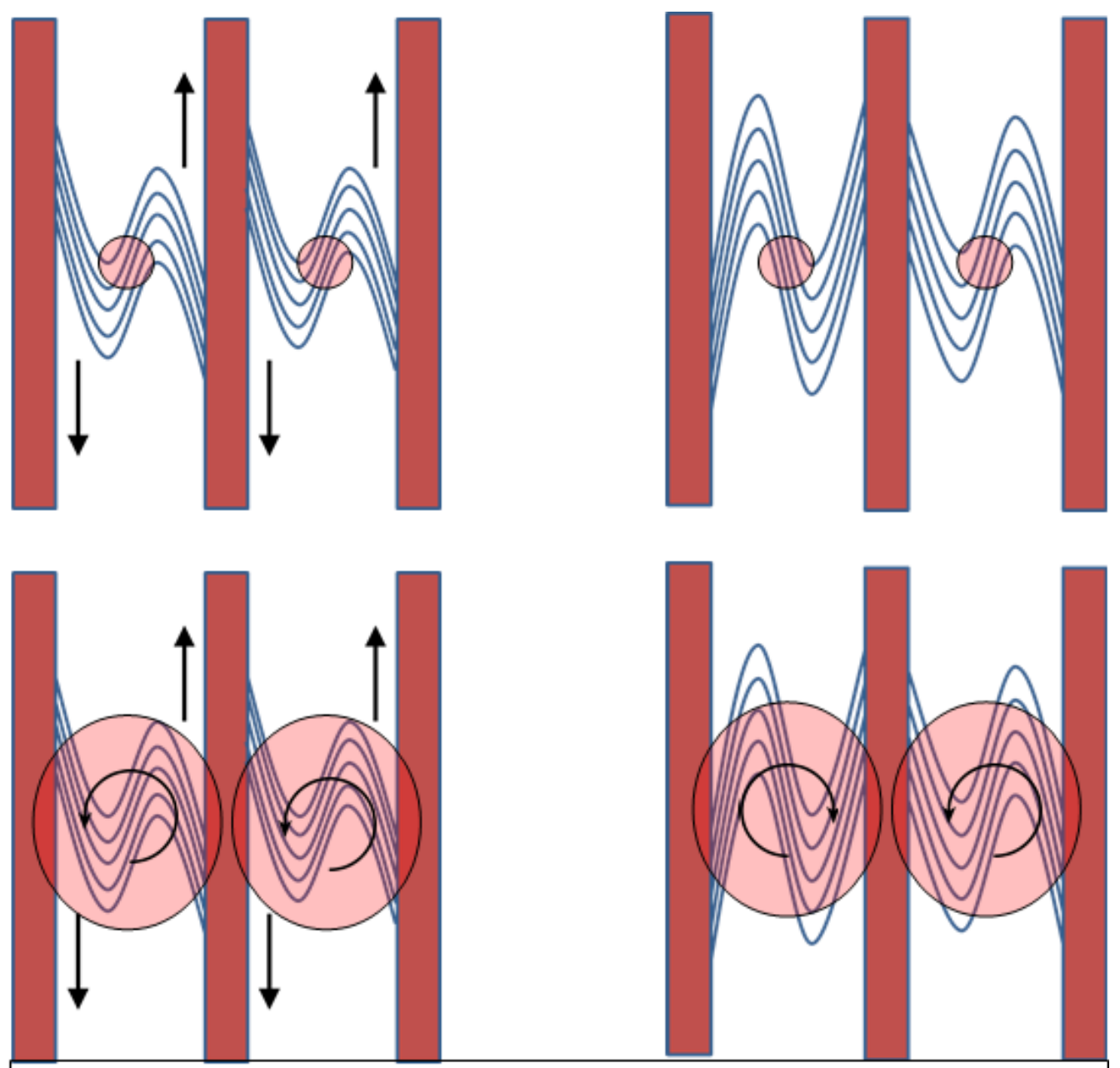

Figure 8.3. Overgrowth of asymmetric vs. symmetric crenulation cleavages. The above figure demonstrates the ability of porphyroblasts to inherit their apparent rotation sense by overgrowing a preexisting crenulation foliation. However, a distinction must be made betwen symmetric and asymmetric crenulation cleavages because an asymmetric crenulation cleavage would generate consistent rotation senses from garnet to garnet whereas a symmetric crenulation would generate inconsistent rotation senses. In other words, garnets overgrowing a symmetric crenulation would have a 50-5o chanoe of inheriting a left lateral or right lateral rotation sense, whereas garnets overgrowing the microlithons of an asymmetric crenulation foliation would have a near $100 \%$ chance of inheriting a given rotation sense.

However, the rims are often poor in quartz inclusions (Appendix 3, Figure 8.4).

The ilmenite and quartz inclusions within the Mn-rich regions of our spiraled garnets are continuous and consistent in asymmetry just as those within the sigmoidal garnets of Williams (1994). Therefore, their sigmoidal garnets may be analogous to the early stages of our spiraled garnets. The relationships between 

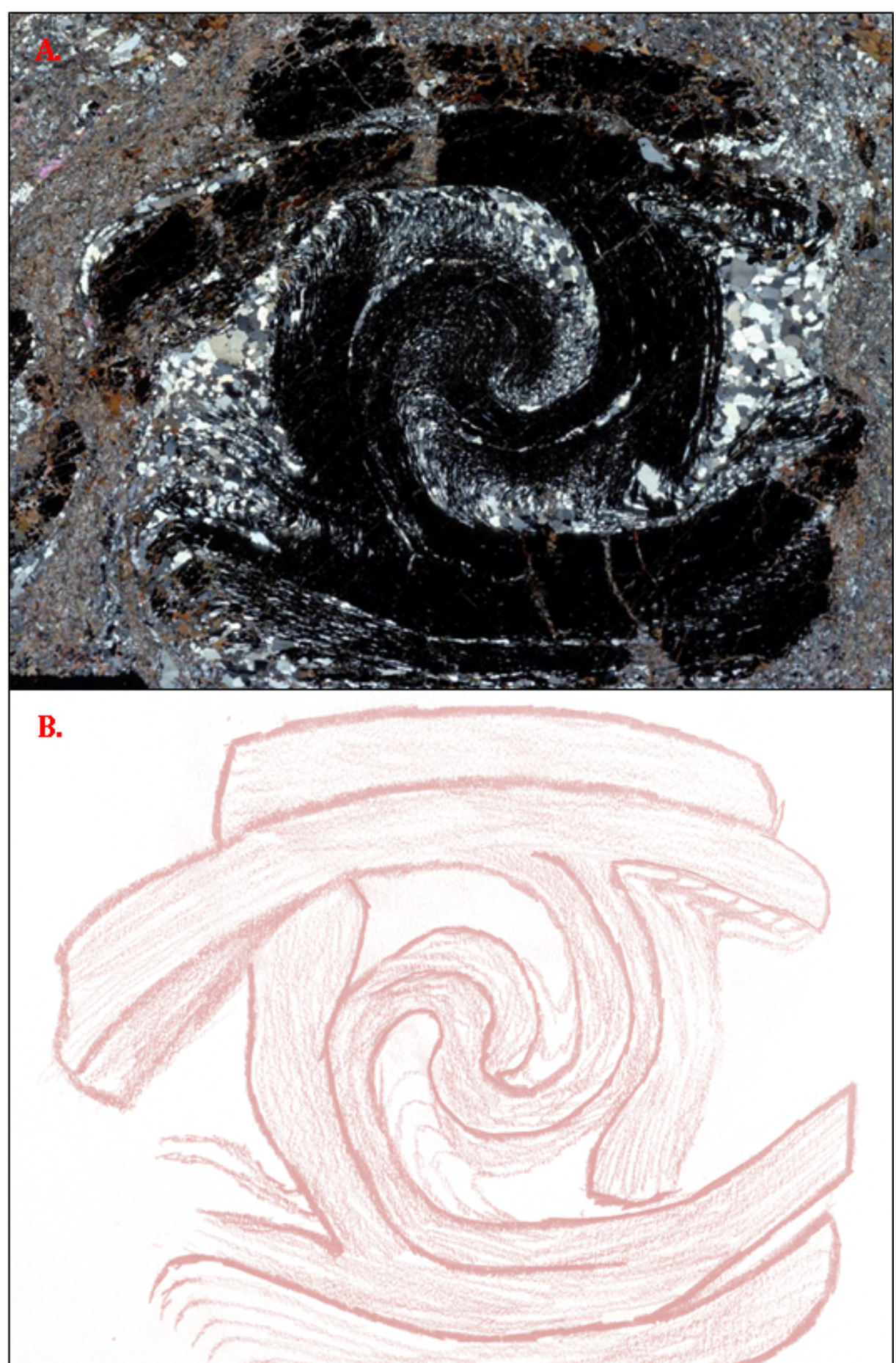

Figure 8.4. The essential elements seen in spiraled garnets from the Laramie Range of Wyoming. Figure $A$ is a garnet thin section image provided by R. Bauer showing the $3^{60}+$ degrees of apparent rotation sense that can be sen in some garnets from the field study area. Figure $B$ is an illustration of Figure A created to capture the essential elements contained within the gamet. Figure $B$ will be used to demonstrate the progressive development of spiraled garnets from our study area. 


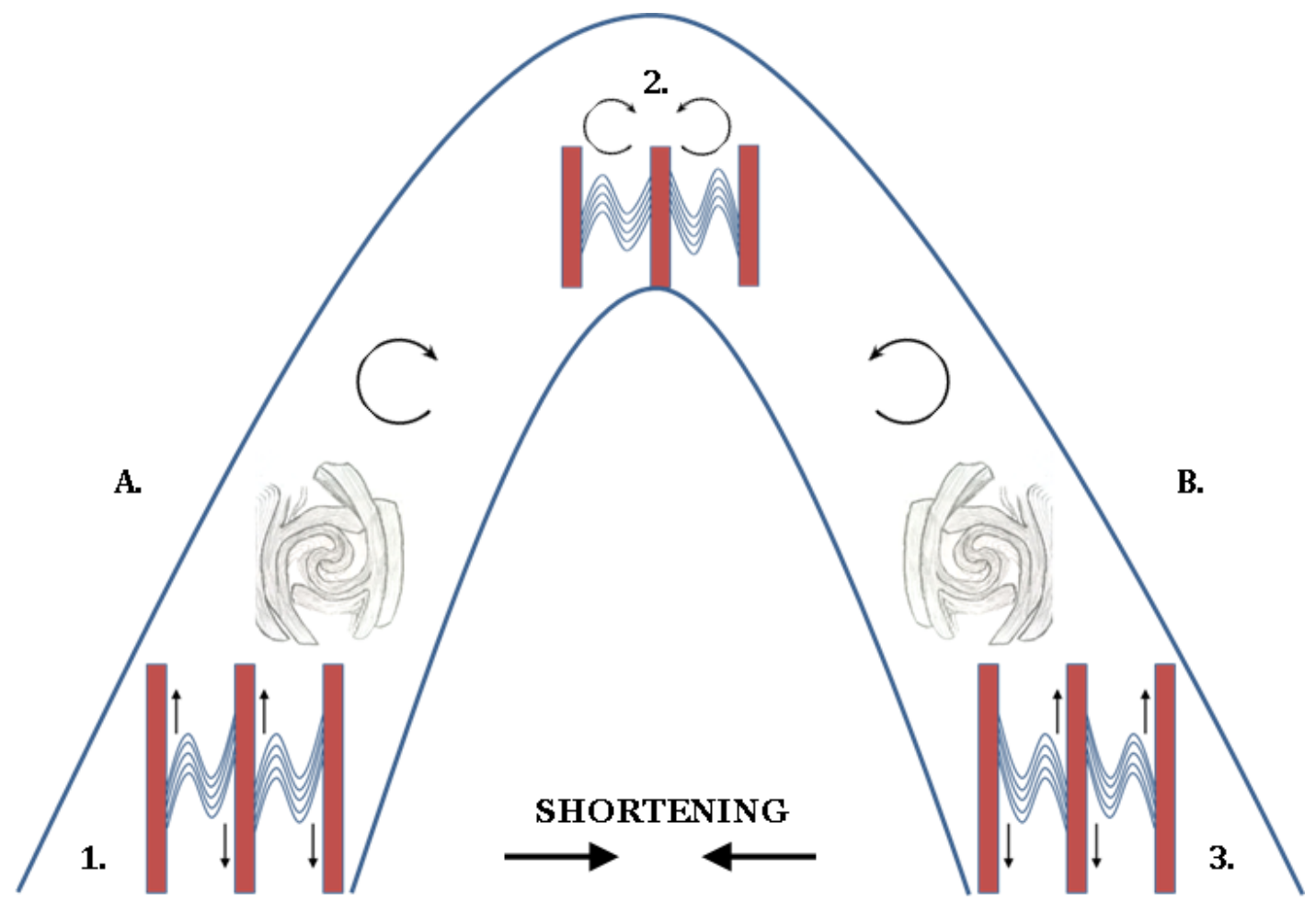

Figure 8.5. Inherited rotation sense from asymmetrically folded crenulation cleavage elements and potential porphyroblast rotation during growth resulting from layer parallel shear consistent with fold development. The figure above contains fabric elements that may form on the left (A.) and right (B.) limbs of fold structures as a result of shortening and layer parallel shear that can develop during folding of interlayered units. The left fold limb would develop right laterally sheared fabric elements and potential clockwise rotation of porphyroblasts as a result of flexural flow or flexural slip during folding. Similarly, the right fold limb would develop left laterally sheared fabric elements and potential counter clockwise rotation of porphyroblasts. In order for an overgrowth model to produce apparent rotation within the cores of garnets, the fabric elements must contain asymmetrically folded crenulation elements (shown in 1 and 3 above). Symmetrically folded crenulation elements, such as those that would form in the hinge-lines of folds (shown in 2. above) would create random left lateral or right lateral apparent rotation senses in the cores of garnets if overgrown.

crenulation cleavage development, metamorphism, porphyroblast growth, and porphyroblast shapes from Williams (1994) are displayed in Figure 8.6. Despite the similarities between the cores of our spiraled garnets and the sigmoidal garnets of Williams, there is no direct evidence within preserved fabrics in the matrix to indicate that chlorite was part of the microlithons of our early garnet forming fabrics. All rocks within the field area have been buried and heated through regional metamorphism beyond the pressure/temperature conditions of 


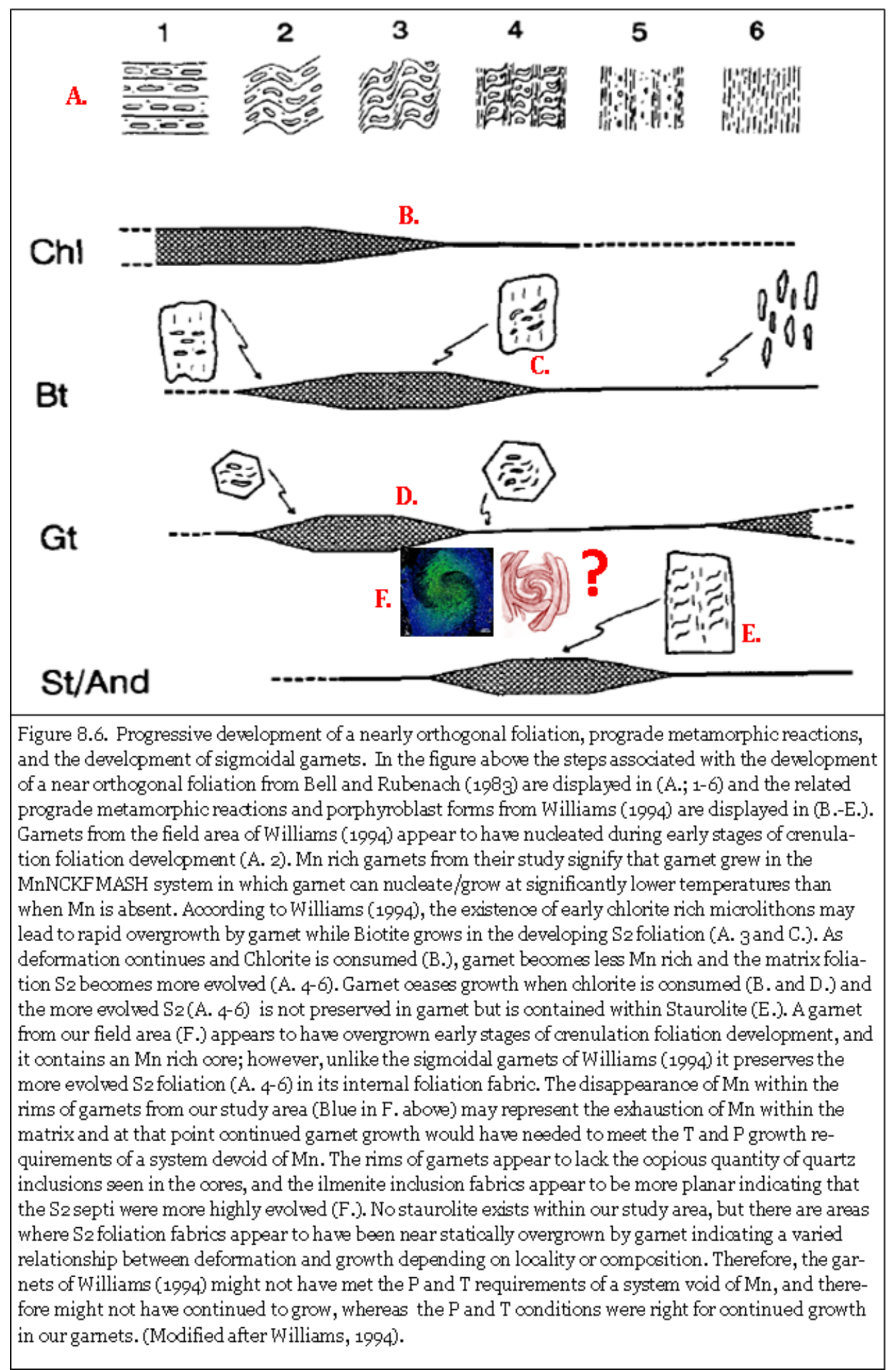


the chlorite out reaction. The work of Bauer et al. (2002) shows that garnet porphyroblasts overgrew multiple septae and microlithons within the same garnet, indicating that the garnets grew after the S2 foliation had formed or during the late stages of S2 development within areas close to our field area. Because garnets appear to overgrow S1 and S2 at different stages of fabric development, garnets either nucleated at different times in different areas based on area specific matrix composition changes or that deformation fabrics varied in intensity from place to place. Therefore, the relationship between the stages of S2 development and garnet growth are not necessarily the same everywhere within the field area. Since chlorite is consumed at low temperatures, there is no direct evidence left within the matrix foliation to confirm the early existence of chlorite in S1.

Because garnets can nucleate at very low temperatures when $\mathrm{Mn}$ is available within the matrix, Mn rich garnets or cores of garnets may record very early stages of deformation events. Areas that do not have matrix Mn, may not nucleate until higher temperature and may record a more developed S2 foliation with multiple septi per garnet. The rims of the garnets from this study are often void of Mn such that very few Mn counts are recorded on the probe (Appendix 3). Even though Mn-rich cores and Mn-poor rims are the natural product of Mn partitioning into garnet during their progressive growth history, once $\mathrm{Mn}$ is depleted from the matrix, the unavailability of Mn once exhausted in the matrix may affect continued garnet growth based on the pressure and temperature requirements for garnet growth in a system void of Mn. In other words, if high 
Mn concentrations are required for low temperature growth of garnet, the transition from Mn available for growth in the cores to Mn unavailable for growth in the rims may have initially halted or slowed garnet growth until higher temperatures were reached. The Mn poor and Si-inclusion poor rims may therefore represent overgrowth of a more evolved matrix S2 foliation following a slight hiatus in garnet growth or slowed garnet growth (Appendix 3). Therefore, the matrix fabric S2 foliation may have evolved significantly during garnet growth. This would potentially explain why none of the spiraled garnet cores preserve the S2 foliation, but instead preserve a folded S1. It would also explain why crenulations do not appear nearly as prominent in the S2 matrix foliation, and would potentially mean that areas that preserve a later overgrowth of a crenulated S1 and more evolved S2 may represent higher temperature garnet growth after the S2 fabric developed (Figure 5.5a). Alternatively, these more evolved areas could have simply been more highly deformed prior to garnet nucleation and growth. Investigating the nucleation and growth histories of these potentially younger garnets or alternatively more evolved garnet would provide a more clear history of garnet nucleation and growth relative to deformation. Unfortunatel, this was not a part of our study.

Because prograde metamorphic reactions often release $\mathrm{H} 2 \mathrm{O}$, the early growth of garnet in a chlorite-rich crenulating matrix may lead to increased rates of fabric evolution in favor of biotite aligned in S2 at the expense of chlorite in S1 (Williams, 1994) (Figure 8.7). In addition, the water produced from the grouth of garnet at the expense of chlorite and other prograde reactions (e.g. garnet and 


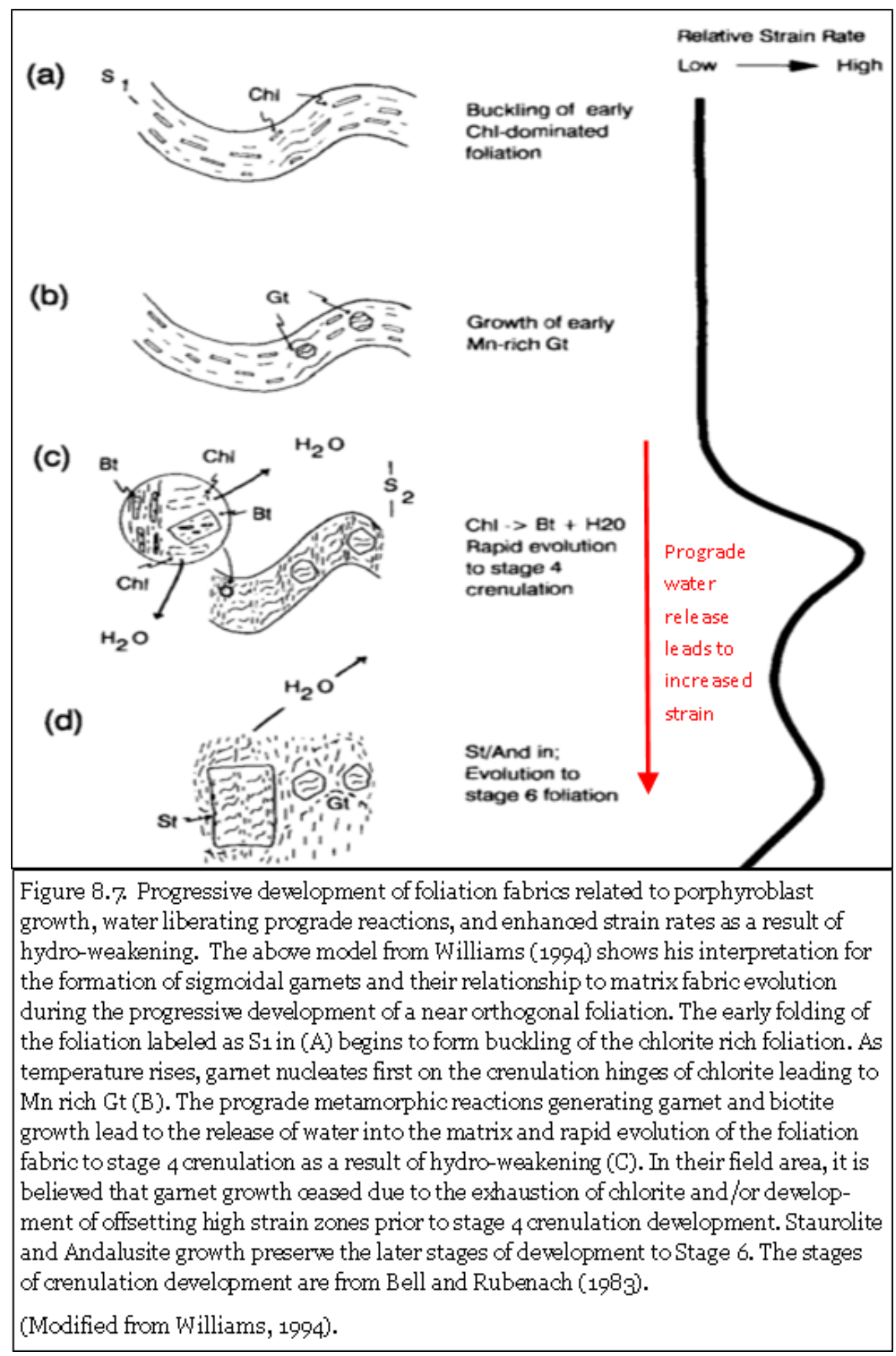

biotite growth) might lead to increased solution transfer reactions (Williams, 1994). For example, the release of fluid during porphyroblast growth in the 
microlithons may increase strain rates in the matrix causing dissolution of deformed quartz from the high strain zones of a developing S2 foliation and, therefore, rapid development of the S2 crenulation cleavage (stages 4-6; Figure 8.6) (Bell et al., 1986; Williams, 1994). According to Williams (1994), the transition from chlorite-dominated to biotite dominated assemblages occurs over a relatively narrow temperature between $400-450$ degrees C. Thus, the cores of garnets within the study area would have had to be nucleating and growing within this temperature range for this mechanism to explain the garnet core shapes and evolution of the S2 foliation during garnet growth. Geothermometry of the spiraled garnet cores from this study would provide evidence to evaluate these mechanisms of early nucleation and growth within our field area. Unfortunately, this thesis does not include this research due to funding shortfalls and initial project scope, but it should be included in future work.

The inclusion trail fabrics ( $\mathrm{Si}$ ) contained within our garnets show a continuous though not perfectly recorded transition from core to rim with somewhat difficult to trace inclusion trail patterns in the quartz-rich zones. Elongate ilmenite inclusions are ubiquitous in all areas of the garnet except the quartz-rich zones. Although ilmenite inclusions are present in the center of all of the garnets, they appear to be smaller than those in the outer part of the garnet porphyroblasts. It appears that ilmenite existed in the S1 foliation prior to garnet growth due to its elongate nature parallel to S1, but there appears to be a potential grain size increase between ilmenite inclusions in the cores of garnets compared to those in the rims that may be the result of continued ilmenite 
growth due to the liberation of Ti through the garnet growth reaction (Appendix 3). The Ti concentration of biotite increases as temperature rises, but once garnet starts growing and biotite breaks down, ilmenite likely begins to become stable again in the presence of excess Ti to form ilmenite in the matrix. Early breakdown of chlorite and its eventual replacement by garnet and biotite would tend to align with the theory that early garnet growth that occurs in the microlithon liberates titanium, which becomes available for increased biotite $\mathrm{Ti}$ concentrations and continued ilmenite growth in the matrix once biotite is overgrown by later garnet growth. Continued shortening that occurs during garnet growth may lead to increased elongation of the growing ilmenite and encroachment of the S2 spaced foliation around the growing garnet prior to overgrowth. This is a hypothesis that is hard to test and is stated only as an observation.

Measurements of elongation in the field by (Bauer et al., 2002) show that strong lineations develop in the hinge lines of F2 fold structures, whereas strong foliations tend to develop in the limbs of the same F2 fold structures. This may be important because garnets may have overgrown parasitic fold structures within the S1 foliation, which was being crenulated by D2 deformation. If this is the case, one could make the case that on a small scale within the hingelines of parasitic fold features, lineations may be common, whereas foliations may be more common in the limbs of those same structures. This may explain why some of the ilmenite inclusions in the center of garnets appear to have smaller inclusions, but 
thin section work parallel to the lineation would need to be completed in order to discern whether ilmenite inclusions are more linear than those in the rims.

The Mn chemical zonation patterns within the garnets from our study appear to contain nearly concentric decreases in Mn concentrations from core to rim with potentially a minor preferred growth pattern parallel to S1 as it curves into S2. The inclusion trail patterns are more obviously spiraled compared to the growth zonation patterns. Garnet inclusion trail patterns preserve opposite rotation senses on either side of the regional fold structure, and the rotation senses are preserved inside the core of the garnets, not only at the rims. 
CHAPTER 9:

DISCUSSION 
The origin of spiral inclusion trails in garnet has been contested for several decades within the literature, but remains unsolved, despite extensive research. The reasons for such ambiguity are in the complex interplay between deformation, metamorphism, and the limited preservation of the evidence of the stages responsible for their existence. During the course of orogenesis, crustal material can be buried miles deep, heated and metamorphosed, deformed, and then exhumed to the surface. As a result of these processes, matrix minerals and foliations can be completely reset, but garnets will often remain. The internal fabric elements that they contain and the chemical zonations within their crystal structures are often the only evidence that remains to discern the history of the burial and exhumation histories of the mountain building events responsible for their growth.

Previous studies have been plagued with ambiguous results, and, to a certain extent, so has this one. There is no simple model that can explain every potential spiraled garnet form, and there is no simple way to reconstruct regional deformation trends using them. Instead, this paper contributes a process of investigation that can help to rule out certain formation mechanisms for a particular garnet, and, potentially, a most likely formation mechanism can be determined (Appendix 4). In the case of this study, the relationships between foliation fabrics, fold structures, and garnet nucleation and growth structures suggest a most likely mechanism for the formation of spiraled garnets within our field area. Because garnets provide/record evidence to aid in our understanding of the deformation and metamorphic histories of ancient mountain belts, they are 
the focus of much research interest; however, our ability to determine these histories from garnets can be highly dependent upon their nucleation and growth histories. In order to limit some of the uncertainty associated with the interpreted histories from our garnets, this study used a combination of textural and analytical techniques, as well as field observations at various scales.

As a result of the field work of Bauer et al. (2002) and the textural/microanalytical analyses completed in this study, the growth of the spiraled garnets within the Laramie Range field area do not appear to be explainable by either of the end member rotational and non-rotational models of Schoneveld (1979) and Bell et al. (1992) respectively. The spiraled garnets from our study exhibit a continuous garnet growth history based on their Mn chemical zonation patterns and their lack of apparent truncation surfaces. This is inconsistent with the model of Bell et al. (1992) which predicts that both chemical and inclusion trail truncations should form in spiral garnets in response to major changes in tectonic stress produced during alternating periods of uplift and gravitational collapse. As part of this process, chemical truncations would form as a result of pressure dissolution or diffusive transport that would remove previous garnet growth or generate reaction rims.

Although a continuous growth history could support the rotational model of Schoneveld (1979), the excessive shear required to create the spiraled garnets via Schoneveld's rotational model does not fit with the deformation history of the field study area. The preservation of both S1 and S2 within the field area, and the relationships that the spiraled garnets have with the F2 fold structures and 
crenulation cleavages preserved in both garnets and the matrix throughout the field area, do not support the existence of high simple shear strains during garnet growth or subsequently (e.g. Figure 5.2). As in studies of sigmoidal garnet forms from other studies (e.g. Williams, 1994; Bell et al., 1986), the garnets within the field area contain ilmenite and quartz inclusion trails that are continuous and consistent in their asymmetry (rotation sense) (Appendix 3, Figure 8.4). The cores of these garnets are interpreted to be matrix crenulations that were overgrown during the crenulating D2 event.

All field, petrographic, and analytical work on garnets from our study support growth of the spiraled garnets during one continuous metamorphic event (M2) that is post D1, synkinematic with D2 or late D2, but definitely prior to D3. Bell and Hayward (1991) and Williams (1994) concluded that garnet porphyroblasts in their study areas do not or cannot grow beyond stage 3 crenulation development due to preferable growth factors within the microlithons as opposed to the high strained zones of the growing septi. However, it is clear that garnet growth within our study area was initiated in asymmetrically folded microlithons and continued into the septi after overgrowing the microlithons-without an interim period of deformation. Bell and Hayward (1991) and Williams (1994) did recognize continued porphyroblast growth of staurolite and andalusite over developing microlithons, but they saw no evidence that garnet could.

Because the spiraled garnets within our field area could not be explained by either of the end member models of Schoneveld (1979) or Bell et al. (1992), Bauer 
et al. (2002) needed to develop a new model for their growth. Their model relied on the following stages to explain the formation of the spiraled garnets they studied:

1. Garnet porphyroblasts overgrew the late stages of a developing S2 crenulation foliation.

2. Continued shortening during the foliation-forming event produced local buckling of the growing garnet across microlithons, resulting in some apparent rotation and some real rotation.

3. More significant rotation occurred when late-stage shear strains were partitioned along $\mathrm{S} 2$

4. The amount of real rotation may be overestimated by as much as $180^{\circ}$ depending on the orientation of S1 during the development of the overgrown S2 crenulation foliation.

The work completed during this study confirms that this overgrowth of the S2 crenulation foliation (bullet 1 above) and other foliation fabric elements fits with the growth and deformation history of the garnets (Appendix 3, Figure 8.4). The continuous chemical zonation patterns and the continuous spiral inclusion trail patterns within all of the spiraled garnets evaluated in this study fit with the overgrowth of a pre-existing fabric when observed in conjunction with the preservation of similar elements in lesser deformed areas of the matrix. This study relies on one modification to achieve the consistent core to rim rotation senses that result from the overgrowth of a crenulated matrix. The S1 foliation that is crenulated within the S2 microlithon must be asymmetric in order to create the garnet forms viewed within our field area.

Based on the apparent lack of low angle truncations within the spiraled garnets we analyzed from the Laramie Range (Appendix 2), there does not appear to be any recorded buckling of growing garnet called upon by Bauer (bullet 2). 
This could result from annealing of crystallographic deformation features during garnet growth, or it could mean that they never existed. Unfortunately, there is no way to know for certain. However, regardless of whether garnet buckled, the overgrowth of an asymmetrically crenulated fabric (Figure 8.3), combined with continued shortening and the wrapping of the S2 foliation around the garnet during growth, could create similar apparent rotation sense without the need to call on buckling or early rotation.

The rotation called upon by Bauer et al.'s model (bullet 3) may or may not always be required for the formation of spiraled garnets. In this part, Bauer et al. call upon the rotation of the garnets during their growth resulting from flexural flow during the continued shortening of F2 folds. Although there is no direct chemical, crystallographic, or inclusion relationships that can refute this mechanism for the rest of the spiral shapes of the garnets within the samples examined in this study, the remaining rotation sense preserved in the rim of the garnets could be the result of continued shortening of the matrix, leading to the wrapping of the S2 foliation around the hard spot created by the garnet core. The opposite rotation senses on either side of the fold are preserved inside the core of the garnets, not just their rims. This suggests that either rotation was the driver throughout garnet growth or that fabric elements overgrown by the garnet cores were asymmetric and already contained their opposite rotation sense prior to garnet growth. It is the author's opinion that this could be the result of the overgrowth of parasitic fold features contained within the matrix fabric elements related to the F2 folding that already existed prior to garnet growth. As the F2 
folds continued to shorten and garnet growth proceeded, the S2 fabric started to deform around the garnets forming the remainder of their apparent rotation senses. This continued rotation may explain why most of the spiral garnets display a tightening of inclusion trails around their core and sometimes appear to preserve an inclusion trail truncation between their core and rim. The continuity of growth zonation patterns from core to rim shows that despite a subtle wrapping of the foliation and a potential minor truncation of the inclusion trails, that an insignificant amount of time passed without a subsequent deformation event as would be implied by the models of Bell and J ohnson (1989) and Bell and Hayward (1991).

Although rotation may not be required to produce most of the spiral garnets analyzed within this study, there are garnets from Bauer et al. that cannot be explained without a component of rotation. In order to address these garnets, Dr. Robert Bauer provided a thin section image to consider this issue (Figure 8.4). Although no chemical data exists for this thin section, the relationship of this garnet to the garnets from this study make it likely that the core section of this garnet had a growth history similar to our garnets. Therefore, it was assumed that the growth and nucleation history of this garnet was similar to that described above. In order to explain the growth history of this garnet from $\mathrm{R}$. Bauer (Figure 8.4), it is required that a component of rotation equivalent to at least 58 degrees be invoked (Figure 9.2). Additional rotation could have occurred prior to garnet overgrowth of the entire crenulation foliation (Figure 9.1), but was not directly addressed in figure 9.2 due to ambiguities that are associated with 
reconstructing the rotational history of the nucleated garnet during tightening of the microlithons in an environment where bulk shortening and partitioned shear strain exist.

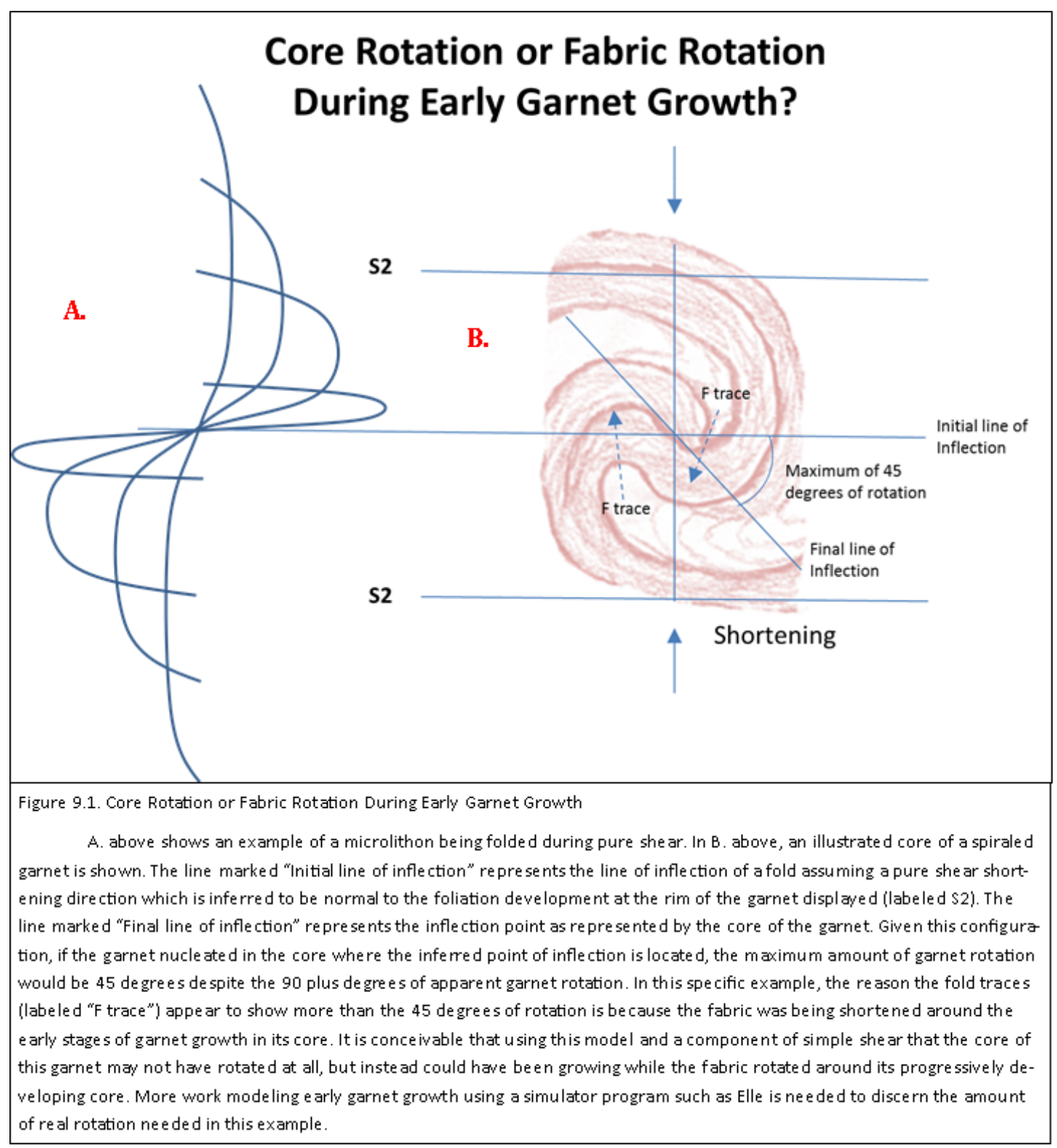

Therefore, the model to explain the growth history of garnets within our study is as follows (Figures 8.5, 9.1, 9.2). 
1. Garnet nucleates and overgrows asymmetrically folded and deforming (shortening/ shearing) microlithons (potentially chlorite rich) during crenulation cleavage development (stage 2-3 from Bell and Rubenach, 1983)

2. Hydro-weakening of the matrix resulting from prograde metamorphic reactions (e.g. garnet and biotite growth) may accelerate strain rates leading to additional shortening and shear potential (Williams et al., 1994)

3. Continued development and shortening of the S2 foliation wraps around the growing garnet leading to a component of additional rotation sense caused by fabric rotation around the growing garnet

4. Garnet may rotate as a result of partitioned shear strain that occurs during garnet growth and results from continued shortening and folding

5. Additional shortening during the late stages of garnet growth can add additional wrapping of the S2 foliation around garnets 


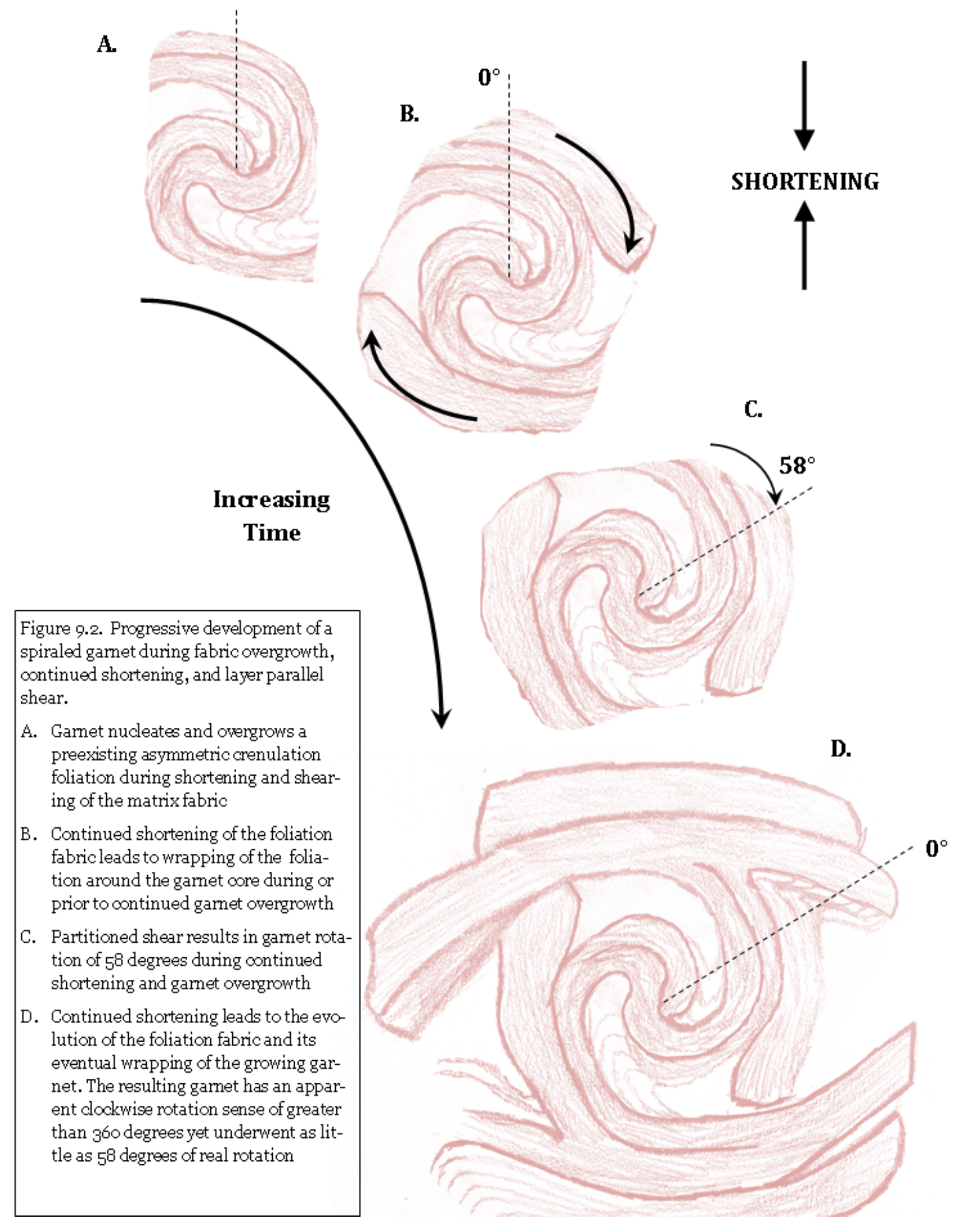

Future work that could be completed to test the conclusions of this study, include: 
1. Creating a more detailed evaluation of the spatial layout of rotation senses within the field study area. Due to the potential for additional implications to the trend and plunge of the elongate axes of the garnet cores, development of an accurate way to measure oriented trend and plunge similar to the measure of cores taken for paleo-mag data may shed additional light on the value of spiraled garnets as fold indicators even after other fabric elements have been destroyed.

2. Detailed Geothermometry of the $\mathrm{Mn}$ rich cores to see if a significant temperature difference exists between the cores and rims. In addition to a stress barrier to continued garnet growth, a significant temperature barrier to continued growth of garnet into the septi relative to the microlithons (created by exhaustion and encapsulation of Mn into early garnet replacement of microlithons) could explain the sigmoidal/ spiral garnet literature that seems to suggest garnet does not overgrow later stages of crenulation development into the septi without a subsequent deformation event (e.g. Bell and J ohnson, 1989; Bell and Hayward, 1991; Williams, 1994).

\section{CONCLUDING REMARKS}

The spiraled garnets explored during this study cannot be explained via the classical models for spiraled garnet grouth. The preservation of crenulated foliation fabrics within porphyroblasts and the apparent lack of sufficient shear within the field area to explain the $360+$ degrees of apparent rotation viewed within garnet samples make it highly unlikely that the uniquely rotational 
mechanism of Schoneveld (1979) could explain our spiraled garnets. On the other hand, the apparent lack of growth zone truncations and the general continuity of inclusion trail geometries make it highly unlikely that the purely non-rotational model of Bell and J ohnson (1989) could explain them.

Based on the work of Bauer et al. (2002) and additional work completed during this study, it is believed that the spiraled garnets within the Laramie Range of SE Wyoming can be explained via a model that combines rapid overgrowth of an asymmetric crenulation foliation followed by progressive shortening and in certain cases a component of rotation during garnet growth. This model explains 180+ degrees of apparent rotation via the overgrowth of an asymmetric crenulation foliation during progressive shortening and continued crenulation foliation development. Additional rotation is the product of foliation wrapping that occurs around the hard spot created by the growing garnet and the onset of rotation that may occur during folding of interlayered units, which can result in partitioning of shear strain around garnet porphyroblasts. An example presented within the text appears to explain 360+ degrees of apparent rotation via as little as 58 degrees of real rotation.

One additional result of this study is that spiraled garnets within the study require the overgrowth of an asymmetric crenulation foliation in order to generate their spiraled shapes. Areas that contain a symmetric crenulation foliation do not appear to contain spiraled garnets. Even if they did, their cores would inherit left and right lateral rotation senses randomly instead of having cores that match the rotation sense of their rims. Asymmetric crenulations 
provide a consistent rotation sense to the cores of garnets within a locality, and their development appears to relate to the shear senses created by D2 fold structures (right lateral on left limbs and left lateral on right limbs).

Based on the results of this study, it is conceivable that spiraled garnets, if evaluated to determine their nucleation and growth histories, may potentially be used as indicators of fabric evolution during crenulation cleavage development, shear sense, and of fold timing and closure direction. In this study, the cores of spiraled garnets exhibit remarkable consistency of apparent S1i to S2i fabrics in relationship to F2 fold structures. The fold relationships are exhibited as asymmetrically crenulated cores of garnets, rotation sense agreement between garnet cores and rims, and their general agreement at the hand sample to thin section scales. Future work investigating the geothermobarometry and geochronology of the spiraled garnets spatially within this field area could yield significant additional understanding about how folds, foliations, and crenulations evolve during metamorphism at mid-crustal levels resulting from collisional orogenesis. 


\section{CHAPTER 10:}

\section{SUGGESTIONS FOR FUTURE WORK IN THE STUDY AREA}




\section{DETAILED FIELD MAPPING OF GEOLOGIC UNITS AND SAMPLING USING HIGH PRECISION GPS}

In order for accurate representation of sample locations, geologic unit boundaries, and foliation and lineation measurements, I suggest that any future field work in the area be completed using a high precision GPS. The geologic complexity of the field area requires mapping and location precision greater than that attainable using a topographic map and compass; the high precision of GPS would greatly improve the final product of any future study.

COLLECT 1 INCH SAMPLE CORES IN THE FIELD USING A CORDLESS DRILL AND DIAMOND IMPREGNATED CORING BIT

Collecting the samples from visible spiraled garnets directly from the outcrop would reduce the complexity and error of orienting the samples. Trend and plunge measurements could be directly measured following the collection of the garnet cores, and with the use of the GPS, could be accurately located on a map. The other advantage to this technique is that the best spirals can be sample instead of having to choose from those that are easily removed.

\section{INCORPORATE HIGH PRECISION GEOTHERMOCHRONOLOGY INTO THE SAMPLE ANALYSIS}

Methods of geochronology using monazite have greatly advanced over the last decade. Analytical precisions of monazite dating in the literature have been cited at $+/$-1Ma or less (e.g. J oly et al., 2010). Combining age constraints of this 
precision with geothermometry estimates using the monazite-garnet thermometer of Pyle et al. (2001), the geothermochronology of spiraled garnets could be reconstructed from core to rim. Assuming the monazite is growing and in chemical equilibrium with the growing garnet that includes it, the rim of the monazite and the garnet nearest the monazite rim could be used to reconstruct, within analytical certainty, the age and temperature at which the monazite were overgrown and included in a growing spiraled garnet. Selecting and sampling monazites at different locations within the spiraled garnet could then be used to reconstruct the growth history of the garnet relative to deformation events in absolute time. This technique, when combined with the other methods presented in this thesis, could lay to rest the debate associated with the growth and deformation histories of spiraled garnet. 
APPENDIX 1:

SEM IMAGES

- 98 - 


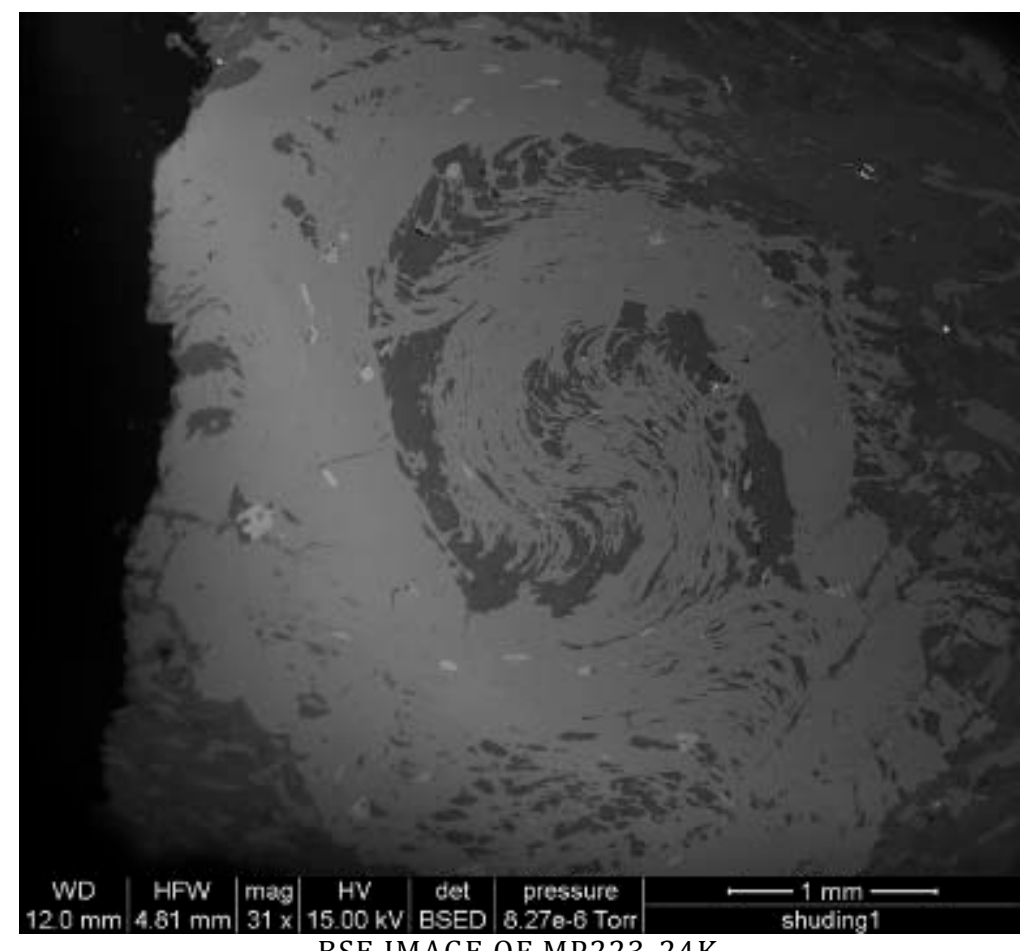

BSE IMAGE OF MP223-24K

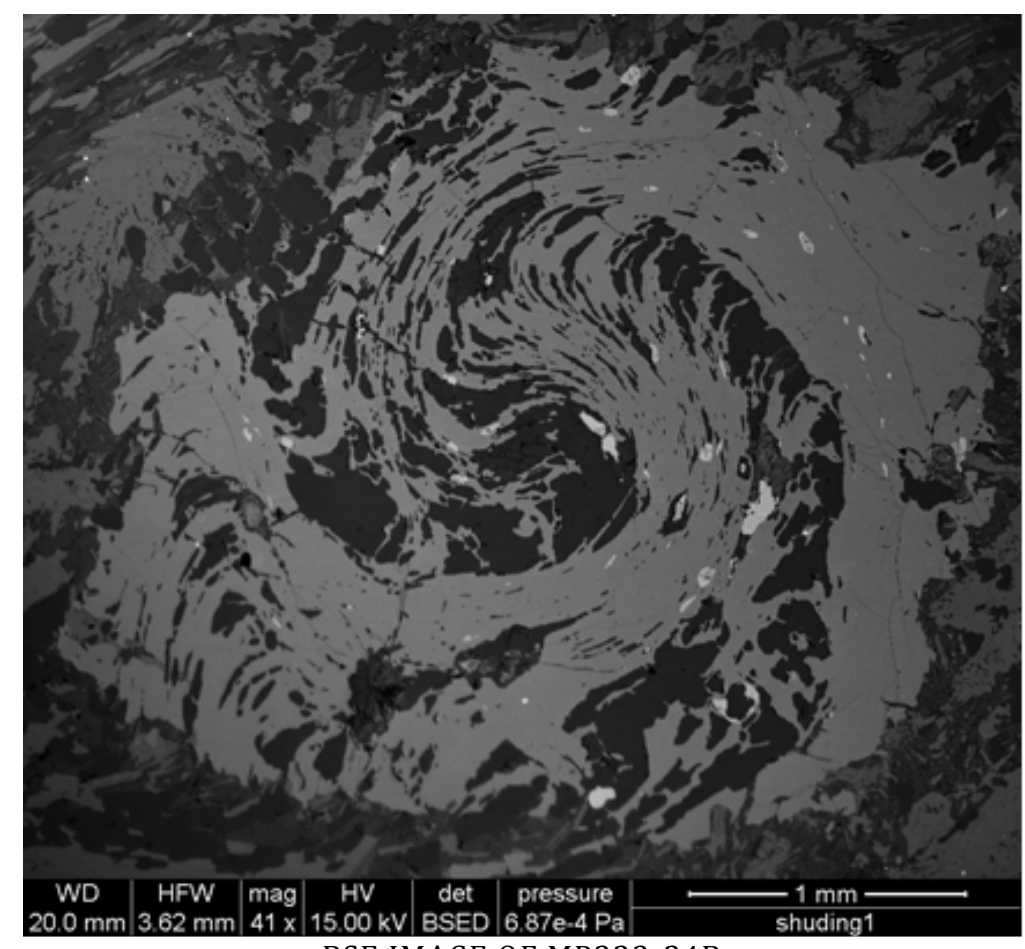

BSE IMAGE OF MP223-24B 


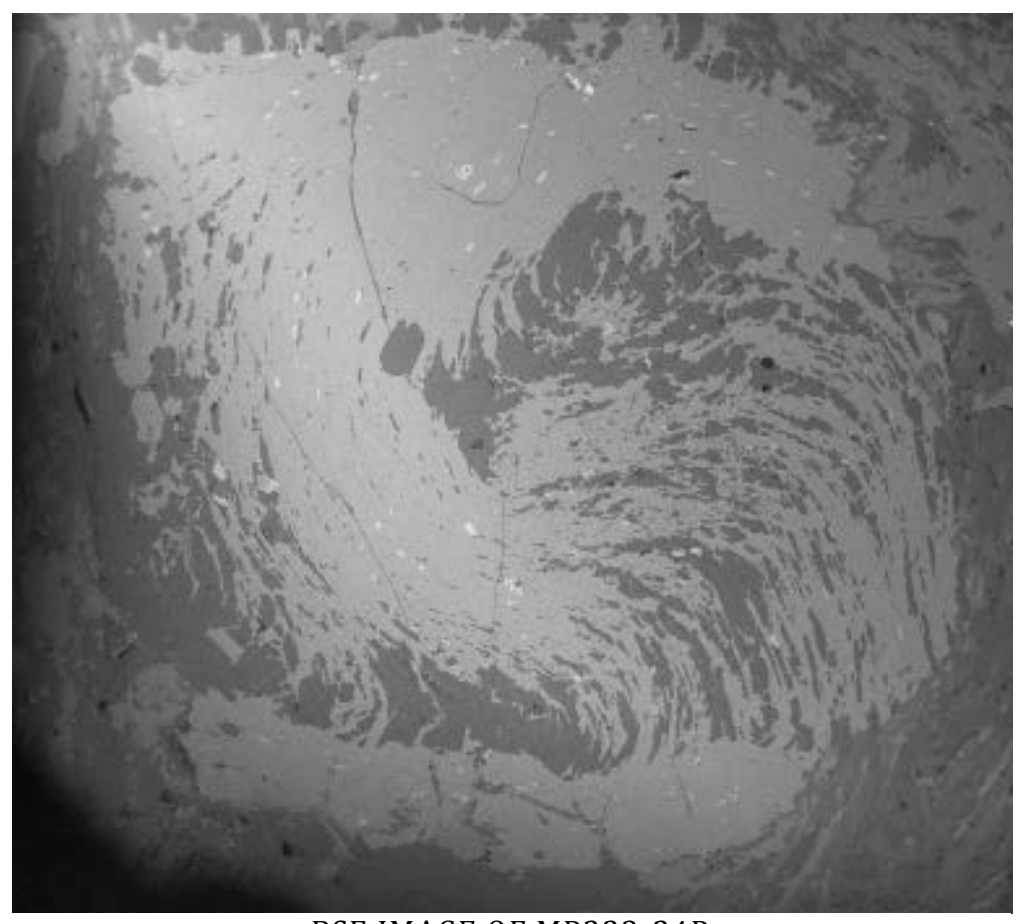

BSE IMAGE OF MP223-24P

- 100 - 
APPENDIX 2:

EBSD IMAGES

- 101 - 


\section{MP223-24P GT3}
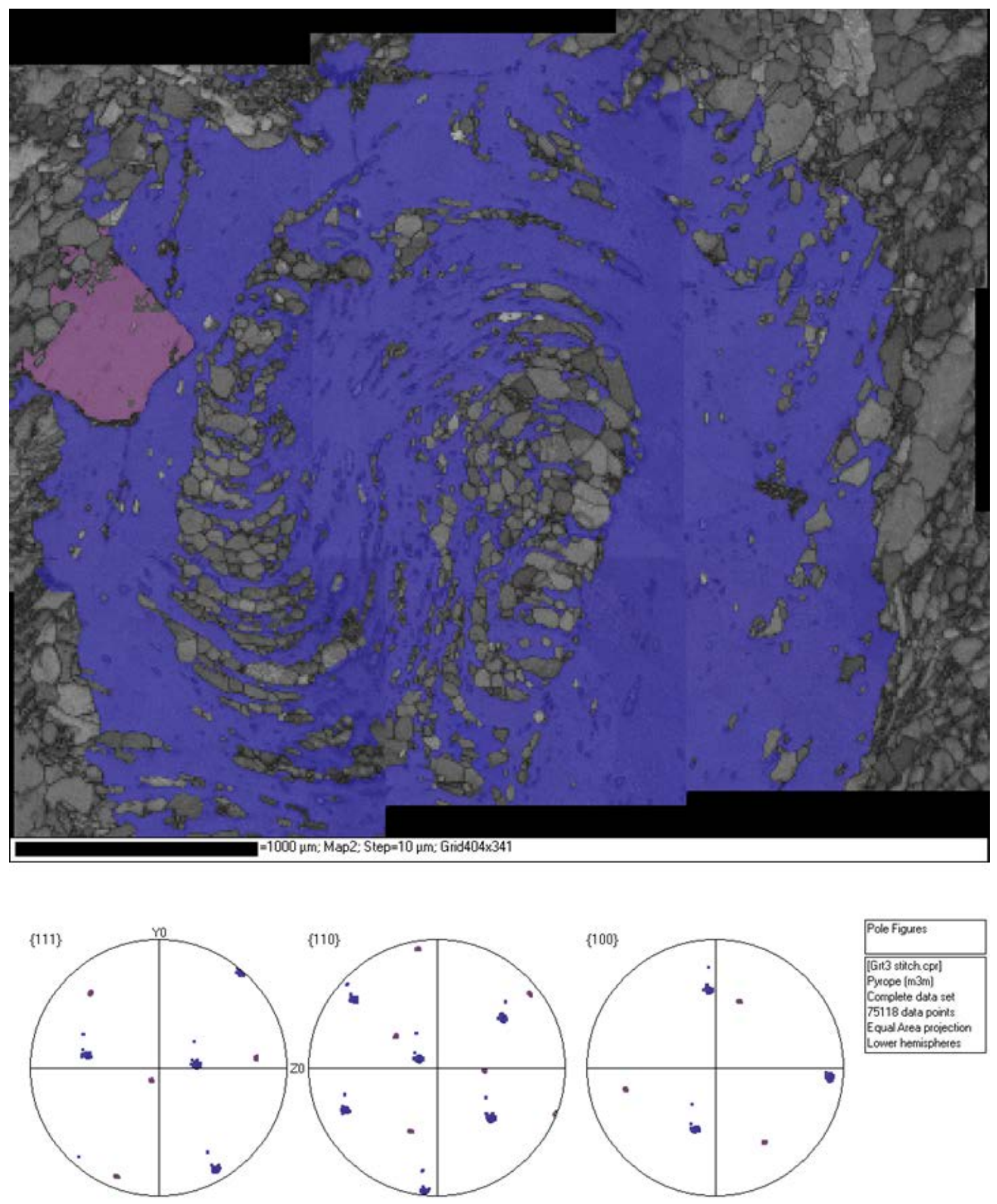


\section{MP223-24K GT1}
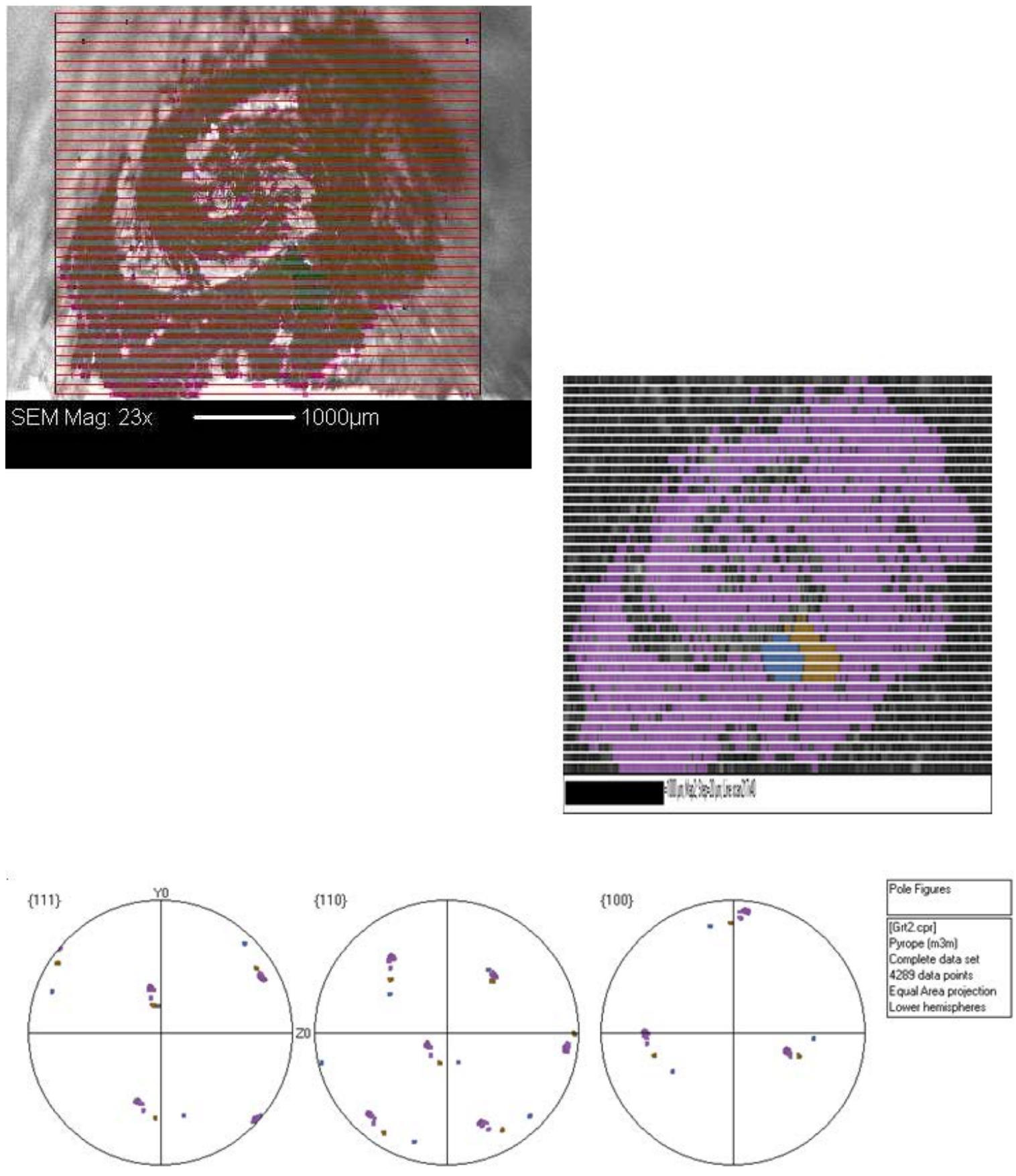


\section{MP223-24B GT3}

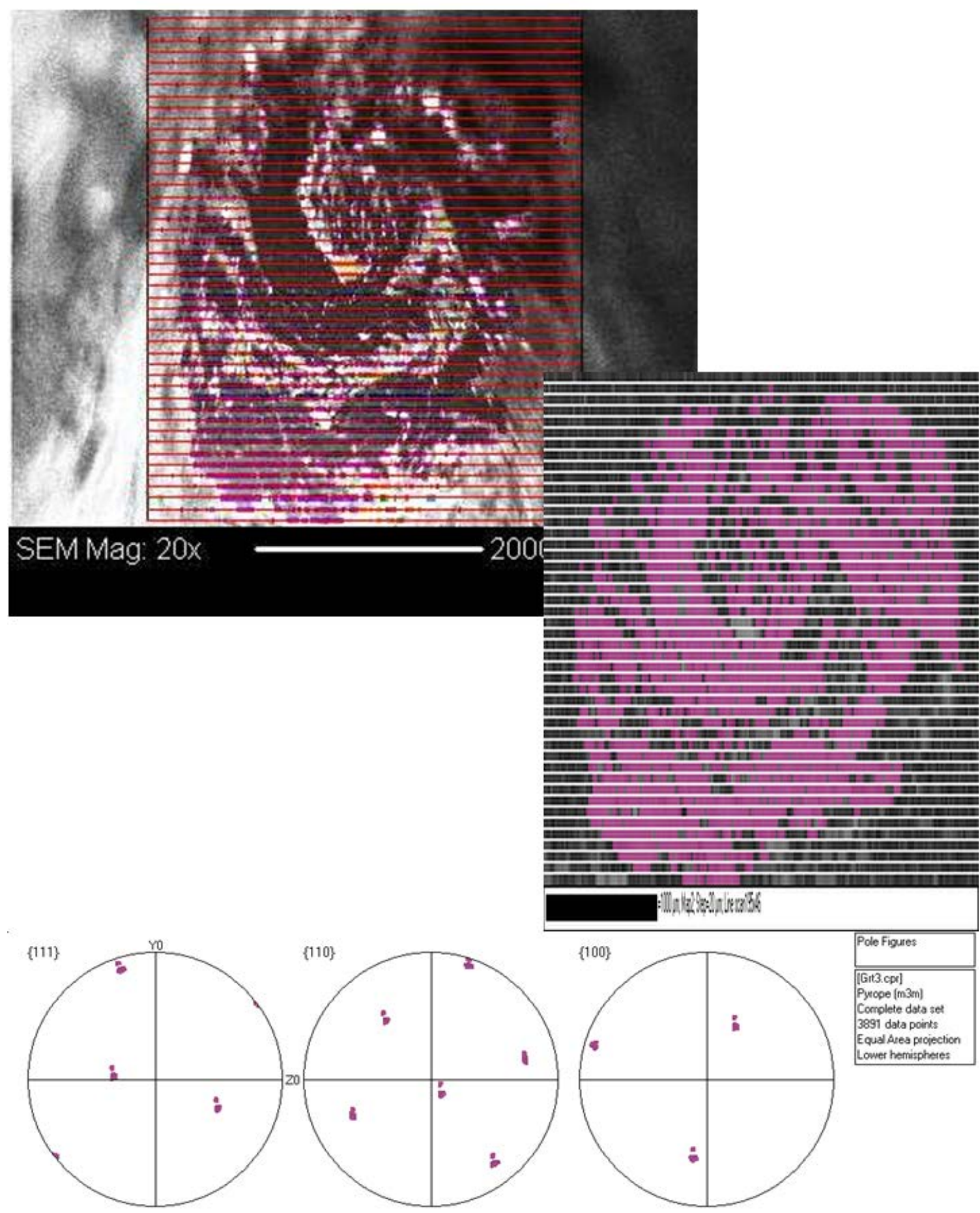


MP223-24B GT3B

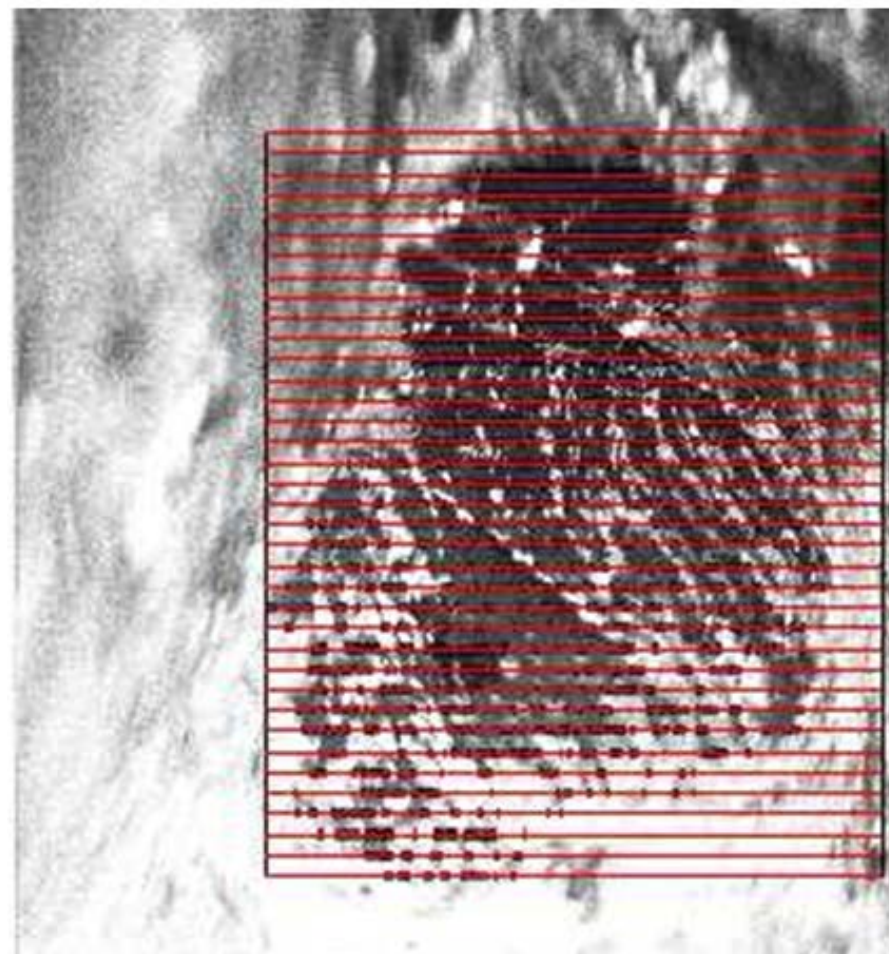

SEM Mag: $20 x$
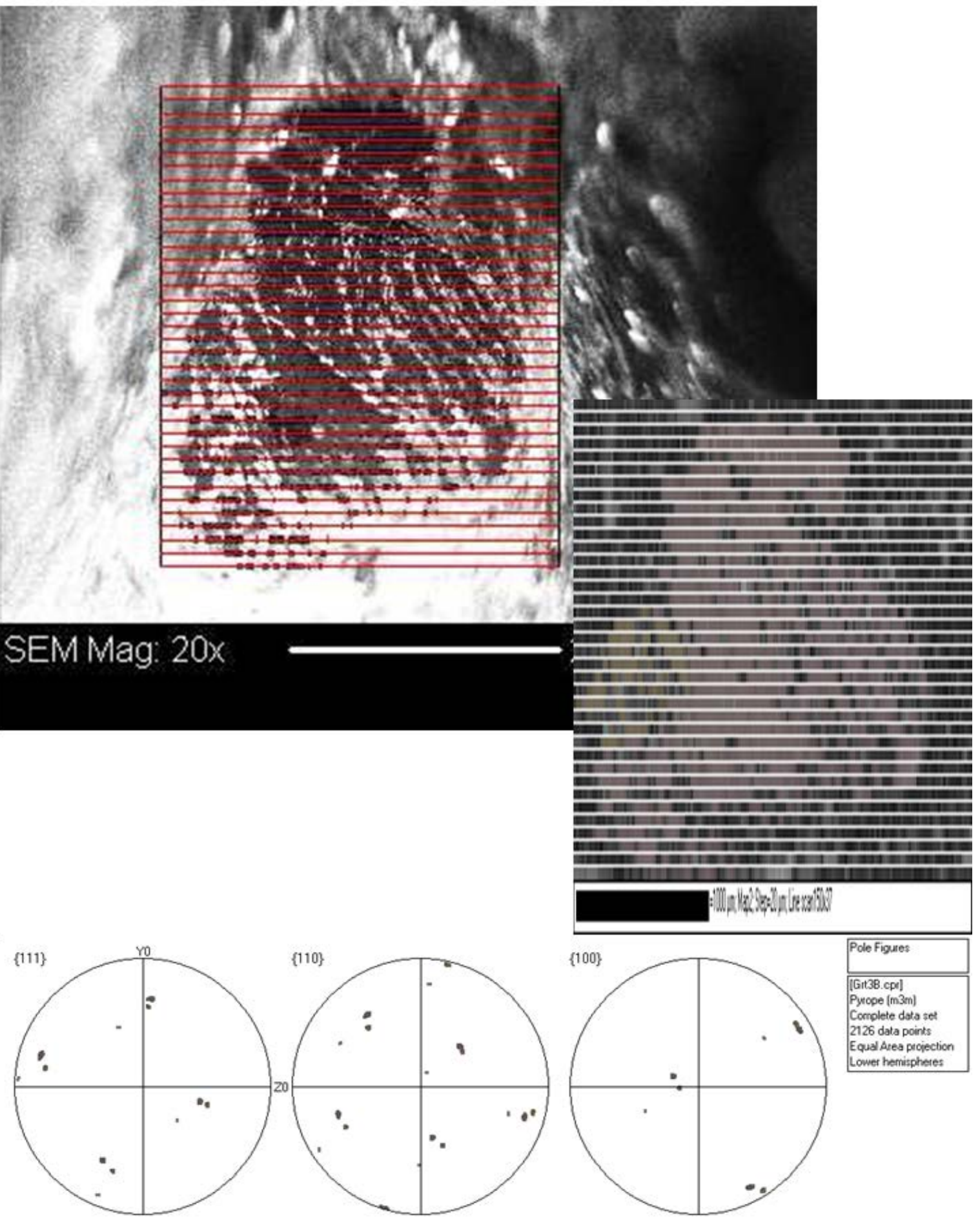

\begin{tabular}{|l|}
\hline Pole Figures \\
\hline \hline$[G r 138 . c p p]$ \\
Pyrope [m3m] \\
Complete dota set \\
2126 data points \\
Equal Atea projection \\
Lower hemispheres \\
\hline
\end{tabular} 


\section{MP223-24C GT1}
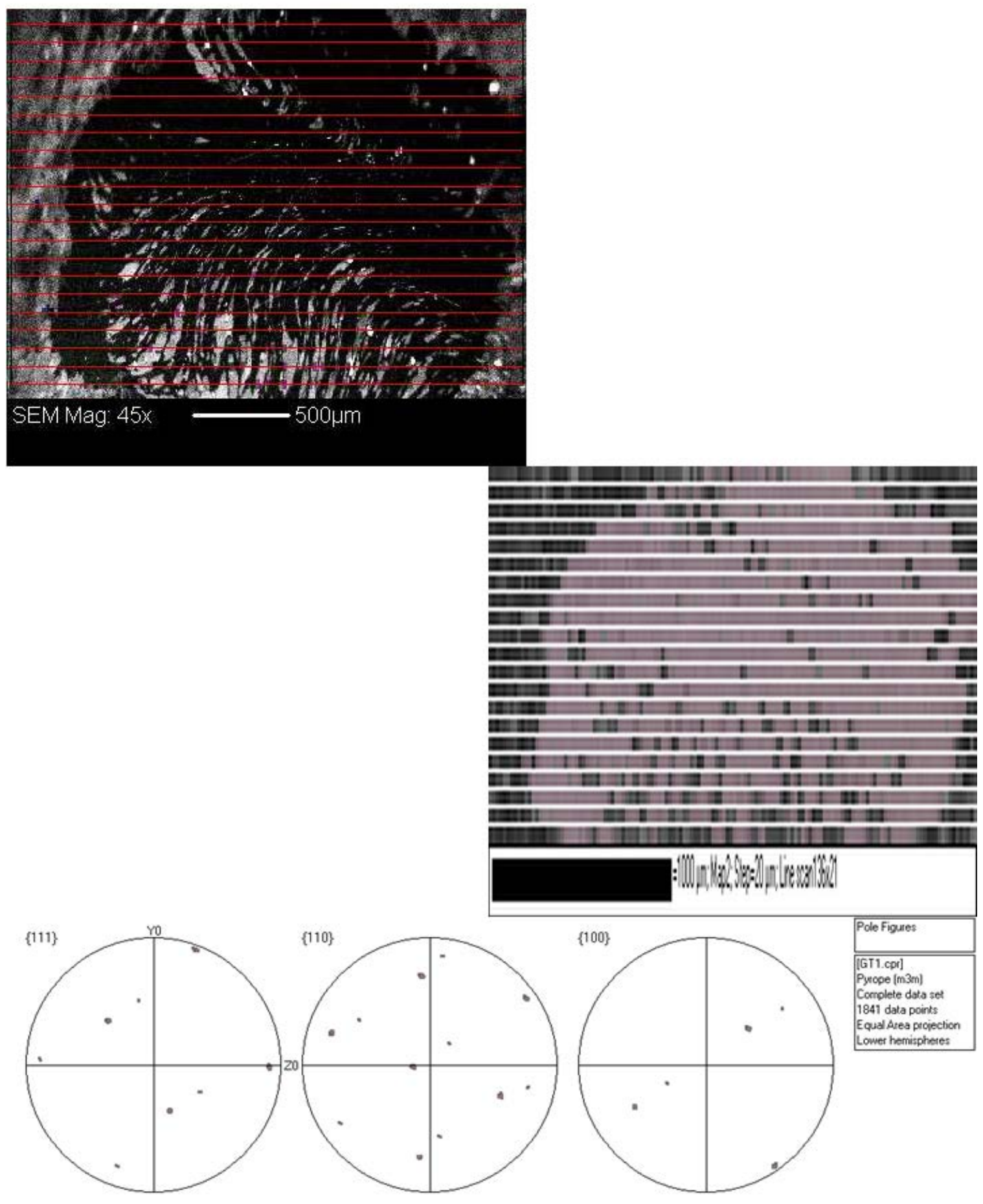

- 106 - 
MP223-24C GT2 A
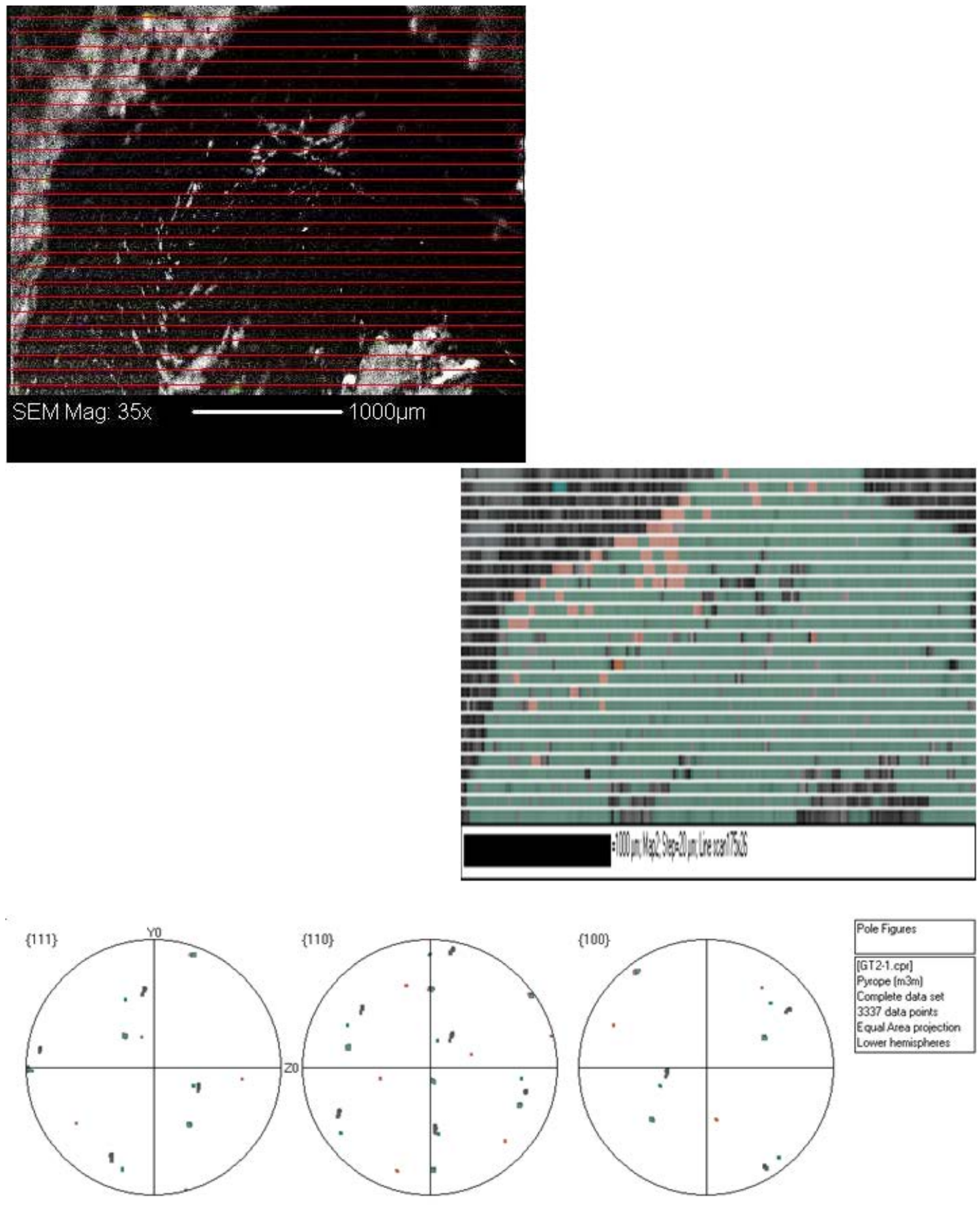


\section{MP223-24C GT2 B}
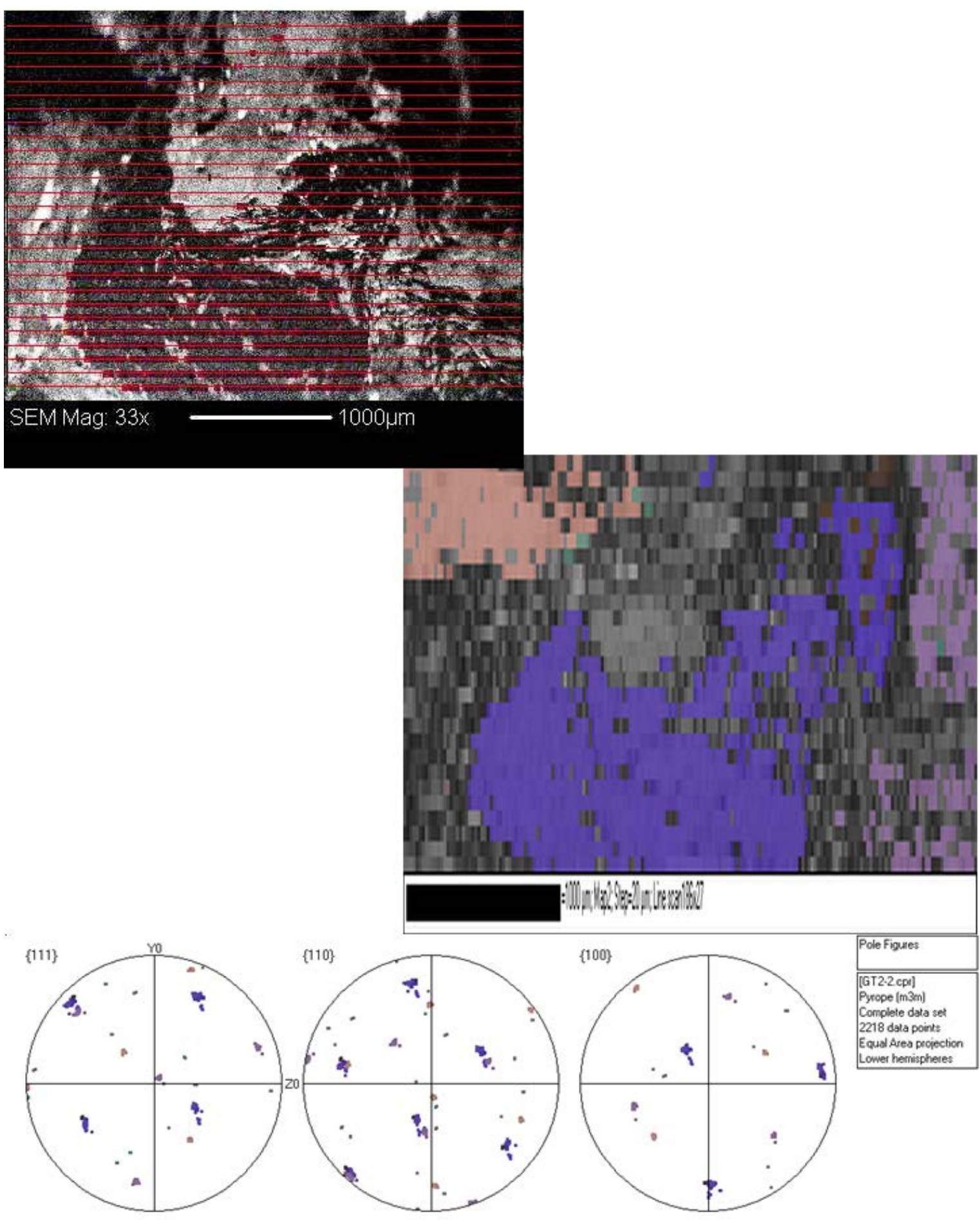


\section{MP223-24C GT3}
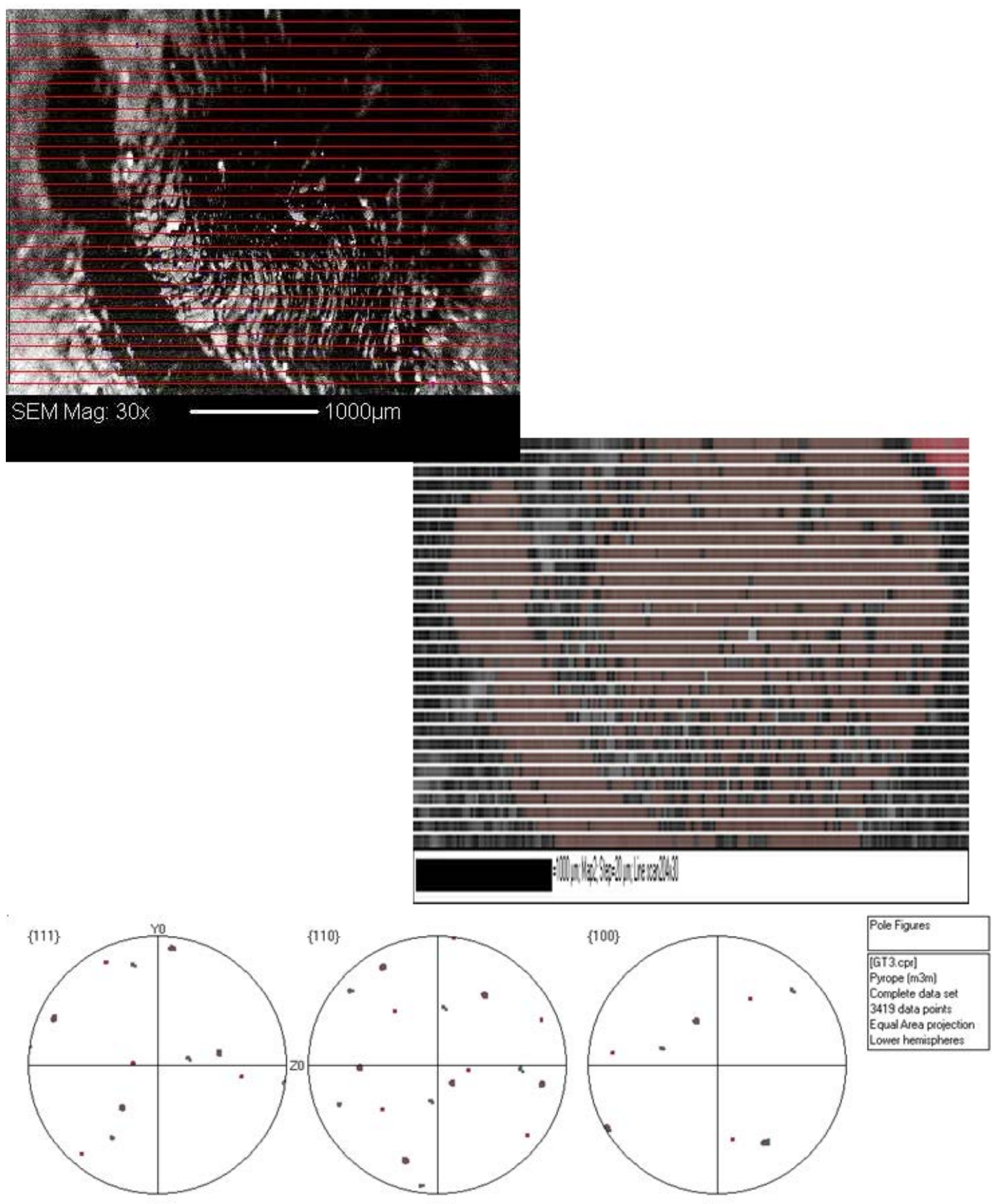


\section{MP223-24C GT4}

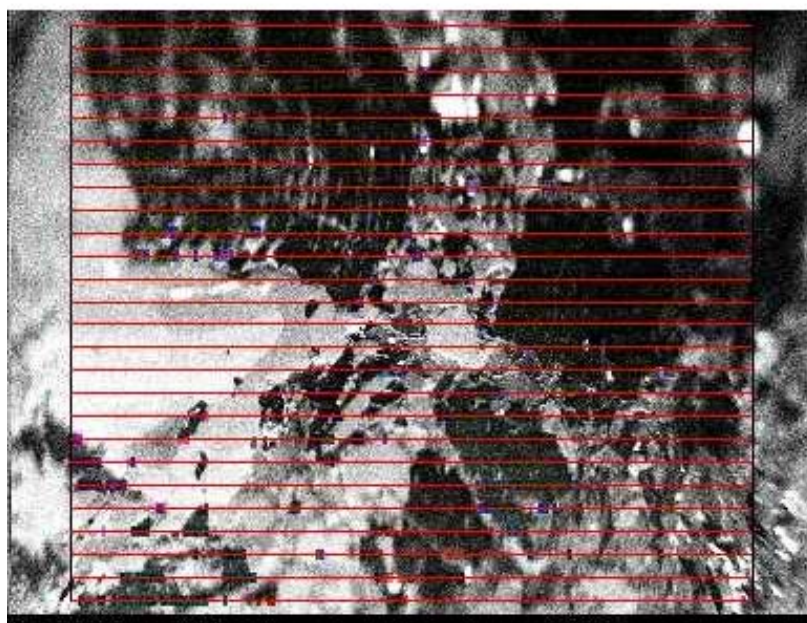

SEM Mag: $37 x$

1000um
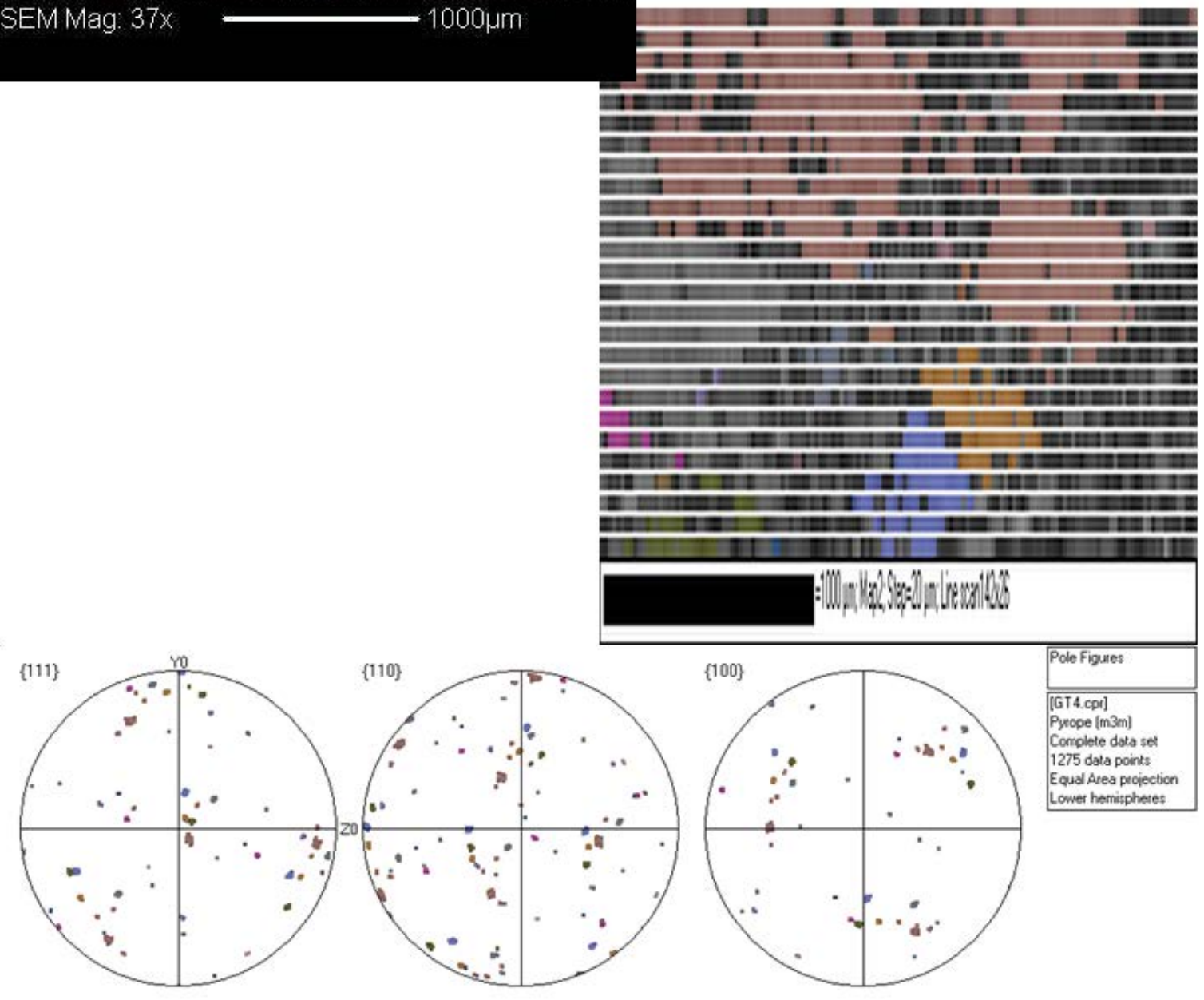


\section{MP223-24K GT3}
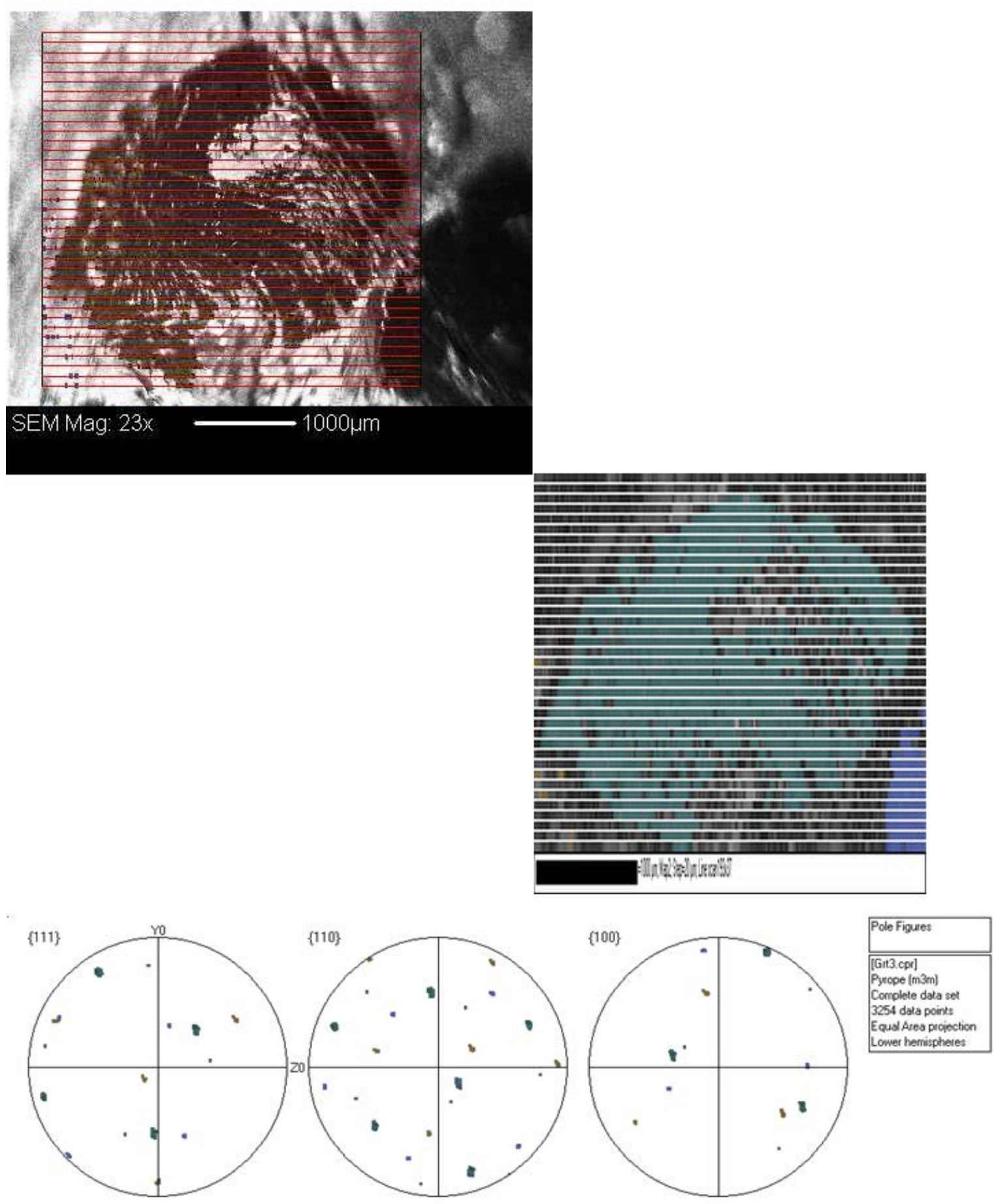
MP223-24O GT1

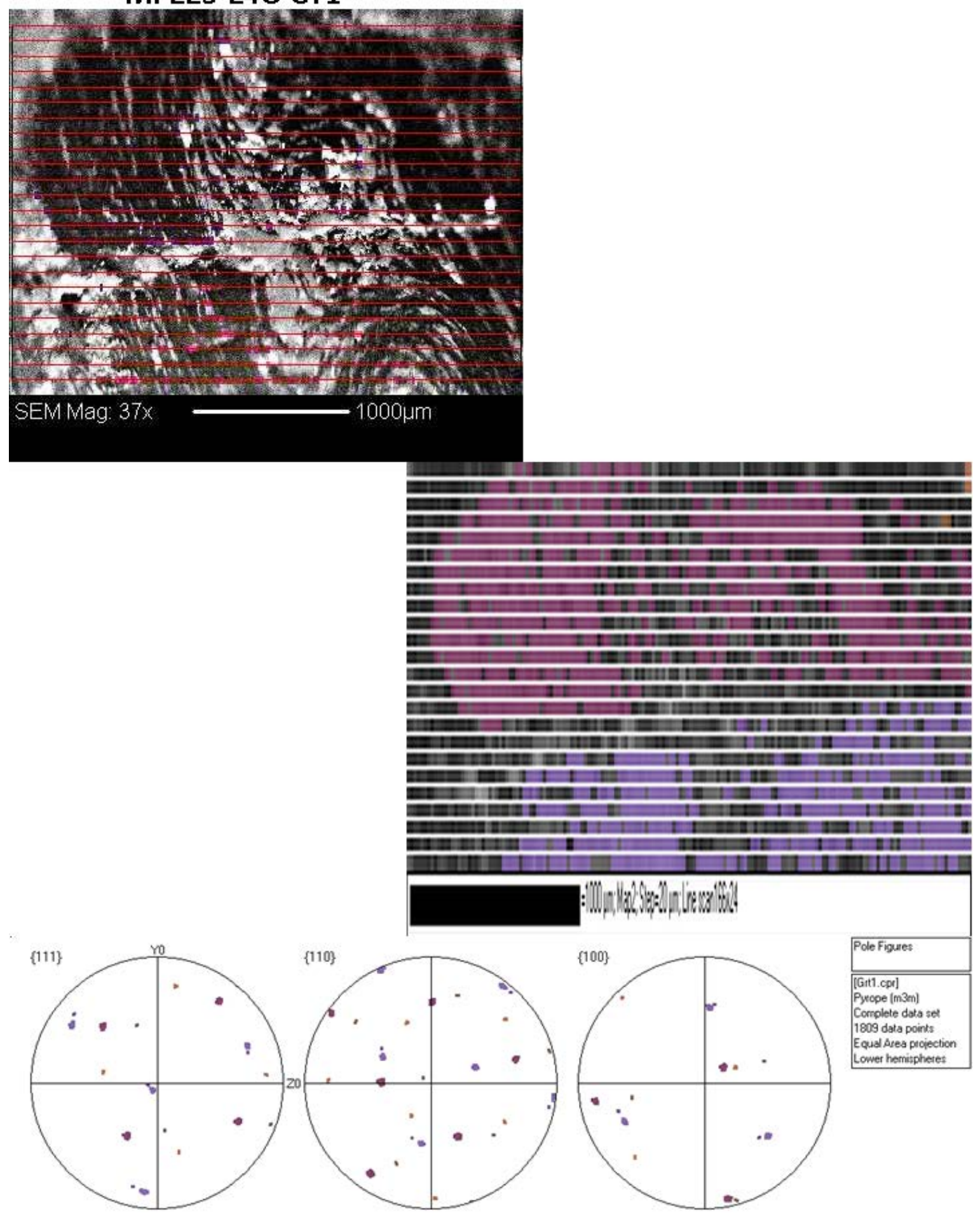

- 112 - 


\section{MP223-240 GT2}
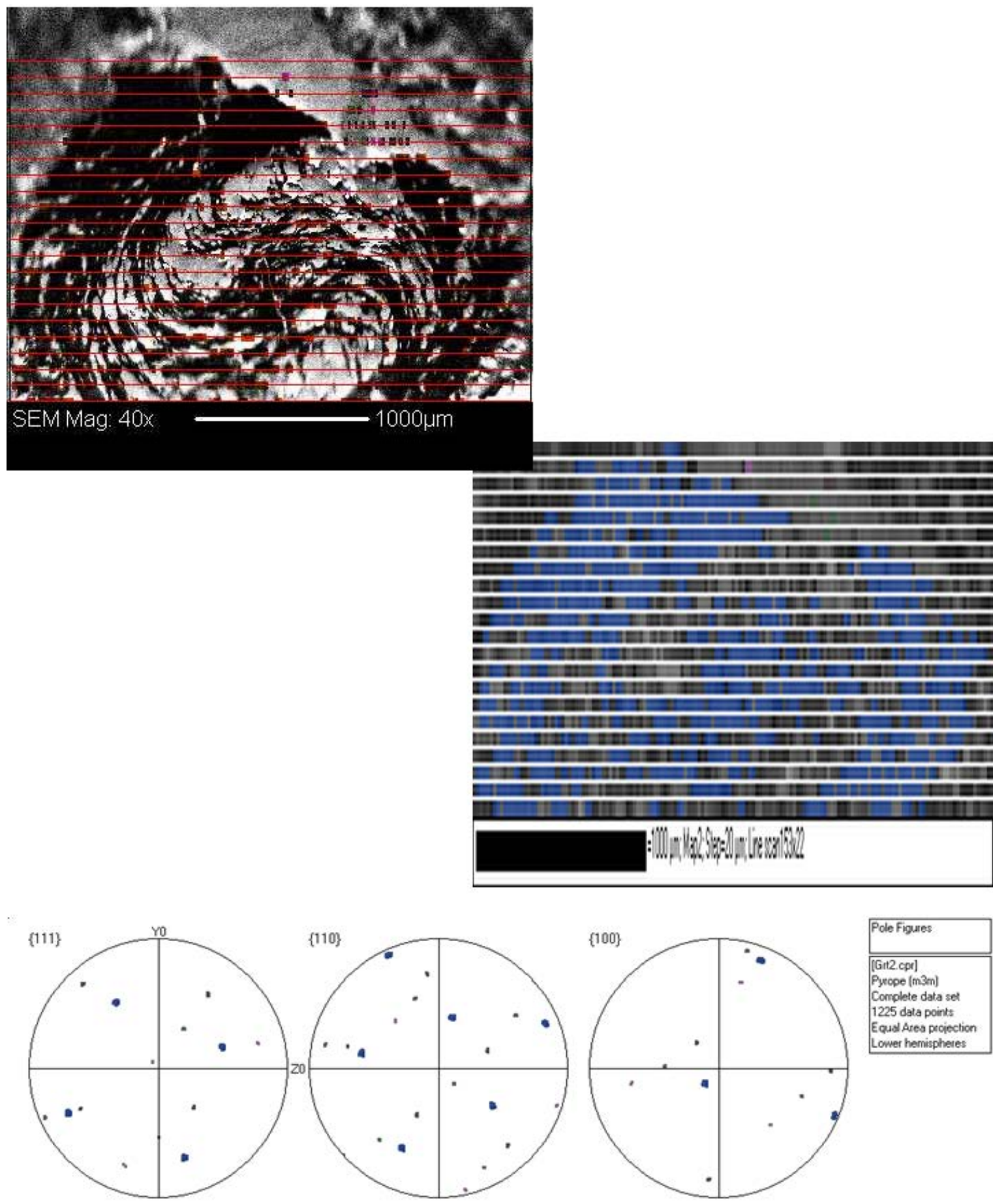


\section{MP223-24O GT3}
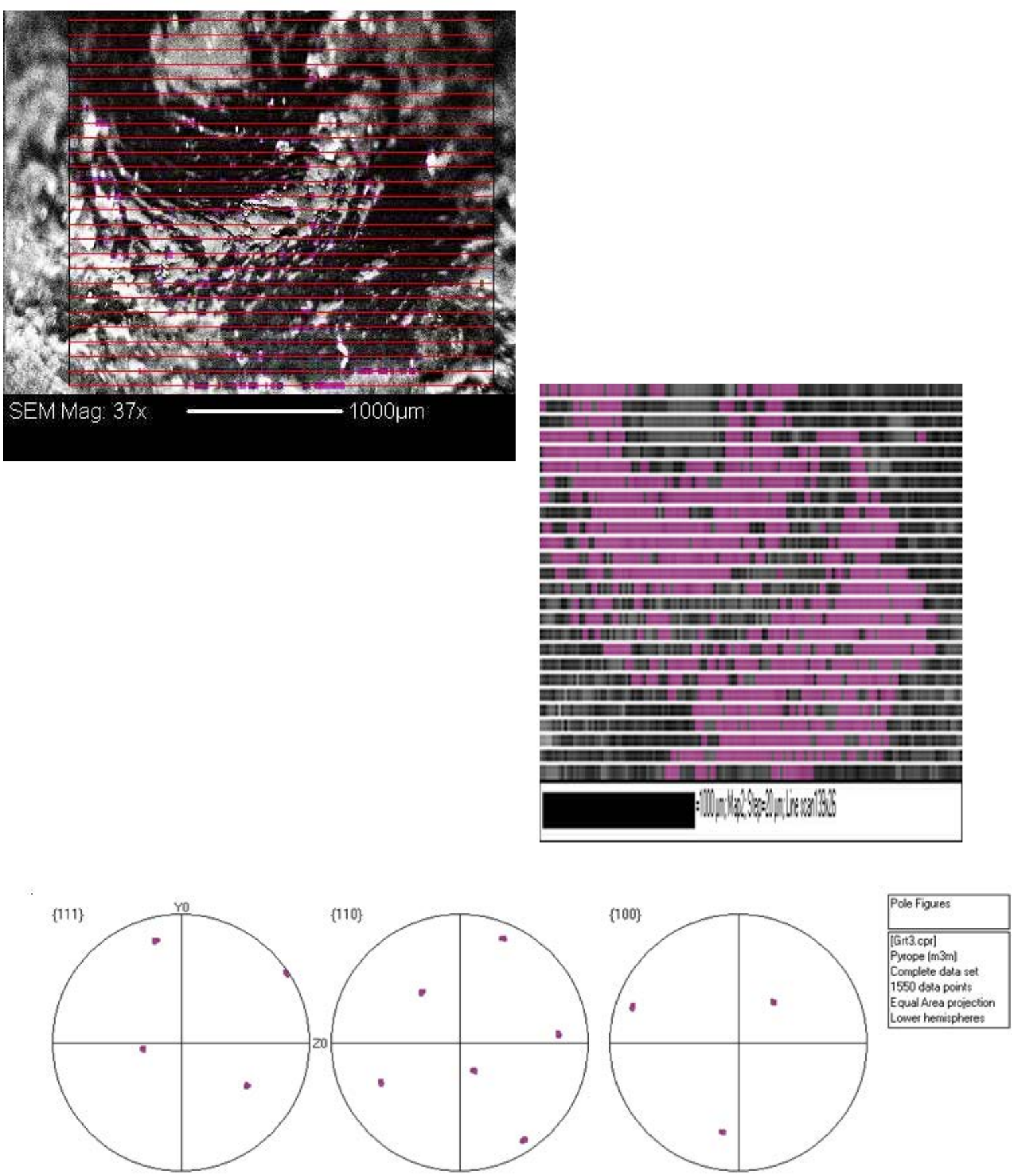


\section{MP223-24P GT1}

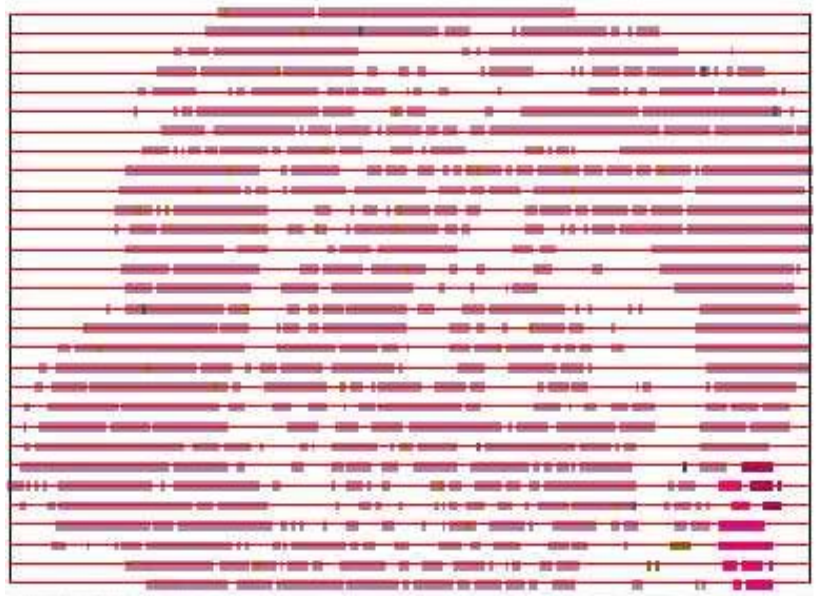

\section{SEM Mag: $30 x$}

1000um

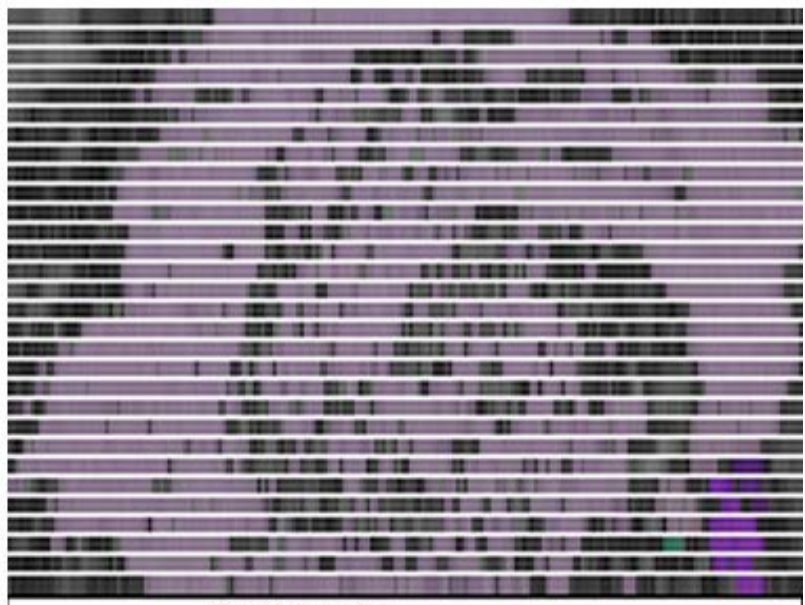

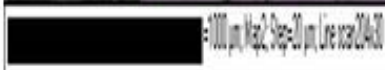

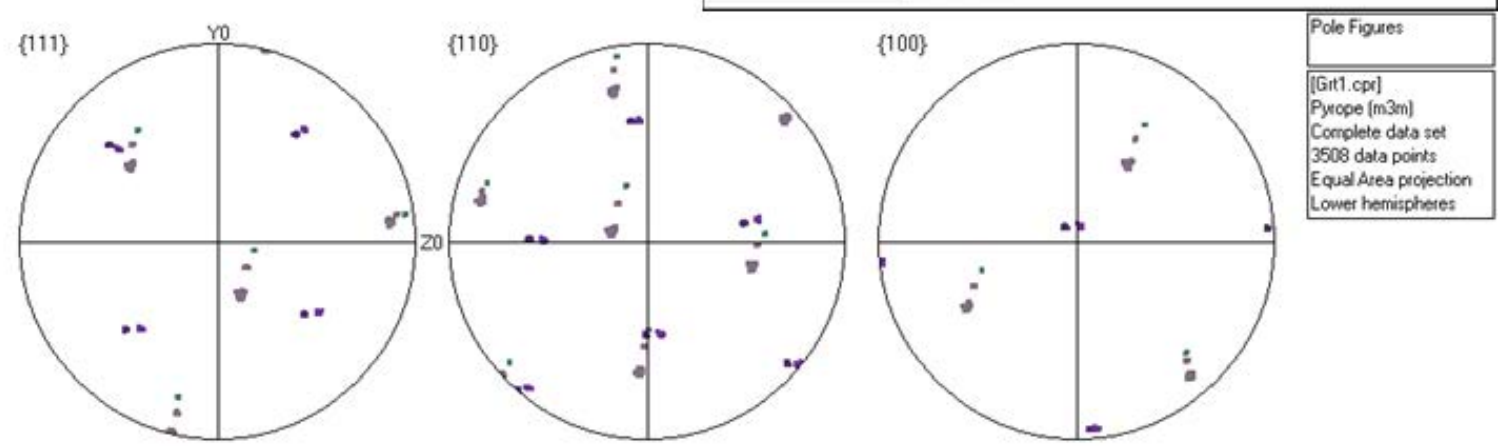


MP223-24P GT1 Zoomed
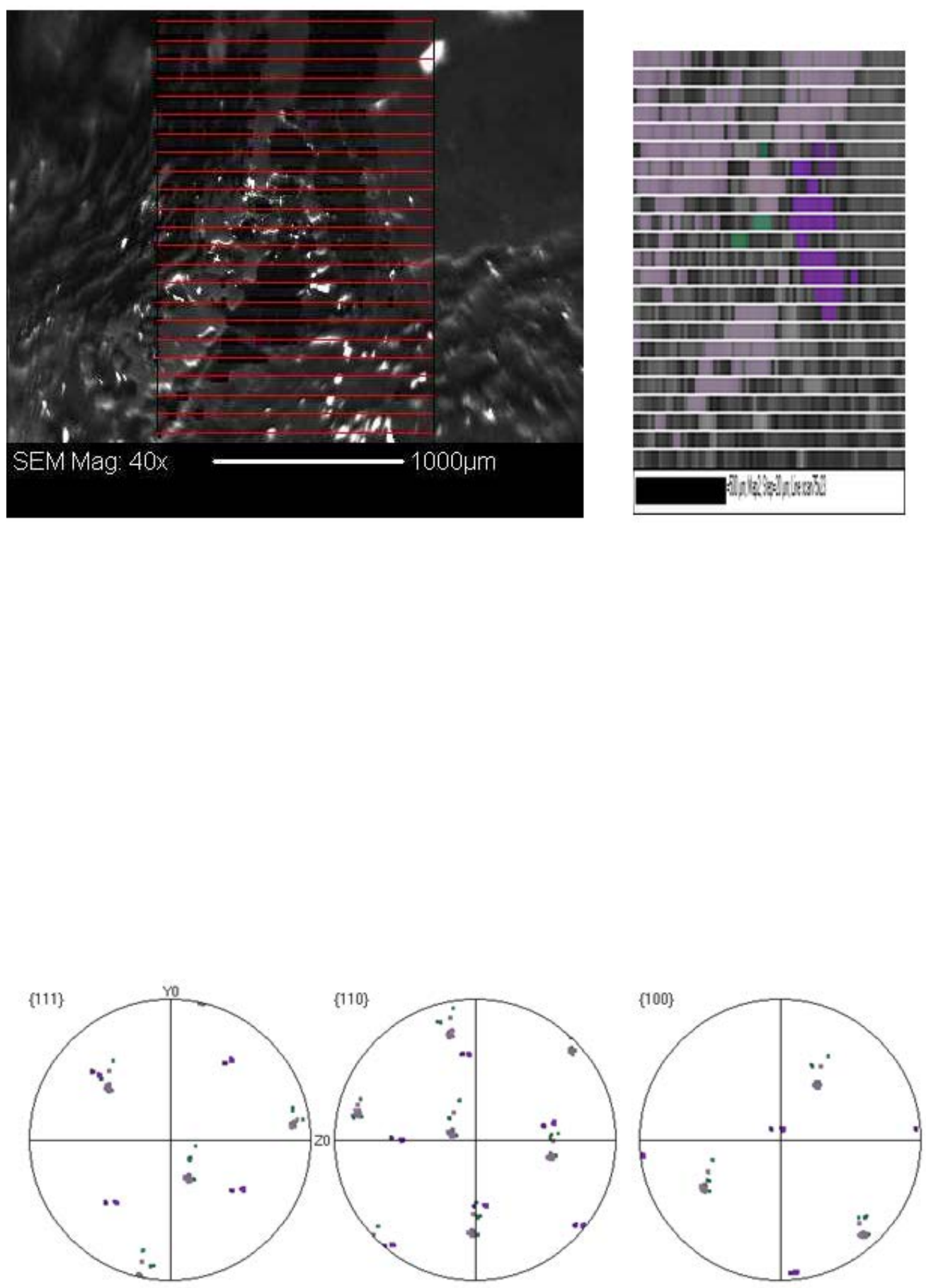

Pole Figures

Equal Area proiection

Lower hemispheres 


\section{MP223-24P GT4}

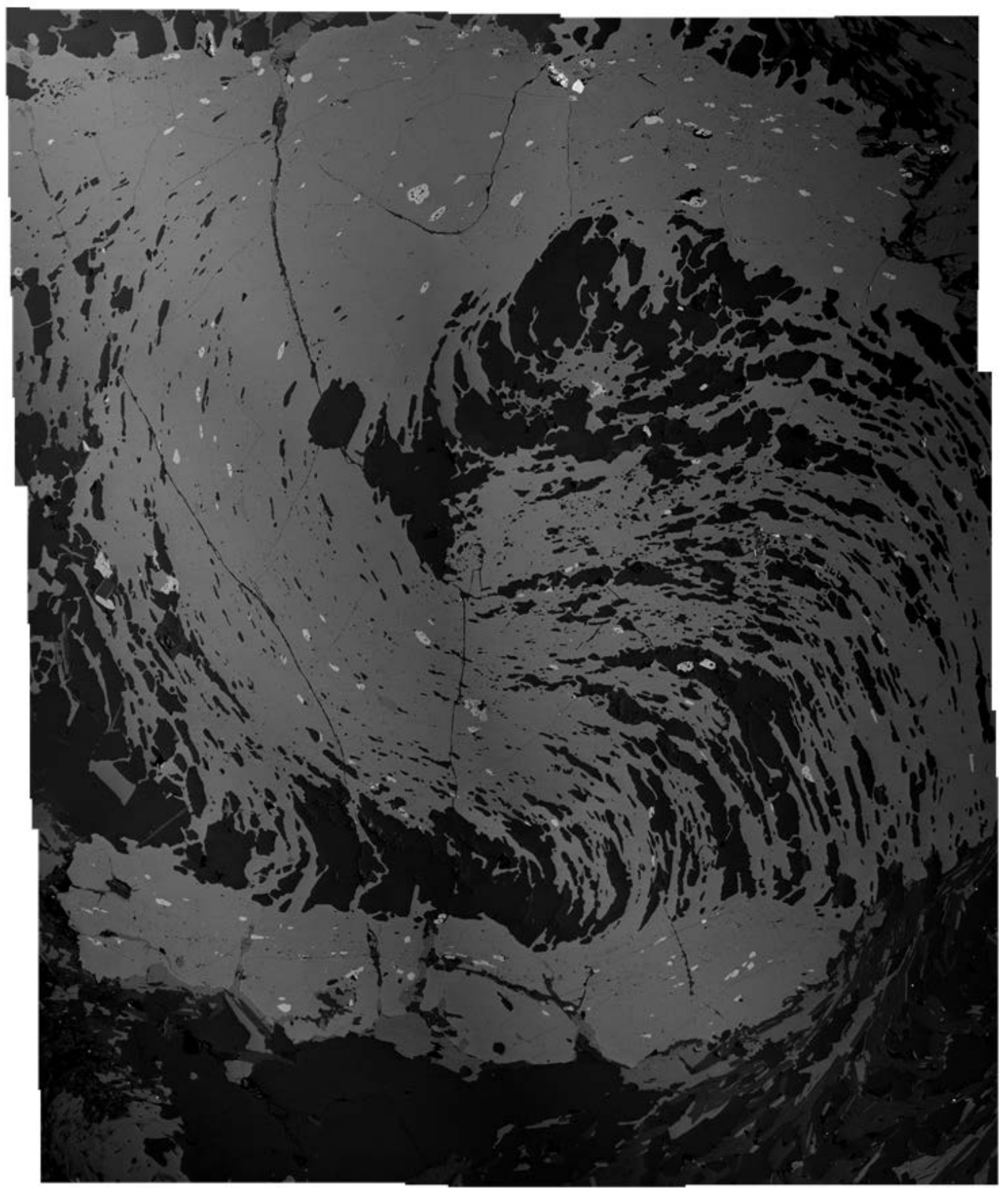


APPENDIX 3:

X-RAY INTENSITY MAPS

- $118-$ 


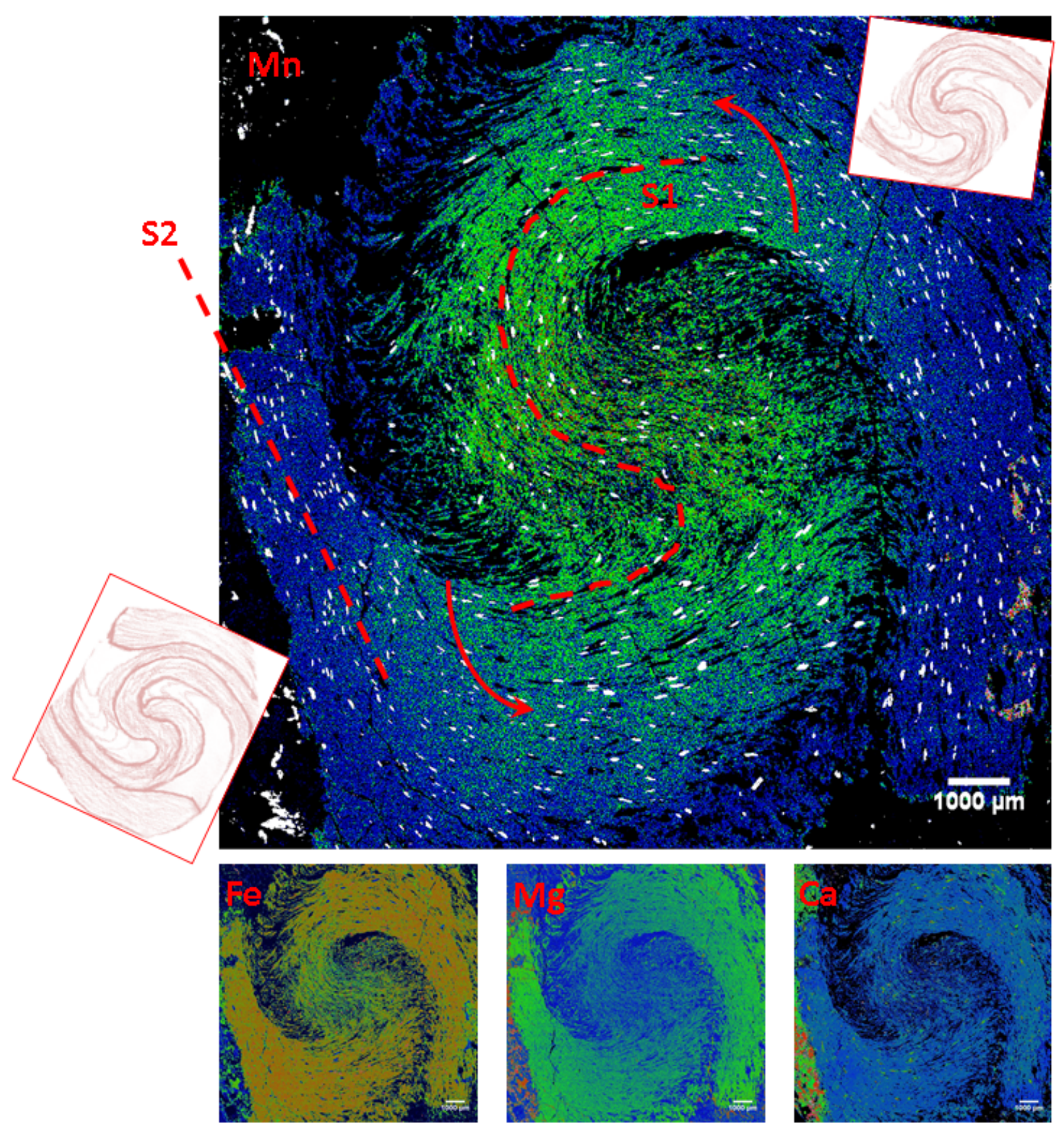

Figure 8.1. X-ray intensity maps. Showing the distribution of elements within a two dimensional thin section slice through a spiral garnet from the Laramie Range of wyoming. The garnet appears to show near concentric zoning in $\mathrm{Mn}$, Fe, and Mg. Garnet rotation sense is counter clockwise and can be explained via overgrowth of an asymmetric crenulation foliation with either subsequent rotation of approximately 25 degrees or wrapping of the $\$ 2$ foliation around the garnet core during continued shortening and overgrowth. 

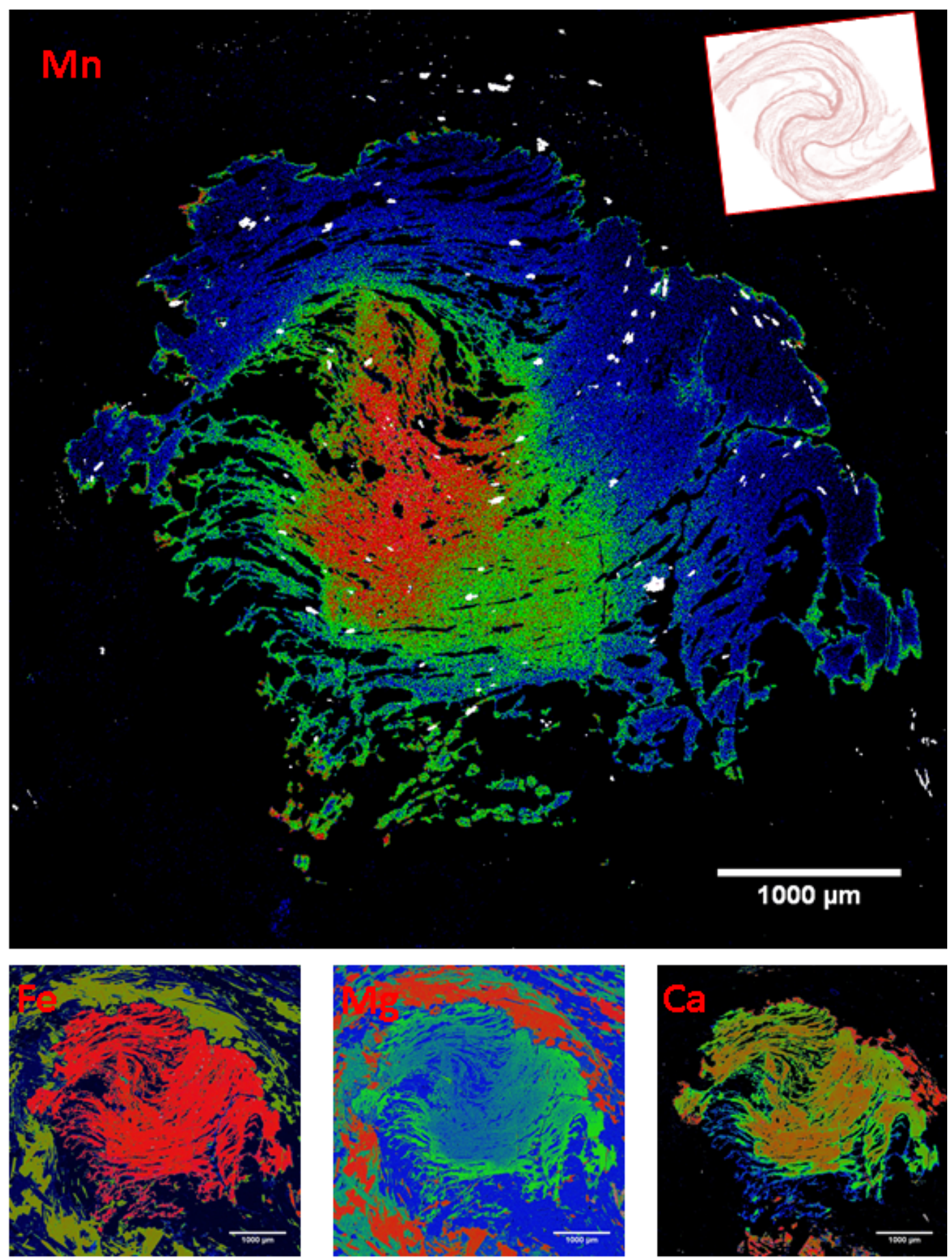

X-ray intensity maps. Showing the distribution of elements within a two dimensional thin section slice through a spiral garnet from the Laramie Range of Wyoming. The garnet appears to show near concentric zoning in $\mathrm{Mn}$ and $\mathrm{Mg}$. This garnet has a very poorly developed clockwise rotation sense from overgrowth of a slightly asymmetric crenulation foliation. 

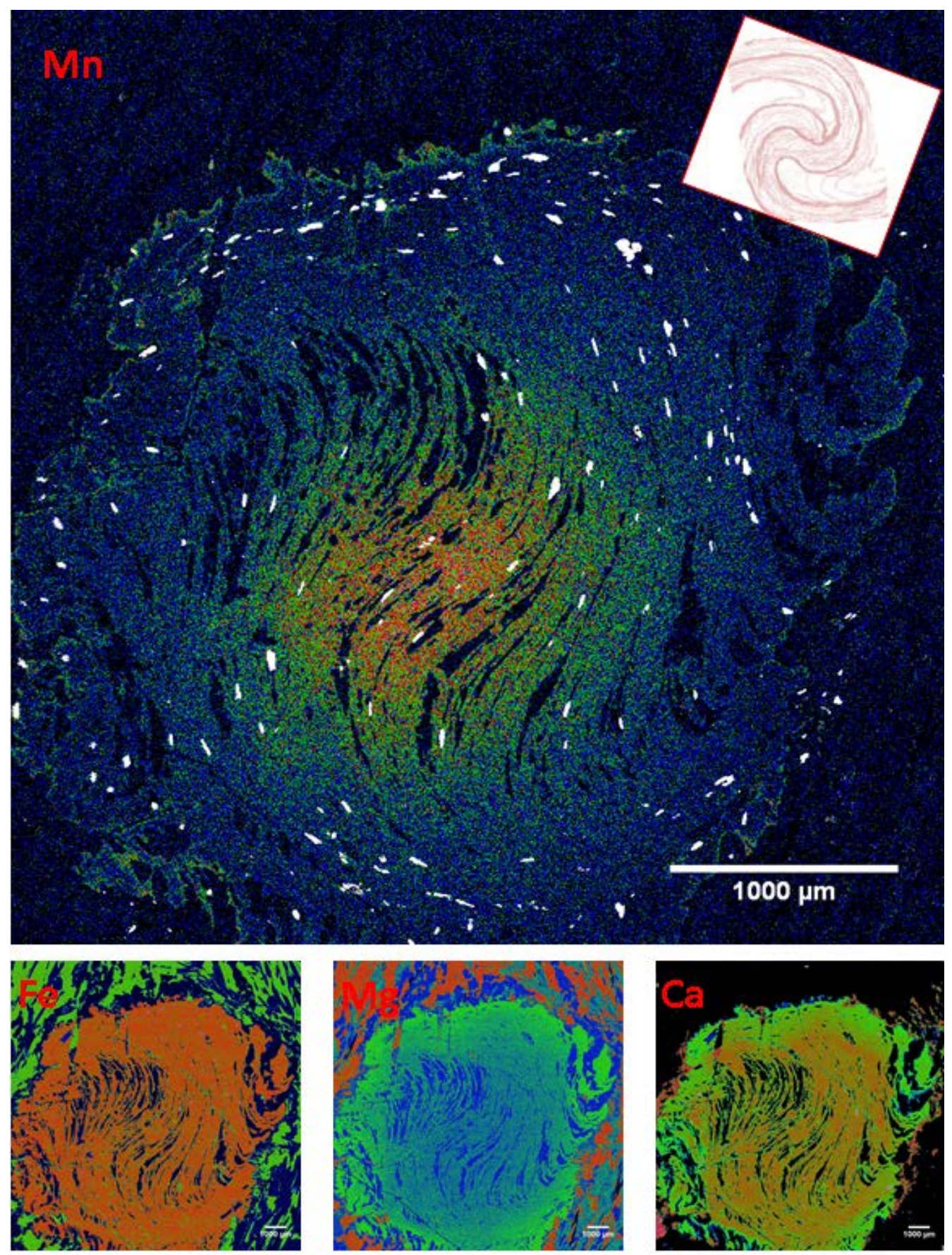

X-ray intensity maps. Showing the distribution of elements within a two dimensional thin section slice through a spiral garnet from the Lar amie Range of Wyoming. The garnet appears to show near concentric zoning in $\mathrm{Mn}$ and $\mathrm{Mg}$. This garnet has a clockwise rotation sense resulting from the overgrowth of a slightly asymmetric crenulation foliation. After overgrowing the core, continued shortening appears to have occurred during the remaining overgrowth. 

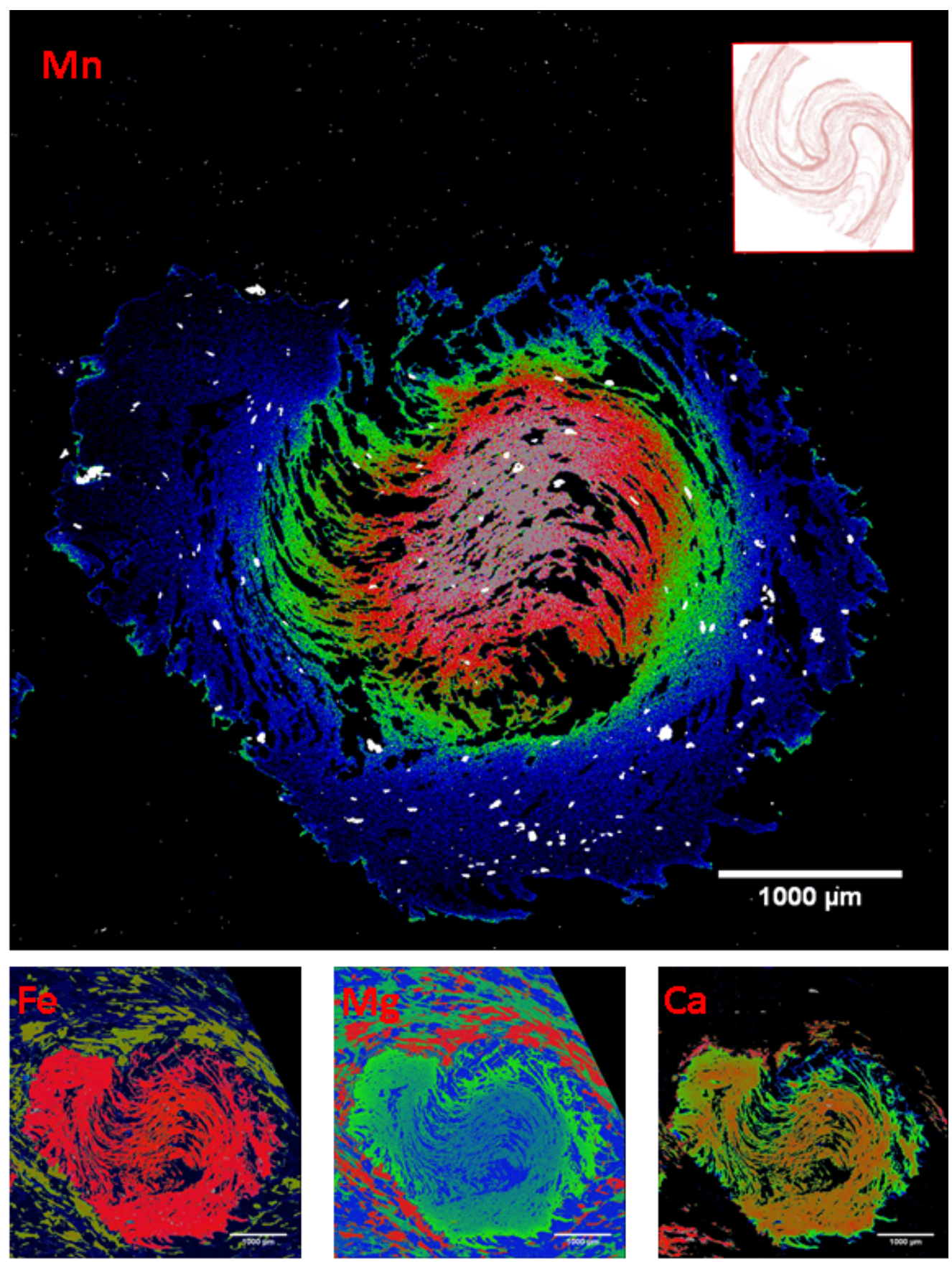

Figure \#. X-ray intensity maps showing the distribution of elements within a two dimensional thin section slice through a spiral garnet from the Laramie Range of Wyoming. The garnet appears to show near concentric zoning in $\mathrm{Mn}$ and $\mathrm{Mg}$. This garnet has a counter-clockwise rotation sense resulting from the overgrowth of an asymmetric crenulation foliation. After overgrowing the core, continued shortening appears to have occurred during the remaining overgrowth. 

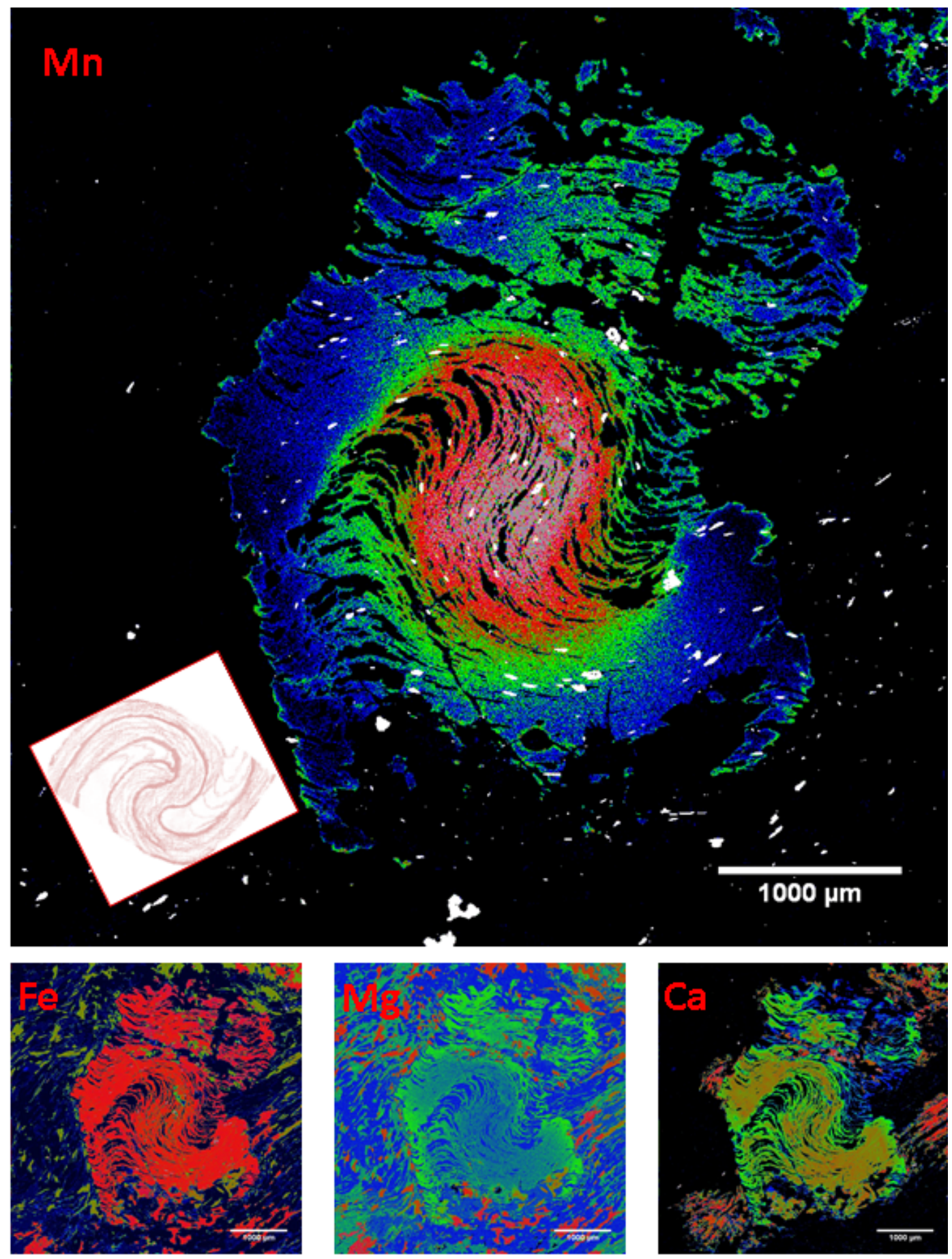

Figure\#. X-ray intensity maps showing the distribution of elements within a two dimensional thin section slice through a spiral garnet from the Laramie Range of Wyoming. The garnet appears to show near concentric zoning in $\mathrm{Mn}$. This garnet has a clockwise rotation sense resulting from the overgrowth of an asymmetric crenulation foliation. 

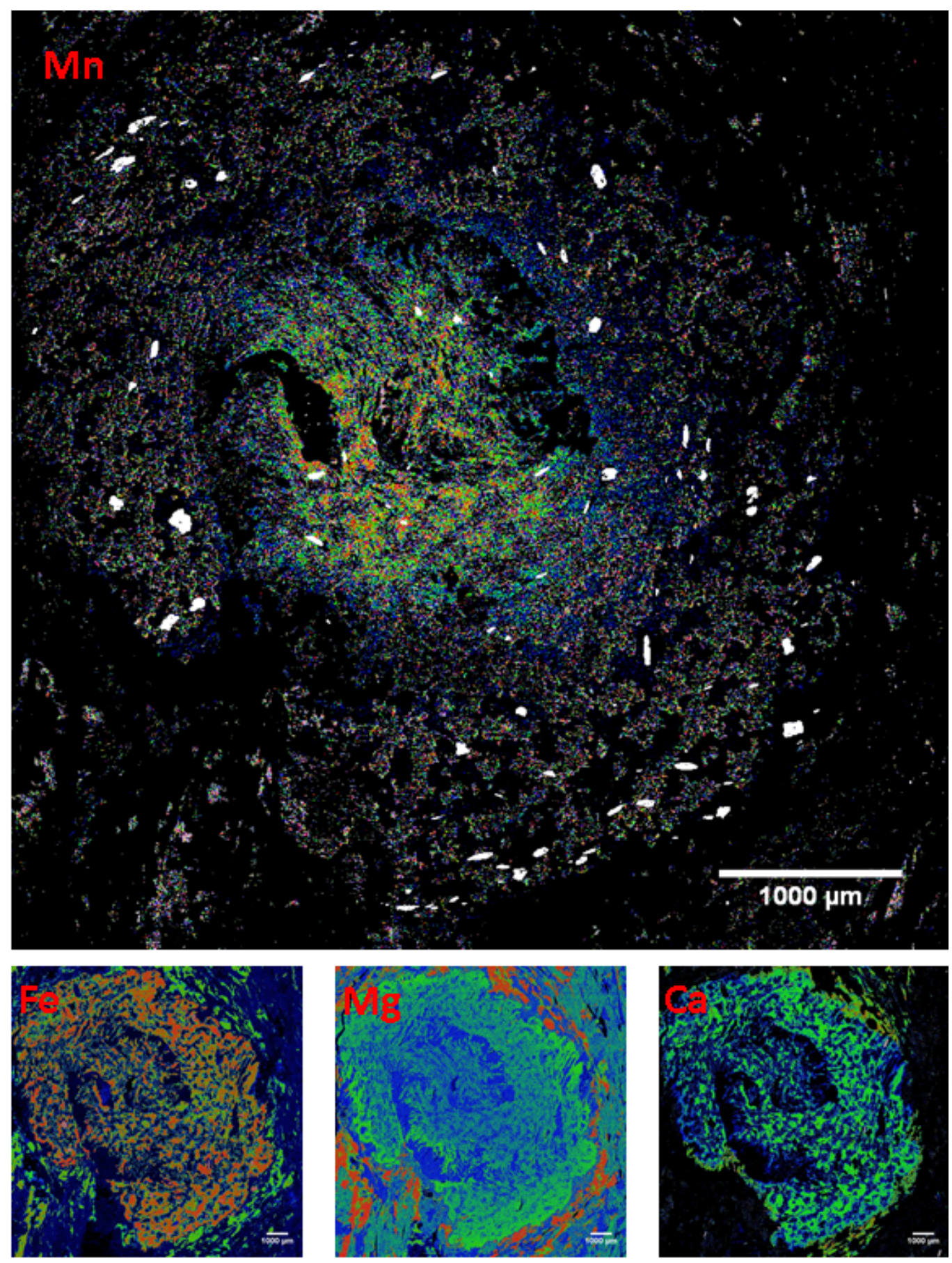

Figure \#. X-ray intensity maps showing the distribution of elements within a two dimensional thin section slice through a spiral garnet from the Laramie Range of Wyoming. Surface aberrations lead to poor microprobe results due to uneven carbon coat, charging, and depth to sample issues that affected the WDS. 

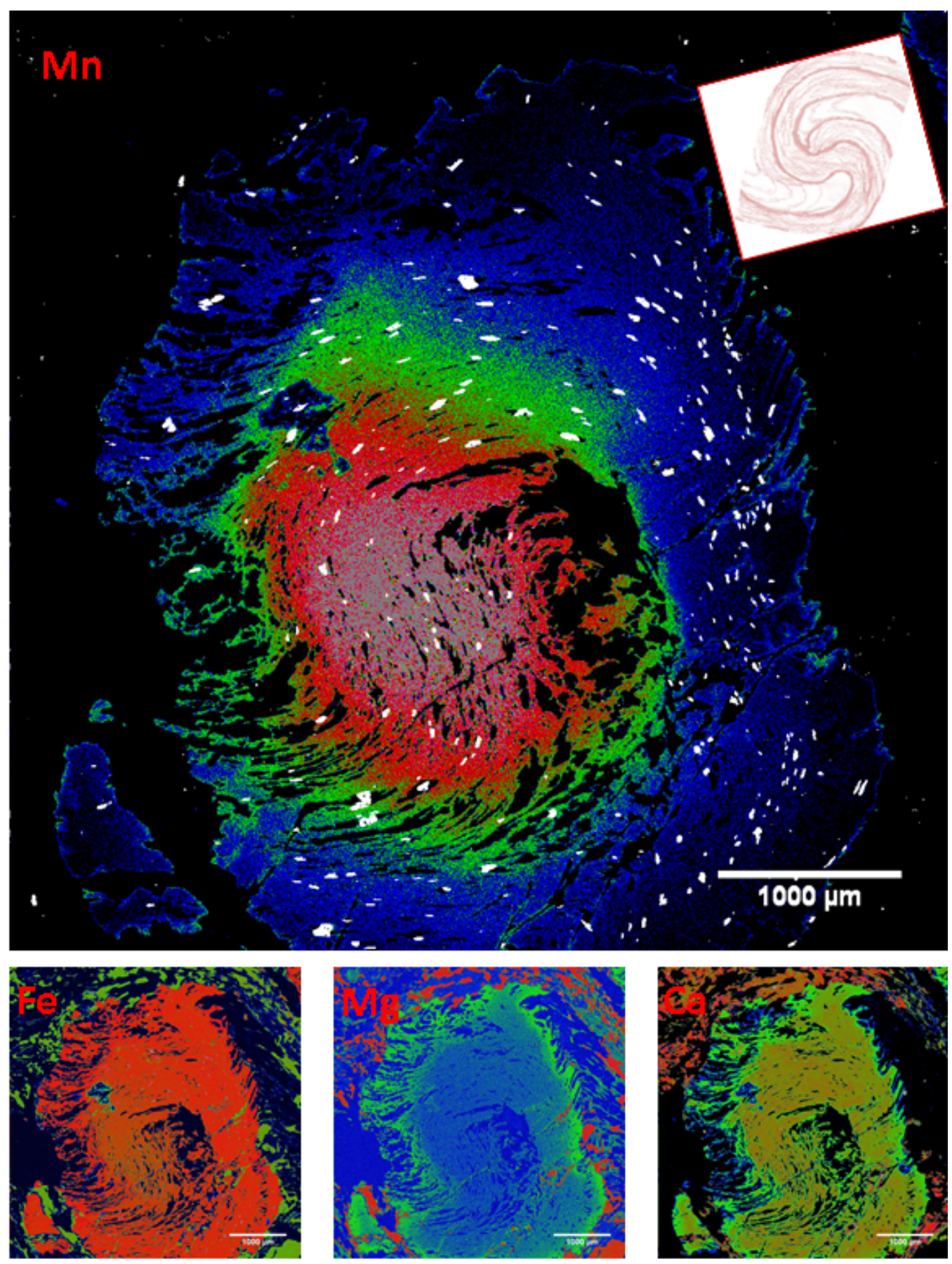

Figure \#. X-ray intensity maps showing the distribution of elements within a two dimensional thin section slice through a spiral garnet from the Laramie Range of Wyoming. The garnet appears to show near concentric zoning in Mn. This garnet has a counter-clockwise rotation sense resulting from the overgrowth of a poorly developed asymmetric crenulation foliation. Continued shortening appears to have occurred following overgrowth of the core. 

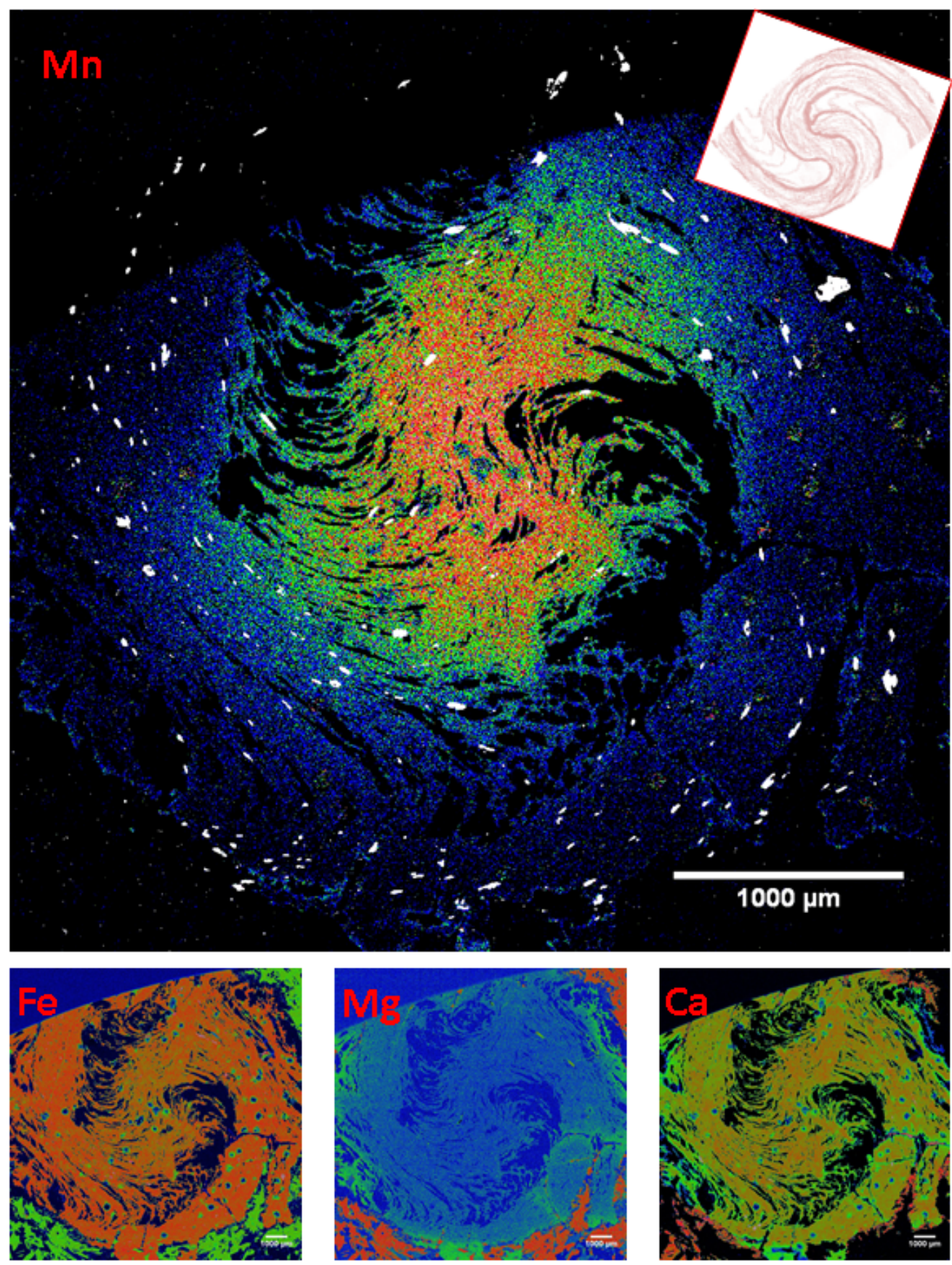

Figure \#. X-ray intensity maps showing the distribution of elements within a two dimensional thin section slice through a spiral garnet from the Laramie Range of Wyoming. The garnet appears to show near concentric zoning in $\mathrm{Mn}$. This garnet has a counter-clockwise rotation sense resulting from the overgrowth of an asymmetric crenulation foliation. Shortening appears to have wrapped the $\$ 2$ foliation around the garnet core prior to or during continued overgrowth. 

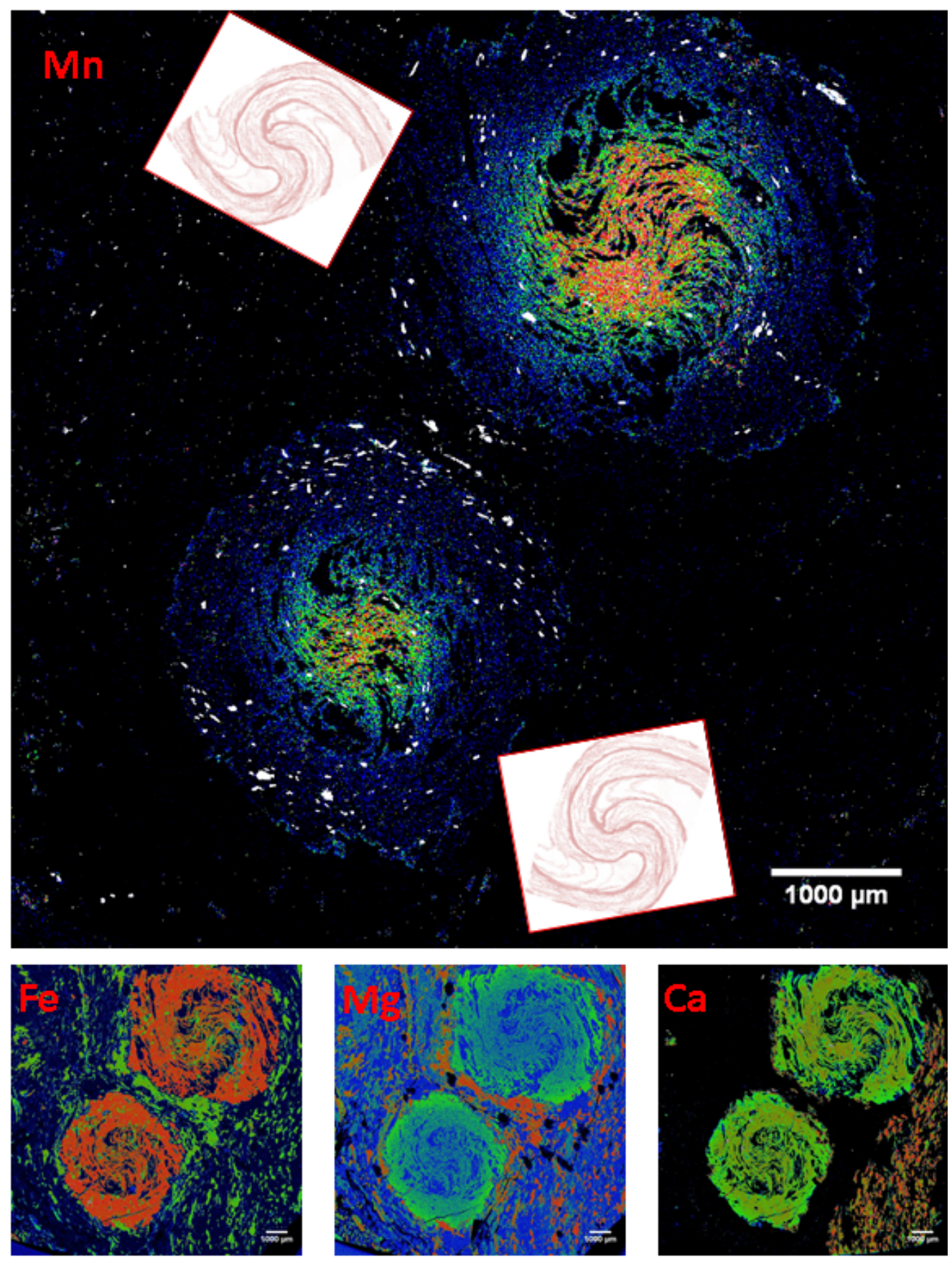

Figure\#. X-ray intensity maps showing the distribution of elements within a two dimensional thin section slice through two spiraled garnets from the Laramie Range of Wyoming, These garnets appear to show near concentric zoning in $\mathrm{Mn}$. These garnets have counterclockwise rotation senses resulting from the overgrowth of an asymmetric crenulation foliation. Shortening appears to have wrapped the $\$ 2$ foliation around the garnet cores prior to or during continued overgrowth. Based on the cores of these garnets the lower garnet appears to have rotated approximately 39 degrees counter clockwise relative to the upper garnet post garnet growth (This assumes the starting fabric was similar). 
APPENDIX 4:

A SPIRALED GARNET EVALUATION WORKFLOW

- 128 - 


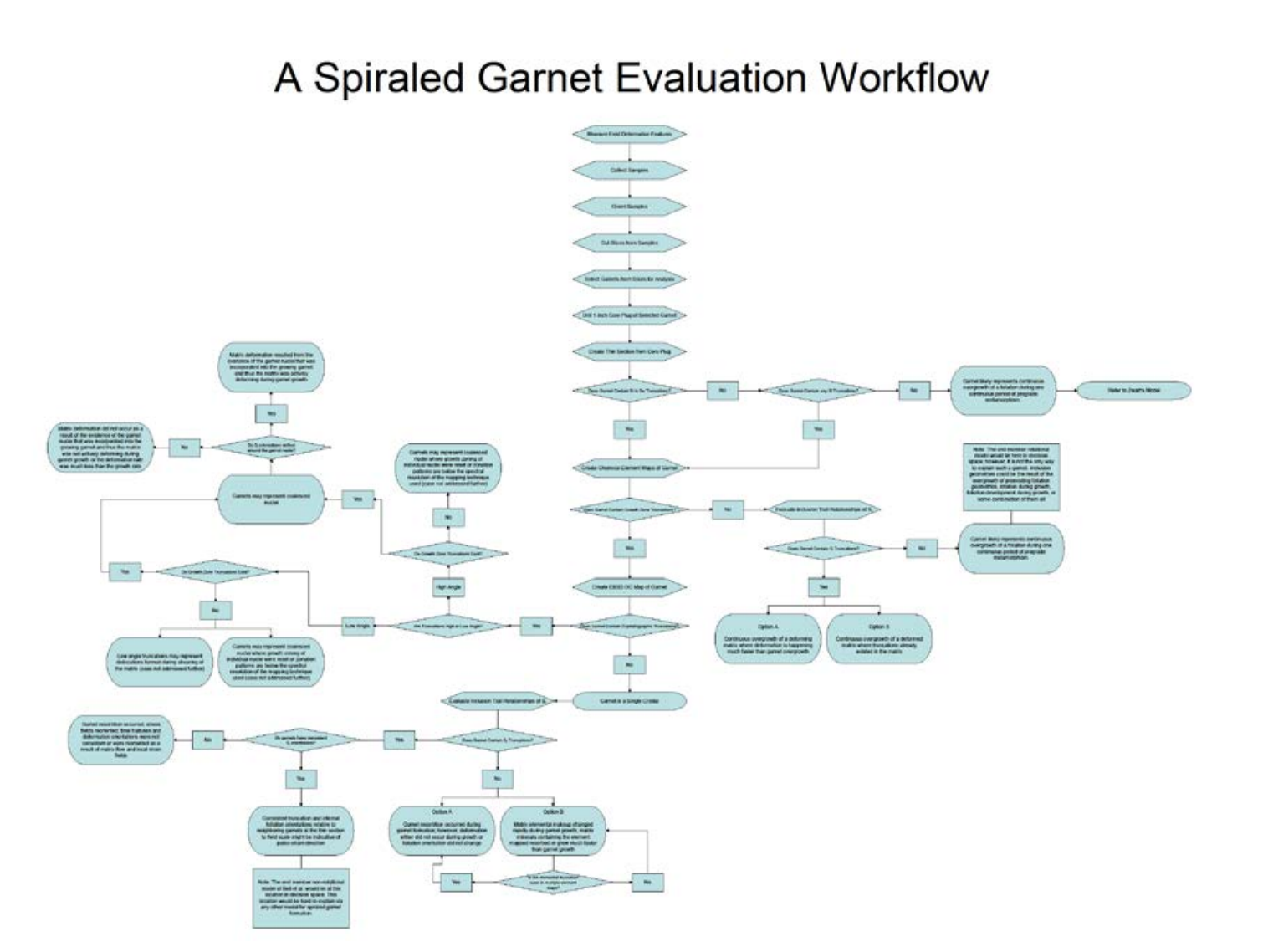




\section{REFERENCES}

Barker, A.J ., 1990, Introduction to metamorphic textures and microstructures: Chapman and Hall, New York.

Barker, A.J ., 1998, Introduction to metamorphic textures and microstructures: Stanley Thornes, Cheltenham, United Kingdom.

Bauer, R., Ketcham, R., and Carlson, W., 2002, Formation of Spiral Inclusion Trails in Garnet During Folding: A Minimum Rotation Mechanism: GSA Abstracts with Programs,.

Bauer, R., Tomlin, K., and Goergen, E., 2010, MULTIPHASE PROTEROZOIC REWORKING OF THE SOUTHEASTERN MARGIN OF THE WYOMING ARCHEAN PROVINCE IN THE CENTRAL LARAMIE MOUNTAINS, WYOMING: GSA Abstracts with Programs,.

Bell, T.H., 1985, Deformation partitioning and porphyroblast rotation in metamorphic rocks: a radical reinterpretation: J ournal of Metamorphic Geology, v. 3, no. 2, p. 109- 118, doi: 10.1111/j.1525-1314.1985.tb00309.x.

Bell, T.H., and Hayward, N., 1991, Episodic metamorphic reactions during orogenesis: the control of deformation partitioning on reaction sites and reaction duration: J ournal of Metamorphic Geology, v. 9, no. 5, p. 619-640, doi: 10.1111/j.1525-1314.1991.tb00552.x.

Bell, T.H., and J ohnson, S.E., 1989, Porphyroblast inclusion trails: the key to orogenesis: J ournal of Metamorphic Geology, v. 7, no. 3, p. 279-310, doi: 10.1111/j.1525-1314.1989.tb00598.x.

Bell, T., J ohnson, S., Davis, B., Forde, A., Hayward, N., and Wilkins, C., 1992, Porphyroblast inclusion-trail orientation data: eppure non son girate*!: J ournal of Metamorphic Geology, v. 10, p. 295- 307.

Bell, T.H., and Rubenach, M.J., 1983, Sequential porphyroblast growth and crenulation cleavage development during progressive deformation: Tectonophysics, v. 92, no. 1-3, p. 171- 194, doi: 10.1016/00401951(83)90089-6.

Bell, T.H., Rubenach, M.J ., and Fleming, P.D., 1986, Porphyroblast nucleation, growth and dissolution in regional metamorphic rocks as a function of deformation partitioning during foliation development: J ournal of Metamorphic Geology, v. 4, no. 1, p. 37-67, doi: 10.1111/j.15251314.1986.tb00337.x. 
Carlson, W.D., 2006, Rates of Fe, Mg, Mn, and Ca diffusion in garnet: American Mineralogist, v. 91, no. 1, p. 1- 11, doi: 10.2138/am.2006.2043.

Carmichael, D.M., 1969, On the mechanism of prograde metamorphic reactions in quartz-bearing pelitic rocks: Contributions to Mineralogy and Petrology, v. 20 , no. 3 , p. $244-267$.

Cox, D.M., Frost, C.D., and Chamberlain, K.R., 2000, 2.01-Ga Kennedy dike swarm, southeastern Wyoming: Record of a rifted margin along the southern Wyoming province: Rocky Mountain Geology, v. 35, no. 1, p. 7- 30.

Daniel, C.G., and Spear, F.S., 1998, Three-dimensional patterns of garnet nucleation and growth: Geology, v. 26, no. 6, p. 503- 506.

Fliervoet, T.F., Drury, M.R., and Chopra, P.N., 1999, Crystallographic preferred orientations and misorientations in some olivine rocks deformed by diffusion or dislocation creep: Tectonophysics, v. 303, no. 1-4, p. 1-27, doi: 10.1016/ S0040-1951(98)00250-9.

Florence, F.P., and Spear, F.S., 1991, Effects of diffusional modification of garnet grouth zoning on P-T path calculations: Contributions to Mineralogy and Petrology, v. 107, no. 4, p. 487-500, doi: 10.1007/BF00310683.

Goergen, E.T., and Bauer, R.L., 2002, Equilibrium and disequilibrium reactions involving staurolite, kyanite, sillimanite, and cordierite - induced by rapid decompression and differential fabric devlopment: central Laramie Mts, SE Wyoming: GSA Abstracts with Programs,.

Hirsch, D., Prior, D., and Carlson, W.D., 2003, An overgrowth model to explain multiple, dispersed high-Mn regions in the cores of garnet porphyroblasts: American Mineralogist, v. 88, no. 1998, p. 131- 141.

Hudleston, P.J., Treagus, S.H., and Lan, L., 1996, Flexural flow folding: Does it occur in nature?: Geology, v. 24, no. 3, p. 203- 206, doi: 10.1130/00917613(1996)024<0203:FFFDIO>2.3.CO;2.

Ikeda, T., Shimobayashi, N., Wallis, S.R., and Tsuchiyama, A., 2002, Crystallographic orientation, chemical composition and three-dimensional geometry of sigmoidal garnet: evidence for rotation: J ournal of Structural Geology, v. 24, no. 10, p. 1633-1646, doi: 10.1016/ S0191-8141(01)00160-2.

Ikeda, T., Shimobayashi, N., Wallis, S.R., and Tsuchiyama, A., 2003, Reply to comment by A. Stallard on ' Crystallographic orientation, chemical composition and three-dimensional geometry of sigmoidal garnet: evidence for rotation": J ournal of Structural Geology, v. 25, p. 1341- 1342. 
Jiang, D., 2001, Reading history of folding from porphyroblasts: J ournal of Structural Geology, v. 23, p. 1327- 1335.

J ohnson, S., 1999, Porphyroblast microstructures; a review of current and future trends: American Mineralogist, v. 84, no. 1978, p. 1711- 1726.

J ohnson, S.E., 1993a, Testing models for the development of spiral-shaped inclusion trails in garnet porphyroblasts: to rotate or not to rotate, that is the question: J ournal of Metamorphic Geology, v. 11, no. 5, p. 635- 659, doi: 10.1111/j.1525-1314.1993.tb00178.x.

J ohnson, S.E., 1993b, Unravelling the spirals: a serial thin-section study and three-dimensional computer-aided reconstruction of spiral-shaped inclusion trails in garnet porphyroblasts: J ournal of Metamorphic Geology, v. 11, no. 5, p. 621-634, doi: 10.1111/j.1525-1314.1993.tb00177.x.

J oly, A., Miller, J ., and McCuaig, T.C., 2010, Archean polyphase deformation in the Lake J ohnston Greenstone Belt area: Implications for the understanding of ore systems of the Yilgarn Craton: Precambrian Research, v. 177, no. 1-2, p. 181- 198, doi: 10.1016/j.precamres.2009.11.010.

Kleinschrodt, R., and Duyster, J .., 2002, HT-deformation of garnet: an EBSD study on granulites from Sri Lanka, India and the Ivrea Zone: J ournal of Structural Geology, v. 24, no. 11, p. 1829-1844, doi: 10.1016/ S01918141(01)00167-5.

Mahar, E., Baker, J., Powell, R., Holland, T., and Howell, N., 1997, The effect of Mn on mineral stability in metapelites: J ournal of ..., p. 223- 238.

Passchier, C., Trouw, R., and Zwart, H., 1992, Porphyroblast rotation: eppur si muove*?: J ournal of Metamorphic Geology, v. 10, p. 283- 294.

Prior, D., Boyle, A., Brenker, F., Cheadle, M., Day, A., Lopez, G., Peruzzo, L., Potts, G., Reddy, S., Spiess, R., Timms, N., Trimby, P., Wheeler, J ., and Zetterstrom, L., 1999, The application of electron backscatter diffraction and orientation contrast imaging in the SEM to textural problems in rocks: American Mineralogist, v. 84, p. 1741- 1759.

Prior, D., Wheeler, J ., Brenker, F., and Harte, B., 2000, Crystal plasticity of natural garnet: New microstructural evidence: Geology, v. 28, no. November, p. 1003- 1006.

Pyle, J.M., and Spear, F.S., 1999, Yttrium zoning in garnet: Coupling of major and accessory phases during metamorphic reactions: Geological Materials Research, v. 1, no. 6, p. 1- 49. 
Pyle, J.M., Spear, F.S., Rudnick, R.L., and Mcdonough, W.F., 2001, MonaziteXenotime - Garnet Equilibrium in Metapelites and a New Monazite Garnet Thermometer: J ournal of Petrology, v. 42, no. 11, p. 2083- 2107.

Robyr, M., Carlson, W., Passchier, C., and Vonlanthen, P., 2009, Microstructural, chemical and textural records during grouth of snowball garnet: J ournal of Metamorphic Geology, v. 27, p. 423-437, doi: 10.1111/j.15251314.2009.00824.x.

Robyr, M., Vonlanthen, P., Baumgartner, L.P., and Grobety, B., 2007, Growth mechanism of snowball garnets from the Lukmanier Pass area (Central Alps, Switzerland): a combined ?CT/ EPMA/ EBSD study: Terra Nova, v. 19, no. 4, p. 240-244, doi: 10.1111/j.1365-3121.2007.00741.x.

Rosenfeld, J.L., 1970, Rotated garnets in metamorphic rocks: Geological Society of America, Boulder, Colo.

Schoneveld, C., 1977, A study of some typical inclusion patterns in strongly paracrystalline-rotated garnets: Tectonophysics, v. 39, no. 1-3, p. 453-471, doi: 10.1016/ 0040-1951(77)90109-3.

Schoneveld, C., 1979, The geometry and the significance of inclusion patterns in syntectonic porphyroblasts.

Slack, J .F., Palmer, M.R., Stevens, B.P.J ., and Barnes, R.G., 1993, Origin and Significance of Tourmalin-Rich Rocks in the Broken Hill District, Australia: Economic Geology, v. 88, no. 3, p. 505- 541, doi: 10.2113/gsecongeo.88.3.505.

Spear, F.S., 1993, Metamorphic phase equilibria and pressure-temperature-time paths: Mineral Soc America, Washington, DC.

Spear, F., and Daniel, C., 2001, Diffusion control of garnet growth, Harpswell Neck, Maine, USA: J ournal of Metamorphic Geology, v. 19, p. 179- 195.

Spear, F., and Daniel, C., 1998, Three-dimensional imaging of garnet porphyroblast sizes and chemical zoning: Nucleation and growth history in the garnet zone: Geological Materials Research, v. 1, p. 1- 44.

Spear, F.S., and Pyle, J.M., 2002, Apatite, Monazite, and Xenotime in Metamorphic Rocks: Reviews in Mineralogy and Geochemistry, v. 48, no. 1, p. 293- 335, doi: 10.2138/rmg.2002.48.7.

Spiess, R., Peruzzo, L., and Prior, D., 2001, Development of garnet porphyroblasts by multiple nucleation, coalescence and boundary 
misorientation-driven rotations: J ournal of Metamorphic, v. 19, no. 3, p. 269-290.

Storey, C., and Prior, D., 2005, Plastic deformation and recrystallization of garnet: a mechanism to facilitate diffusion creep: J ournal of Petrology, v. 46, no. 12, p. 2593-2613, doi: 10.1093/ petrology/ egi067.

Tinkham, D., Zuluaga, C., and Stowell, H., 2001, Metapelite phase equilibria modeling in MnNCKFMASH: The effect of variable Al2O3 and MgO/ (MgO+ $\mathrm{FeO}$ ) on mineral stability: Geological Materials Research, v. 3, no. 1.

Trouw, R.A.J., and Passchier, C.W., 2005, Microtectonics: Springer, New York.

Vernon, R.H., 2004, A practical guide to rock microstructure: Cambridge University Press, New York.

Vernon, R.H., 1975, Microstructural Interpretation of some Fibrolitic Sillimanite Aggregates: Mineralogical Magazine, v. 40, no. 311, p. 303- 306, doi: 10.1180/minmag.1975.040.311.10.

Vernon, R., Paterson, S., and Foster, D., 1993, Grouth and deformation of porphyroblasts in the Foothills terrane, central Sierra Nevada, California: negotiating a microstructural minefield: J ournal of Metamorphic, v. 11, p. 203- 222 .

Vernon, R., Paterson, S., and Geary, E., 1989, Evidence for syntectonic intrusion of plutons in the Bear Mountains fault zone, California: Geology, v. 17, p. 723- 726.

Vernon, R., and Powell, C., 1976, Porphyroblastesis and displacement: some new textural criteria fron1 pelitic hornfels-a comment: Min Mag, v. 40, p. 787788.

Whitney, D.L., Goergen, E.T., Ketcham, R. a., and Kunze, K., 2008, Formation of garnet polycrystals during metamorphic crystallization: J ournal of Metamorphic Geology, v. 26, no. 3, p. 365- 383, doi: 10.1111/j.15251314.2008.00763.x.

Whitney, D.L., and Seaton, N.C. a., 2010, Garnet polycrystals and the significance of clustered crystallization: Contributions to Mineralogy and Petrology, v. 160, no. 4, p. 591-607, doi: 10.1007/ s00410-010-0495-1.

Williams, M.L., 1994, Sigmoidal inclusion trails, punctuated fabric development, and interactions between metamorphism and deformation: J ournal of Metamorphic Geology, v. 12, no. 1, p. 1-21, doi: 10.1111/j.15251314.1994.tb00001.x. 
Williams, P., and Jiang, D., 1999, Rotating garnets: J ournal of Metamorphic Geology, v. 17, no. November, p. 367- 378.

Williams, P.F., and Schoneveld, C., 1981, Garnet rotation and the development of axial plane crenulation cleavage: Tectonophysics, v. 78, no. 1-4, p. 307-334, doi: 10.1016/ 0040-1951(81)90019-6.

Yang, P., and Rivers, T., 2001, Chromium and manganese zoning in pelitic garnet and kyanite: Spiral, overprint, and oscillatory (?) zoning patterns and the role of grouth rate: J ournal of Metamorphic Geology, v. 19, no. 4, p. 455474, doi: 10.1046/j.0263-4929.2001.00323.x.

Yardley, B.W.D., 1989, An introduction to metamorphic petrology: Longman Scientific \& Technical, Harlow, Essex, England.

Zwart, H., 1962, On the determination of polymetamorphic mineral associations, and its application to the Bosost Area (Central Pyrenees): Geologische Rundschau, v. 52, no. 1, p. 38- 65. 